\title{
Towards human and nature reconciliation: a Māori worldview approach to ecological landscape architecture.
}




\section{Abstract.}

This research explores how applying Māori worldview principles can reconcile and allow mutualism between people and ecologies within the post industrial urban setting of Wellington wharf. The aim of this thesis is to develop three possible solutions to reconcile people with ecologies and allow for mutual benefits within natural ecologies of the intertidal zone below Wellington wharf.

This research explores how a nonconventional ecological approach that includes human interaction in restorative landscape design can create beneficial interactions between humans and microorganisms. 


\section{Acknowledgements.}

To Mum and Dad, thank you for your unconditional

love and guidance. You have always provided me with

opportunities to learn and grow and have never stopped believing in me.

To Nicole, thank you for your patience, support and care throughout my years of study.

To my supervisors, Penny Allan and Peter Connolly, thank you for your sincere encouragement and direction. 


\section{Table of contents.}

\section{Introduction}

1.1. Introduction

1.1.1. Problem

1.1.2. Motivations for research

1.1.3. Scope of research

1.1.4. Aim and objectives

1.1.5. Outline of thesis

1.1.6. Description of methodology

1.1.7. Role of design with respect to research

\section{Founding Cultural Identity through Māori worldview} principles

2.1 Cultural Identity

2.2 Implications of an alternative existential perspective

2.2.1 Introduction

2.2.2 The Māori worldview vs. Western worldview

2.2.3 The Māori worldview

2.2.4 Principles inherent of the Māori worldview

2.2.5 Wairuatanga

2.2.6 Mauritanga

2.2.7 Whānaungatanga

2.2.8 Time; past resonating in the present
2.2.9 Components of significance; Taonga, Kaitiakitanga and Rāhui

\section{Addressing the Human and nature dichotomy within} conservation

3.1 Conservation beyond preservation

3.2 Towards a conservation that is redefined by The Māori Worldview

3.3 Towards a "humans in nature consonance"

3.4 Conclusion

\section{Site history}

4.1 Introduction

4.2 Māori association with the Foreshore 30

4.3.1 Wellington Waterfront History 30

4.3.2 Early History 32

4.3.3 Wharf construction 32 


\section{Site analysis}

5.1 Introduction

5.2 Existing land and sea interface exploration

5.3 Occupance and activity

5.4 A focus on the intertidal zone

5.5 Opportunistic ecologies

5.6 Substrate findings

5.7.1 Fundamental survival considerations for design

applications

5.7.2 Environmental conditions

5.8 Specie selection process for future ecological diversity

\section{Design methodology}

6.1 Introduction

6.2 Design methodology and strategies

6.3 Design criteria

\section{Design}

7.1 Introduction

7.2 A Hunch

7.3.1 Experiential qualities

7.3.2 Sounds of a sanctuary

50

7.3.3 Haptic initiation

34

34

34

\subsection{Design Moves}

7.4 Design Moves

7.4.1 Reciprocal Mauri regeneration platforms

spatial, historical, and cyclic orientation

7.4.4 Active Terraces to promote cultural association

intertidal zone

7.4.5.1 Deriving a "humans in nature consonance"

Micro Substrate; A contemporary rocky shore

7.4.5.2 Rope as a substrate

63

66

68

7.6.1 Introduction

7.6.2 Caravan rocky shore

7.6.3 City to Sea lagoon

7.6.3 Chaffers Street Fish market 84

$\begin{array}{ll}8.1 \text { Conclusion } & 90\end{array}$

Bibliography 94 


\subsection{Introduction}

This thesis investigates the potential of applying a pre European indigenous worldview to landscape architecture and attempts to develop a design solution to restore a lost connection between humans, the land, and its occupants.

\subsubsection{Problem}

Traditional Māori Worldview

The traditional Māori worldview expresses a way of life. It inculcated an intrinsic connection that Māori develops with the environment. Following the arrival of European settlers, the Māori worldview was marginalized as traditions of Europe take Precedents. While the allure of European principles remains, what can be discovered if we integrate traditional Māori worldview values into design and specifically ecological landscape architecture?

\section{Human and the nature dichotomy}

Colonialism with influence of Christianity, regards 'man' as the dominant entity over nature. It immediately implies a disconnection that has consequently influenced the western traditional approach to conservation. The western worldview definition of "conservation" carries misplaced implications of protectionism such as returning to an original pre historic state. The envisioned state is free of human influence altogether, implying a picturesque unattainable goal. The revision of conservation principles and consequently design implications will introduce interactions within the environment to facilitate mutualism between people and ecologies. "Conservation beyond preservation" and "conservation for use" are explored. Research of related topics explores the viability of instilling a theme of Māori cultural identity within the context of a European anthropocentric urban environment.

\subsubsection{Motivations for research}

Throughout my studies, I have developed a respect for the holistic principles of Māori tradition and a belief of their validity to design. The initial motivation surfaced from an interest in pre settlement traditions, in particular the possibility of these traditions enhancing contemporary practices and informing public interactions with ecologies. I have also acquired a proclivity towards ecologically considerate design applications within urban environments. This thesis allows me to investigate my acquired interests further.

\subsubsection{Scope of research}

Previous studies have inculcated an understanding of two important insights; the first is the distinct holistic nature of intricate yet connected ecologies. The second is the distinct holistic nature of Māori traditions research explores similarities and opportunities for integration. The Literature reviews relate to the following topics: 


\section{The pre-European Māori worldview}

In an attempt to learn from Māori traditions, it is important to adhere

to its nature and explore important principles closely associated to the Māori worldview. This will reduce the chance of misguided implications that may arise if I were to focus on isolated specifics, which may entail variances amongst Māori.

\section{The pre-European Māori worldview}

In an attempt to learn from Māori traditions, it is important to adhere to its nature and explore important principles closely associated to the Māori worldview. This will reduce the chance of misguided implications that may arise if I were to focus on isolated specifics, which may entail variances amongst Māori

\subsubsection{Aim and objectives}

Identify the Māori worldview and explore its relevance in improving our relationship with the environment.

To find alternative approaches to ecological conservation that informs a more mutually beneficial relationship between man and nature.

Define a site as driven by traditional Māori worldview principles through design. A focus is put on the overlooked opportunity of designing ecologies that can be used and engaged with by the public.

This is to increase cultural identity within a Eurocentric urban landscape and enhance public life in conjunction with ecological conservation.

\subsubsection{Outline of thesis}

Chapter Two discusses the importance to assimilate landscape architecture that promotes cultural identity for Māori, in a Eurocentric urban landscape. The chapter also discusses literature about the Māori worldview and the significant benefit it has had in inculcating mutualistic bonds between Man and Nature. The aim of this chapter is to identify specific principles that associate with ecological and human relational implications within design. Included are case studies of designs responding to similar contextual issues.

Chapter three begins with criticisms formed in chapter two. It juxtaposes innate cultural principles against equivalent contemporary ecological practices. The aim of this chapter is to establish a revised ecological conservation approach defined by cultural constructs.

Chapter four and five discuss site history, constraints, and opportunities. The aim of these chapters is to establish a contextual canvas to inform design decisions and moves.

Guided by conclusions of the preceding chapters, Chapter 6 explores and investigates application of relevant landscape architecture aspect to a design methodology. The sites are further analyzed and associated design development is documented.

Chapter seven is a written and visual description of the design including explanations of how it responds to the problems and theory.

Tavete Fau 11 


\subsubsection{Description of methodology}

- The initial Literature review informed the selection of the region, which then informed the specific site and further literature studies.

- Literature studies were conducted associated with themes that relate to site problems.

- Landscape architectural methods of site analysis and design development were used to integrate literature studies with specific site opportunities and problems.

\subsubsection{Role of design research}

The final design answers and tests arguments explored throughout the development of the thesis. It also presents an alternative vision for the development of Wellington city that consciously answers environmental problems currently faced by the local Council. The design suggests objectives that improved public space can be achieved alongside a more meaningful relationship between humans and the natural environment through spatial retrofitting of an urban context for the benefit of the people living beside it and/or experiencing it. This is achieved by understanding the current notions of the natural environment, human activity and other contextual elements surrounding the site. This thesis builds an argument that the suggested approach is more beneficial than typical designs that limit humans and the natural environment interaction. 


\section{Site Map: Lambton Wharf.}

Fig. 1-1 Site and contex

Image by Author, 2014.

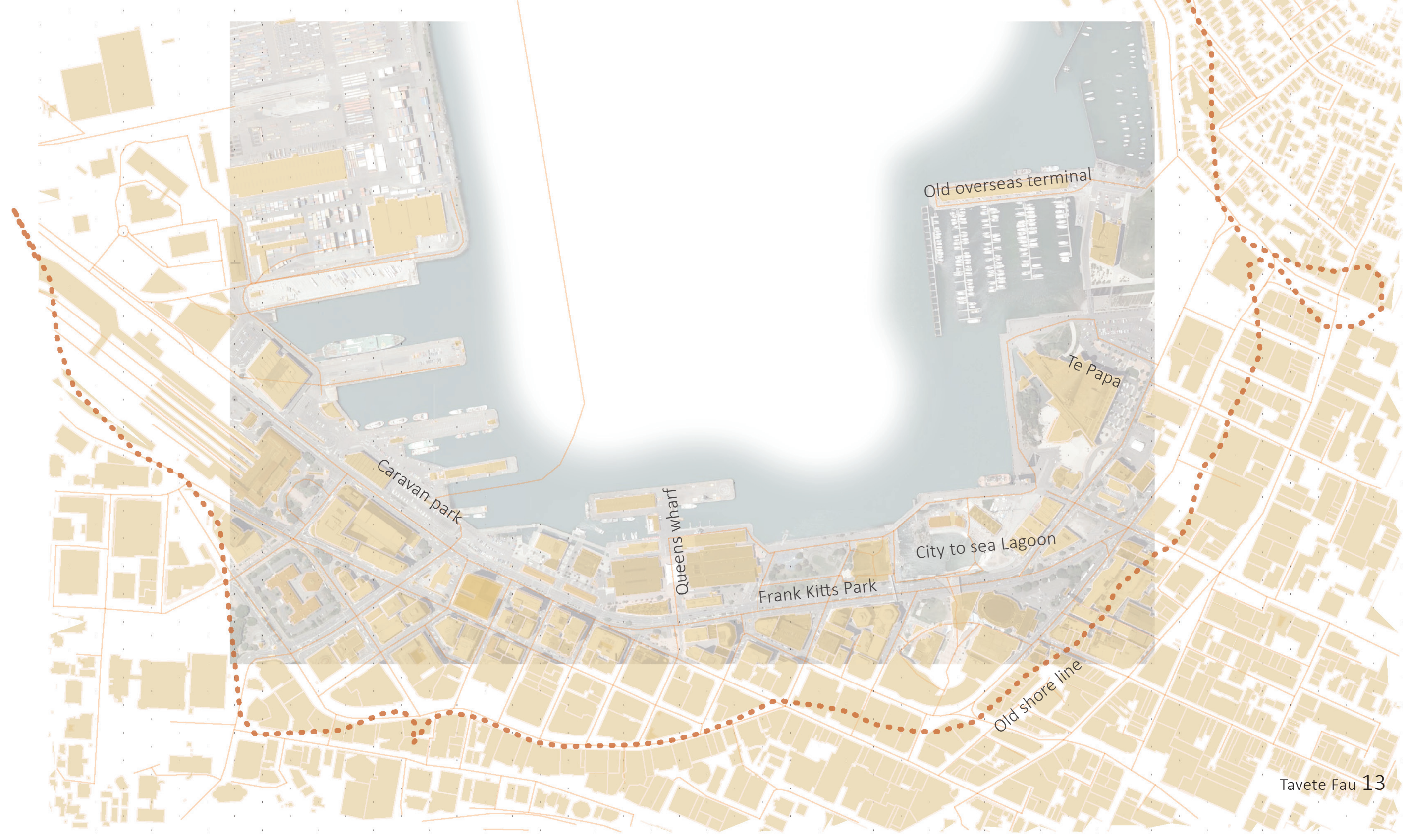




\section{Founding Cultural Identity through Māori worldview principles}

\subsection{Cultural Identity}

New Zealand is proudly a bicultural society; this chapter advocates the benefit of creating interesting interactions between humans and the natural environment. These interactions are more culturally accessible for Māori people and may inform a more vivid cultural identity. This chapter further discusses how landscape architecture can present a way to embrace biculturalism along Wellington wharf, which is a culturally significant threshold between land and sea. European settlers introduced the urban landscape, a westernized cultural landscape that marginalized traditional social relations and structures. Identity holds close ties to memory, theses memories include: the personal memories we hold (such as who we are, where we are from) As well as the social memories that are built on the interconnected ties linked through generations. Cities or urban landscapes can hold these social memories due to the idea that "streets, buildings and patterns of settlement, frame the lives of many people" (Hayden). Hayden advocates that the significant power of place, if handled appropriately, can considerably enrich the cultural identity of non-European groups in an urban environment. She draws on her extensive experience in the multi cultural urban communities of Los Angeles.

A redefined approach is required to support urban resident demands for a more inclusive "cultural citizenship" as Rina Benmayor and John Kuo Wei have described it, " an identity that is formed not out of legal membership but of a sense of cultural belonging" (Hayden). This thesis suggests that "belonging" in Wellington can be reinforced by landscapes (urban) that nurture public memory, to encompass shared time in the form of shared territory. Landscape features vividly inform and frame Māori personal and social memories. Years of urban renewal and redevelopment have distorted landscape features and in consequence, important collective memories are marginalized within the immediate site. Wellington harbour is an example of urban development that has marginalized the intertidal zone. The foreshore between land and sea holds particular value for Māori in the treaty of Waitangi. It states, "We find, therefore, on the basis of the evidence before us, that the treaty of Waitangi recognized, protected, and guaranteed te tino rangatiratanga over the foreshore (intertidal zone) and seabed as at 1840". (Waitangi Tribunal). The proposal of reconnections between Humans and the natural environment directed by the fundamental elements of Māori culture may be able to answer the problematic lack of cultural citizenship towards the indigenous people within urban environments of Wellington.

This thesis suggests that retrofitting waterfronts to encourage these connections will aid in creating a sense of belonging and "cultural citizenship". The proposal will strengthen cultural citizenship by creating interesting ways to reconnect Māori and Pākehā city dwellers with the natural environment. 


\subsection{Implications of an alternative existential perspective}

\subsubsection{Introduction}

The Māori worldview is tied to the history of the indigenous people; it encompasses a traditional philosophy of life. The Māori worldview perspective referred to in this thesis represents distinct principles practiced before the arrival of settlers. The most prominent factors are considered, discussed, and applied to the design. This study is not a definitive representation of the Māori worldview in its entirety but a step in a direction to explore possibilities of its application in urban landscape design.

\subsubsection{The Māori worldview vs. Western worldview}

Every culture evidently holds a basic existential perspective or a set of fundamental beliefs that forms the culture's structure. These beliefs are referring to a worldview. "a worldview is an everyday, ordinarylanguage description of the world, that shapes and guides our lives, helping us to understand, explain and explore that world around us, and everything in it, and how these are all related to each other, by giving us a way in which we see them". In this sense then, it is "the comprehensive framework of one's basic beliefs about things and their relationships". (Gousmett 2).

The Māori worldview stands in peculiar contrast to the conventions of a western influence. The western worldview does not particularly support religious beliefs and often marginalize indigenous cultures. Marginalization is no exception in New
Zealand yet the Māori word view is resurfacing as a compelling and relevant perspective in the world. This acknowledgment has come due to both the growing respect for indigenous people and for practical reasons. For example, the holistic nature of the Māori worldview has an ability to deal with some environmental issues where the western scientific worldview struggles. The reductionist scientific worldview follows Western science's tendency to reduce things to smaller and smaller parts for analysis. On the other hand, the Māori worldview promotes a holistic approach that is more closely associated to nature's larger and interconnected ecologies.

Attempts to amalgamate such approaches have proven to be problematic due to each holding such distinct principles. Bielawski highlighted significant contrasts between the scientific and traditional indigenous knowledge bases of arctic regions; that the Inuit (indigenous arctic people) do not separate people from nature, while Arctic scientists do. Because of this fundamental difference, management models seek to combine the expertise of both scientists and aboriginal land users yet remain "primarily western, scientific, and bureaucratic" (Bielawski). 


\subsubsection{The Māori worldview}

Te Aro Māori or "the Māori world" holds a deep philosophical premise that stands in contrast to that of Western science and culture. In Māor philosophy, creation plays a fundamental role. At the basis of the Māori world is the creation, the account of Rangi and Papa is usually the one used to describe creation. Irwin (1984) shares his version;

"Ranginui (Sky father) looked down upon Papatuanuku (Earth mother) and, loving her, descended and mated with her. Locked in deep embrace they produced numerous progeny (in some accounts 70 in number) all of whom were male. These offspring were imprisoned between the primeval parents in stifling darkness. Faint glimpses of light filtered in and the children became restless and anxious to escape to the world of light (Te ao marama). After much discussion amongst the brothers some agreed to force the parents to release them if Rangi and Papa would not agree to set them free. Those sons (some 28 in number) made a number of abortive attempts to escape. Tumatauenga considered the most effective means would be to slay the parents but the others disagreed. ... Finally Tane [Mahuta] lay down on Papa, bracing his feet against Rangi and extending his arm against Papa. Upside down and struggling fiercely, with the brothers giving him support, as they were able, the reluctant parents were inexorably forced apart. Finally separated, Rangi became the Sky Father and Papa the Earth Mother. Following the forcible separation, Rangi and Papa grieved for each other, Rangi's tears becoming the rain and Papa's the
The offspring of Rangi and Papa were all male. "Tane produced trees, birds, insects, and a wide range of natural phenomena ... but always the female element eluded him. Finally he inquired of Earth Mother who bade him go to the beach Kurawaka, and there gather the red earth into human form. This, with the aid of his brothers, he did. They made a figure resembling them. Tane then breathed into the form hauora (life giving force) and it stirred, sneezed, and breathed and woman had entered the world. Following purification rites to remove the tapu of creation, Tane named this first woman Hineahuone (earth-formed maiden). Tane now mated with Hineahuone and she conceived and bore a daughter, Hinetitama. Subsequently Hineahuone bore Tane a further ten daughters and it is from these that humankind (te ira Tangata) is descended". (Irwin 14).

Māori see humanity and all things within the natural world as the offspring of Papa and Rangi, and consequently related. With this perspective, people are regarded as being directly related and thus connected and intrinsic to all living and non-living things. This common bond situates man firmly inside the natural environment. The personification of the natural environment through various atua (spirits) reinforces that harm is done to oneself when harm is done to the environment. 


\subsubsection{Principles inherent in the Māori worldview}

The explicit Māori worldview informs principles that strongly influence the proposition to redefine a existing Eurocentric urban site within the thesis. The following principles hold fundamental significance to Māori life, traditions, and beliefs as simplified and expressed by Barlow. Research into these principles initiated design research. This part of design research included exploration through abstract drawings, modeling and researching contemporary design Precedents. All of which further develop opportunities for Māori principles to inform design strategies in the field of landscape architecture.

\subsubsection{Wairuatanga}

Wairuatanga pertains to a deeper more explicit insight to humans and relations with other entities, Māori recognise an immortal element in man, referred to as the wairua. Wairua refers to inherent spiritual nature of a person and their extended relationships to natural, physical, and supernatural characteristics of their environment. Wairuatanga is a form of spiritual and emotional connection. Within a design context, wairuatanga represents the emotional relationships and connections people make with spaces. A design strategy will inherently explore spatial capacity to create intimate bonds with the environment.

The investigation of Ortus-Artis by Paratelier found interesting ways landscape architecture can facilitate heightened attentiveness to the natural environment.

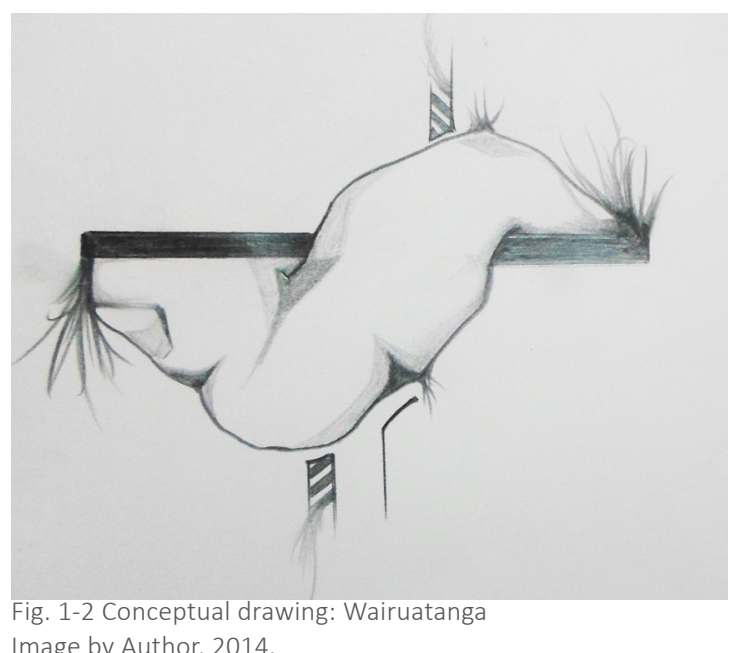




\section{Design precedent}

Location: Certosa di San Lorenzo, Padula Italy

Landscape Architects: Jorma Giannoccaro, Luca Sartor, Maya Seppacher Photographer: Monica Ravazzolo

This design is not directly linked to the definition of wairuatanga; however, it displays an avenue of reconciliation between people and land on an intimate scale that is insightful and coherent. The relationship between Māori and land expresses reciprocal interaction. Māori learn from the land and grow to further connect and respect it. This design by landscape architects Jorma Giannoccaro, Luca Sartor and Maya Seppacher initially challenged or subverted the idea of "garden=green".

The design approach explores an alternative approach to gardening by first introducing a level change that creates a sensation of walking through paths excavated a couple of meters below the hypothetical surface of the garden. The "earth" pictured is a mixture and stratification of natural materials that surround the recipient. The deliberate width of trenches force association between the visitor and the earth on an intimate scale, this encourages the "minding" and "meditation" of the space. Furthermore, the process of earth composting radiates warmth and odor to allow cognitive acknowledgement of earth processes. The paths consist of loose chip that swirl and move as one traverses through. This accentuates the
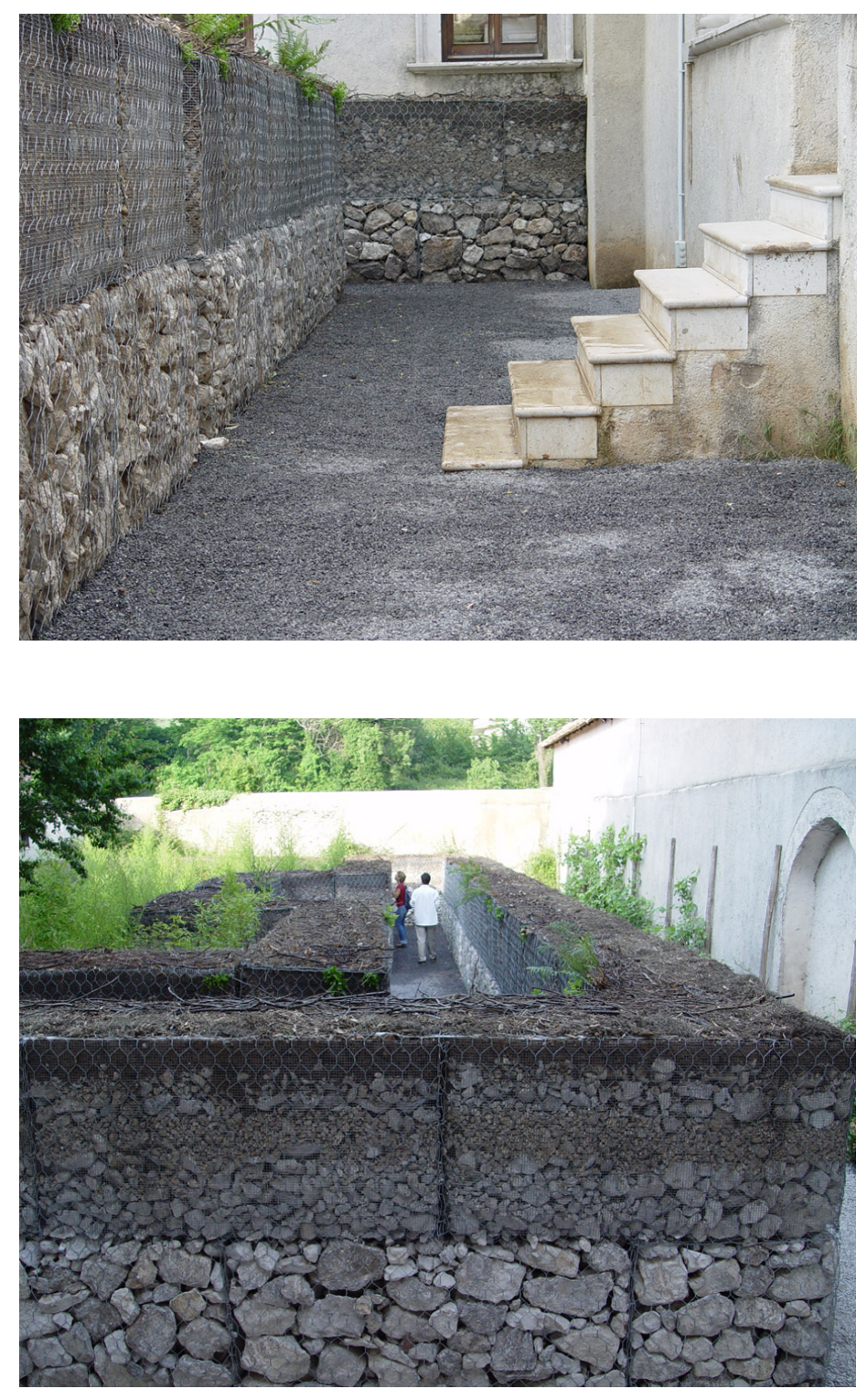

Fig. 1-3 ortus-artis

Source: www.landezine.com 
encourages cognitive acknowledgement and interaction between

human and land, and is in essence a design strategy to facilitate the translation of wairuatanga. The scale of the design does not explore the potential design application of wairuatanga at a larger scale. Research on this topic suggests a design feature that will spatially facilitate heightened attentiveness of the environment.

\subsubsection{Mauritanga}

A central component of the Māori worldview is the recognition of Mauri by which Mauritanga originates. Mauri is the life principle present in all objects, animate and inanimate. It is important to constantly have recognition of the divine origins of all things and is an expression of the holistic way in which the environment is perceived by Māori. This recognition entrusts people to further appreciate and respect natural resources. The Mauri inherent in objects is susceptible to damage and restoration by tikanga (customary practices) to regulate activities concerning the conservation and use of natural resources in order to protect the Mauri inherent in all objects. (Barlow). Awatere expressed insightfully that communities are in essence animate environments, similar to that of a living breathing organism (Rolleston, Shadrach and Awatere, Shaun). The design strategy will take into account the presence and development of the existing Mauri of an environment, whilst also maintaining or enhancing the Mauri of the community.

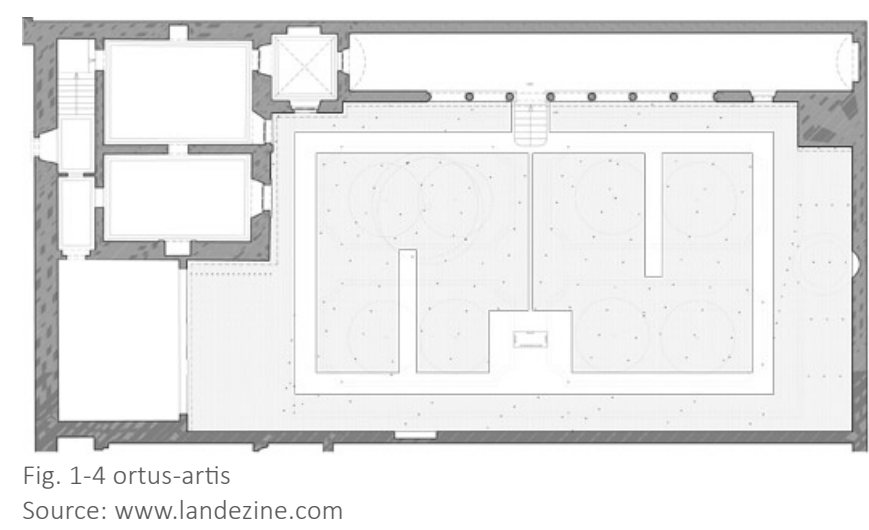




\section{Design precedent}

Landscape Architecture firm: OLIN

Location: Stamford, Connecticut, USA

J.B. Jackson describes associated theory, in his book Discovering the Vernacular Landscape; "No group sets out to create a landscape of course. What it sets out to do is to create a community, and the landscape as its visible manifestation is simply the by-product of people working and living, sometimes coming together, sometimes staying apart, but always recognizing their interdependence". (Jackson) The design Precedent of Mill River Park and Greenway by OLIN has created a spirit of community along the meandering Rippowam River, reminiscent of the inhabitance of past indigenous Algonquin people along its banks. Mill River had suffered from the ill effects of industrial and economic progress. Excessive amounts of silt, branches, rubbish, and other debris littered the site. The design features a dynamic park with a continuously programmed edge along the banks. Significant programmes that can relate to the notion of valuing Mauri values from this design are the play with topography to create a flexible expansive green carpet for large events and waterfront entertainment. The design also boasts reconciliation of ecologies with sufficient planting that further educate the community this consideration relates to concepts of mauritanga. The design is limited in its attempt to engage the community with the ecological processes. Design research will further flesh out and explore this inherent design strategy of communal contribution and benefit.
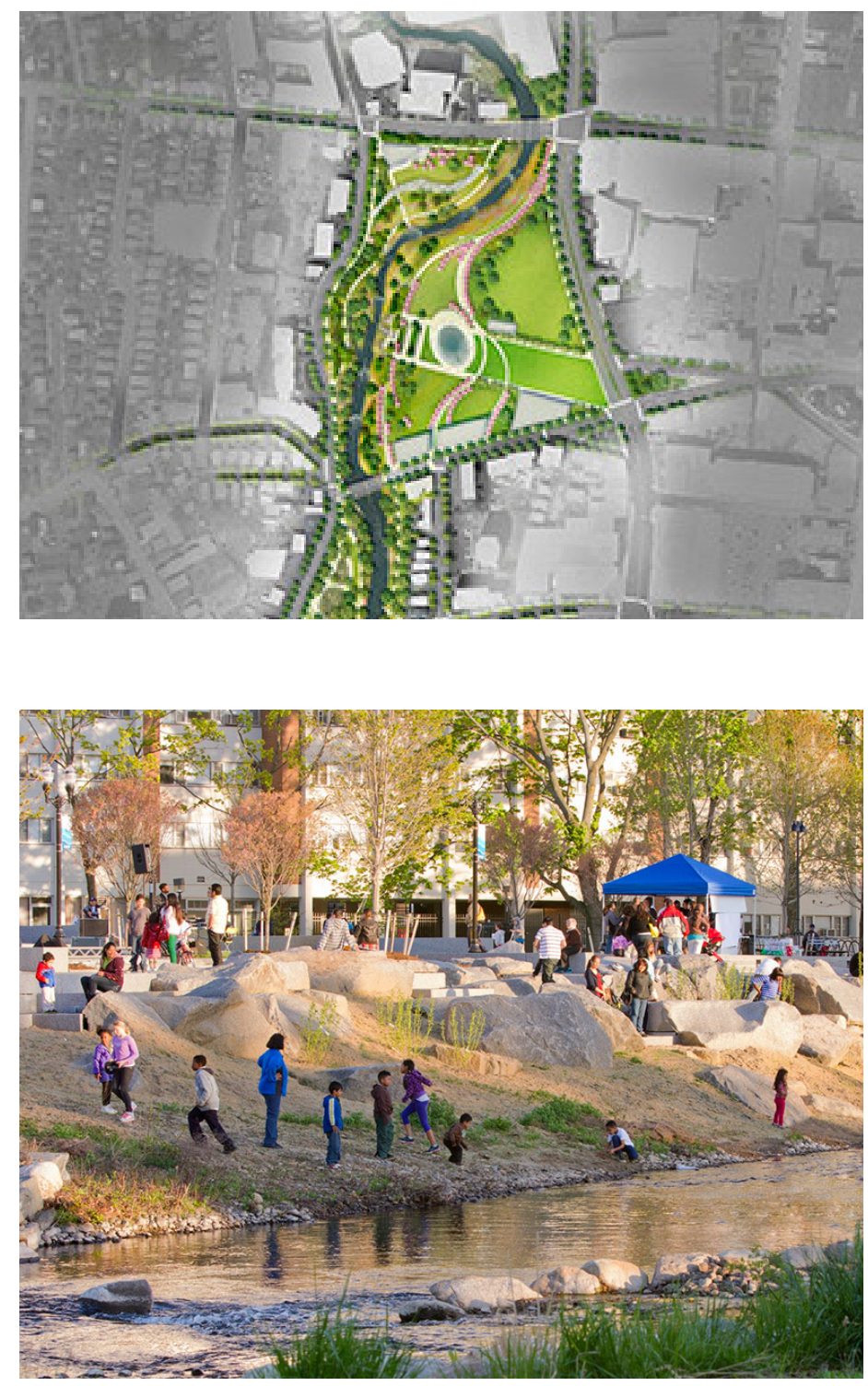

Fig. 1-5 Mill River Park and Greenway

Source: www.landezine.com 


\subsubsection{Whānaungatanga}

Whānaungatanga comes from whanau, which means family and refers to the relationships or bonds of kinship. In the traditional Māori worldview, relationships were all important. These include relationships between people, the physical world, and spiritual world. Further insight was raised in a cultural impact assessment for Nelson "In traditional society it (mutual interaction) emphasized the role and responsibility of the individual as part of a collective. It gave people a sense of belonging, togetherness, and relatedness. Whānaungatanga remains a strong part of modern Māori society and continues to

shape the relationships between Māori people and the environment". (Walker). The personification and identification of natural landscape features was also used to maintain the close relationship ties with the environment. All of these factors contribute to the notions of membership participation within communities that refer to Whānaungatanga. The translation of this principle into a design strategy will inherently include a drive of community participation towards a collective idea of membership or definitive community identity without segregation. Initial responses may include the overt addition of communal facilities, open reserves. Design research will explore these to develop opportunities for collective communal development and recognition towards community identity.

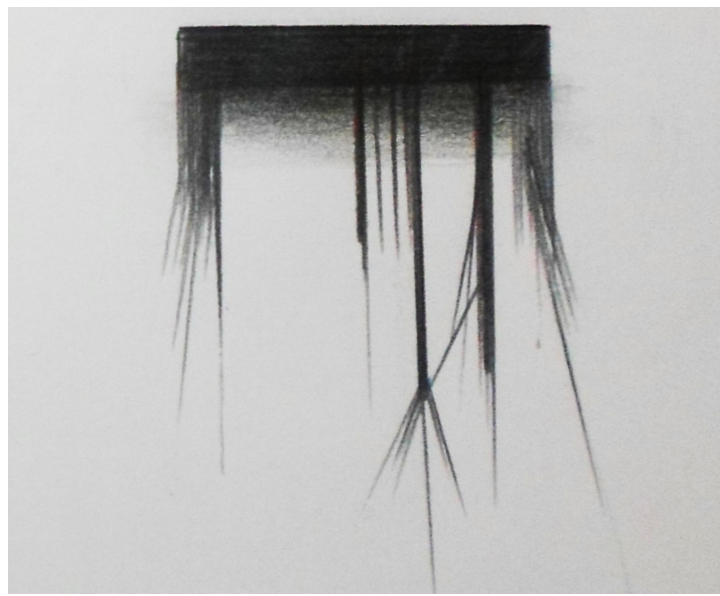

Fig. 1-6 Conceptual drawing: Whānaungatanga Image by Author, 2014 


\section{Design precedent}

Location: Place André Meunier, Bordeaux France

Landscape architect: OOZE

Théâtre Évolutif is, fundamentally, a shelter and, a gathering place where groups and individuals can collectively come together with a common purpose to engage with and learn from one another. Visitors and nearby residents can engage with and learn from the interactive structures. These structures include the open-roof structure, the water-supply infrastructure, the vegetable gardens, and the animals. This design actively addresses the design strategy in similitude to Whānaungatanga whereby individuals can join a metaphoric membership that involves interactions and transference of knowledge. The design successfully achieves this by introducing structures that encourage discussion amongst people. The structures inform and promote three cycles; the dynamic cycle of citizenship (participating in the remaking and adjusting of public space), the human water cycle (the drinking water station juxtaposed yet connected to the public toilet), and the bio-dynamic cycle (interacting with the natural world for example, through gardening and beekeeping). The combination of cycles of this project enacts coexistence between the architectural site (Chantier architectural) and the social site (Chantier social). Exploring a machine to connect social interaction with ecological processes is developed through design research.
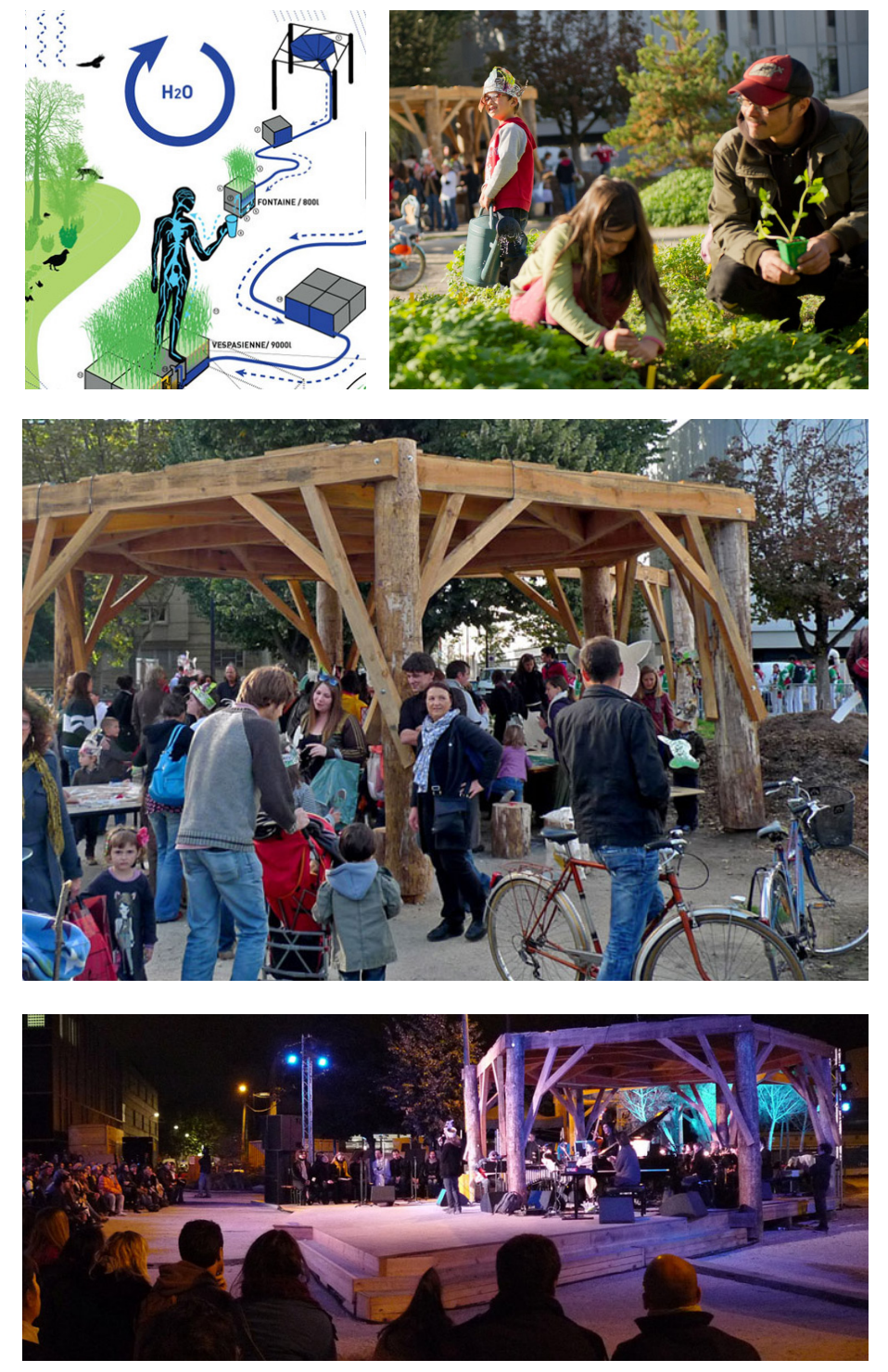

Figure1-7 Théâtre Évolutif Source: www.landezine.com 


\subsubsection{Time as past resonating in the present}

The traditional Māori worldview expresses a separate concept of time. The Māori conception of time has been expressed as cyclic spiral and resonant. Common traditional practices such as hunting, planting, and harvesting show that Māori interpreted and took advantage of time whilst acknowledging its eternal resonance. Māori interpreted time by the tide and seasons, using these and others seasonal and ephemeral changes as indicators. For Māori while they understood the immediate implications of time, it was regarded that the past resonated in the present. Māori constantly drew from both. The Māori word for future is muri which also means behind. The Māori word for past is mua, also meaning in front. Māori paradigm of time inherently implies dwelling in the present and the past. In this time frame one has before him the living, their forebears, the dead, the founding ancestors, and cultural heroes back to the primeval pair Ranginui and Papatuanuku. This time frame is the basis of Marae protocol.

The western approach to time is that the present is all important. Donna Awatere shares insights concerning the European influence and states in her thesis that with the settlement of Europeans "time began to be measured and quantified. It was no longer tied to the cyclic rhythm of nature". (Awatere). Awatere goes on to state: '... the intimate, mimetic reciprocal relationship between the human being, nature and the living past of the ancestors, was replaced by a time experienced as space and mediated by a history 'frozen' into a mechanically measured dimension by genealogically unrelated people' (Awatere 61). Focus is placed on the now, quantified with a time index and in the process old ways and people are devalued. European traditions generally live more out of the continuity of time; they are removed from history, easily putting it behind them living purely in a spatial and physical world. Emphasizing the natural processes within the site coupled with the references of traditional practises of collecting kaimoana will create considerable progression towards establishing intrinsic connections between humans and the natural environment evident during pre-European settlement times. This approach to design will facilitate the interconnection of past and present, and further cultivate an indigenous cultural identity within the city. 


\subsubsection{Components of significance; Taonga, Kaitiakitanga and Rāhui}

Taonga represent treasures, kaitiakitanga informs guardianship of these treasures and govern application of certain practices. Rāhui represents restriction of particular resources abiding by sustainable procedures. These additional components are also drivers of strategies put forward from the Māori worldview.

Taonga refers to something treasured; it may be tangible or intangible. Tangible examples can be passed down heirlooms, artifacts, land, and fisheries. Intangible examples include language passed down or knowledge and riparian rights. Taonga needs be protection because it holds intrinsic value to Māori. Taonga also have legal significance in New Zealand, namely in the second article of the treaty of Waitang guaranteed that the Māori Signatories would retain the possession and enjoyment of their taonga whilst under British rule. The resource management act 1991 orders decision makers to "recognise and provide for the relationship of Māori and their culture and traditions with their ancestral lands, water, sites, wahi tapu (sacred sites), and other taonga' as a matter of national importance". In 2004 the foreshore and seabed were and indeed are taonga for many groups

\section{Kaitiakitanga}

Kaitiakitanga represents the stewardship or guardianship of the environment. Māori settlers initially had a huge impact on plants and animals species. For example forests were burnt and some species 
discussed has developed over time (Nathan). This guardianship is to ensure the sustainable use of natural resources and the interconnection between the natural environments and people is key (Hamsworth). This component is ancient yet similar to the modern term "sustainable management". This stewardship was expressed in former times on a number of levels. One level was represented by an atua or spirit, one by the hapū or whanau (extended family) and another by the individual. The role of each was to manage a particular natural resource in a healthy and productive state. "The atua, people and individual acted in unity to maintain the resource and its physical and spiritual productivity, potential and balance" (Walker).

It is paramount to identify and protect important natural resources as a taonga for current and future generations. Māori understood the interconnectedness of various ecologies and applied it as a tool for guardianship/kaitiakitanga. If a region such as a coastal environment was healthy for example, it can be read as an indicator for the health of the wider environment (James). Empowering people to further relate to the land and identify its larger scale health will be an important aspect to translate and pursue towards a design strategy. The design strategy derived from this principle consists of innovative design solutions to be applied in preserving where needed and protecting significant natural assets. Where resources are identified, settlement and community design should support and provide for its sustainable management while balancing its use. There is a vital balance to be explored in design regarding decisions for ecological processes to be interacted with or strictly inhibited. To further investigate specific site analysis is essential and is to be further explored after the specific site is chosen.

\section{Rāhui}

Rāhui is a form of temporary restricting access to particular vulnerable resources and expresses Māori's eventual sustainable use of natural resources. Hirini presents Rāhuias a procedure for conservation "its purpose is apparently not to destroy but rather to restore the productivity of the land" (Mead 197). Piri Sciascia recalls that their chief at Porangahau always controlled the Karengo (seaweed) season. No one could take any until he had obtained the 'first fruits', it ensured steps towards a sustainable harvest and resources that would replenish. (Mead 198).

Sustainable management is not restricted to protection and preservation; it is also concerned with allowing and providing for its use and potential development. Professor Durie discusses that Traditionally, Māori depended on a balance between protection, conservation and use (Durie) this overall approach is further explored later on in the thesis. 


\subsubsection{Conclusions and interpretations}

This chapter has explored The Māori worldview and identified specific principles and components that informed design strategies. Implementation of these strategies informed a new perspective on urban landscape architecture. The design strategies were developed predominantly through design exploration of abstract sketching. Based on this research the following design strategies have been developed further in the thesis.

\section{Wairuatanga}

To create spaces that provide opportunities to create intimate bonds between humans and other entities. At the moment the domains of human activity and ecological activity are generally separated domains.

\section{Whānaungatanga}

To encourage community participation towards a collective idea of membership reinforced by creating a definitive community identity without segregation. Without inhibiting (ecologies).

\section{Mauritanga}

To acknowledge the existing Mauri of an environment by restoring it to good health, whilst also maintaining or enhancing the Mauri of the community, by means of interaction. At the moment ecologically sensitive recovery is separated from the public. At the moment the intertidal zone along Wellington harbour and its communities are barely

\section{Kaitiakitanga}

To empower the individual and community to evoke a collective guardianship. This may include clear indicators of ecology health that create accessible and legible interaction opportunities for regeneration.

These fundamental strategies need to be explored further with sketching and modeling.

The design strategies further reiterate a problem that inhibits development: that a restoration of any ecology typically becomes separated from public interaction or participation which severely constrains the application of those strategies. For these strategies to develop any further, a new conservation approach will need to be developed.

Note: The particularly spiritual and tapu or sacred components related to the traditional Māori worldview are not explored directly in this research. Focus is placed instead on the under pinning principles that can evoke a visceral relationship with our natural resources. The implementation of undisclosed spiritual narratives and sacred tikanga (practices) reside with discretion of local Iwi. While this thesis does not directly introduce these particularly sacred concepts it facilitates opportunities for Māori to perform sacred practices as occasion permits and apply sacred concepts at their discretion. 


\section{Addressing the Human/nature paradigm within conservation}

\subsection{Conservation beyond preservation}

The traditional Māori approach to conservation stands in contrast to the prevalent western paradigm of conservation by preservation. A revision of conservation will positively change the landscape and allow Māori to re establish their past intrinsic associations with nature through working in the land and being a part of its cyclic processes. The basic history of "conservation" within New Zealand relates how people slowly but eventually realised the effects of human activity on the environment. This realisation consequently introduced attempts towards the end of the twentieth century to repair the subsequent damage.

Around the 1960s, 'nature conservation' was a term used in New Zealand, and eventually became the general meaning of conservation in this country. It consists of the belief that natural features should be preserved for their inherent value, so they can be appreciated rather than exploited by future generations (Diamond). This meaning has essentially been formalised by an explicit definition in the 1987 Conservation Act:"Conservation means the preservation and protection of natural and historic resources for the purpose of maintaining their intrinsic values, providing for their appreciation and recreational enjoyment by the public, and safeguarding the options of future generations". "Preservation" as prescribed by the Conservation act was the reigning 20th century nature protection paradigm.

According to this model, to protect nature we must preserve and set aside nature preserves and keep them "untrammeled by man" as prescribed by the wilderness act (Zahniser). Basically for preservationists, nature's key value is its "naturalness" or "wildness", further defined by the extent to which it is independent of human influence. This supports the paradigm, that humans are, generally separate from nature and human participation or involvement with nature corrupts it. This conservation paradigm reflects a Humans and the nature dichotomy that positions Man separate from nature.

A persisting dominant motivation behind preservationist conservation is a erroneous desire for an absolutely pristine nature and the even more erroneous insistence that real nature must be a virginal nature and untouched by man. In relation to the Māori worldview, this thesis suggests that nature retains its inherent significance even while being impacted by humans to a significant extent. "There are degrees of naturalness and being somewhat less natural does not entail being unnatural or losing the status of nature" (Hettinger)

The contradictive nature of the common preservationist conservation approach is explicitly highlighted by Baldwin "the definition of nature includes evolution by natural selection, which obviously entails change. If nature is ever changing, preservation is a strategy for making nature stay the same and is inherently problematic because nature is not static. From this perspective, preservation is not natural, even in those areas still in relatively pristine condition. "(Baldwin 5).

Tavete Fau 27 
The term "conservation" carries misguided implications of protectionism such as returning to an original pre settlement state. A perfect restoration is literally impossible, Humans are dependent on nature, and conservation needs to acknowledge this. With traditional principles assisted with a scientific approach these thesis intents to usher in an example of "conservation for use" within the parameters of my chosen site.

\subsection{Towards a conservation that is redefined by The Māori Worldview}

The thesis suggests that the influence of pure protectionism dampens conservation from being developed. Over exploitation of natural resources throughout New Zealand is history and in most cases is not to be tolerated in the future. This experience should not, however produce an overreaction, for example conservation projects shouldn't fall back on their "precautionary principle" morals that won't budge without "full scientific certainty". Scientific findings will always have an element of uncertainty. Healthy and stable fauna, wildlife, and marine resource populations should be the legacy we leave for past generations. Why can't provisions be shaped towards a valuable return from areas at the same time as being kept healthy?

This thesis argues for the right of Māori to have a substantial role in directing an alternative strategy in conservation management and defines one possible approach that is coherent with studied portions of the Māori worldview. Māori did not perceive themselves to have dominion over all things as colonialism brought through possible influence of Christianity. They embedded themselves into the ecological processes of the landscape, learning to extract medicinal and material uses of plants, anticipating harvest seasons. The traditional Māori kainga or home would benefit socially with this confidence in the land. This association and "working" of the land directly relates to an alternative form of conservation that will respect and retain traditions of old. It is also the Department of Conservation (DOC's) goal to bring this synthesis in to play with "effective

management of historic places in co-operation with the community and iwi, and significant gains in their conservation and appreciation". The discussed considerations inform a revision of conservation that:

- Incorporates human association and interaction; to break free from the misguided Human/nature paradigm of the past and allow Man to intervene, participate, and positively contribute.

- Does not chase an impractical pristine nature; is comfortable acknowledging that sites and particularly urban sites contain environments that have been altered so drastically that "Native" plant species are impractical.

- That can be "used"; allowing the use of potential resources while ensuring sustenance of ecologies

These conservational strategies are to ensure further compatibility between over arching themes and application in design. Additionally multiple species management issues, historical, cultural considerations and economic factors will all play a role in establishing a rational strategy. 


\subsection{Towards a "humans in nature consonance"}

A revision of this approach will allow intrinsic connections between humans and nature to re surface and act as a core fundamental position for the design methodology and landscape architectural response to an urban site. "Humans in nature" reconciles the two entities as one; it expresses an equality contrasting to that of the past. This is explored further through design research.

Consonance by definition means "agreement or compatibility between opinions or actions", notably its musical definition describes it as "a combination of notes which are in harmony with each other due to the relationship between frequencies" (Press). Consonance as prescribed in this thesis in relation to Humans and the natural environment is used metaphorically to represent agreement, harmony, and compatibility between man and nature. It also draws contribution from its musical definition that the source for this agreement resides in relationships between frequencies. These relational frequencies of human and nature can be derived from past interactions and associations implicit in the historical interdependence of the two.

Past interdependencies include immediate sustenance from nature (crops), orientation from nature (landscapes), mental stimuli and education from haptic discovery with nature (exploration), all of which are governed by the natural index of time (cyclic processes). These interdependencies are fundamentally nonexistent within the urban environment due to the exponential progress of technology; crops are now supermarkets, orientation is simplified and literally spelt out to people on signs, and mental stimuli is digitalized. These factors are governed and controlled by the quantified time index.

\subsection{Conclusion}

The Māori worldview creates a vivid stance with implicit principles that holds significance in the approach to design. It fundamentally redefines the "human/nature" dichotomy, which has far reaching implications for conservation. The established position and design strategies will strongly inform the development of a landscape architectural response. 


\section{Site history}

\subsection{Introduction}

The proposed landscape architectural intervention will inform a

"human in nature consonance" with associated design strategies. It will respond to a damaged ecological zone that can be potentially restored and assisted by human interaction within an urban context. This chapter will discuss the historical significance of the foreshore for Māori and why the equally historically significant Wellington waterfront and intertidal zone is an appropriate site for this thesis.

\subsection{Māori association with the Foreshore}

Traditionally Māori have regarded themselves as people of the land and the children of Tāne, god of the forest. The marine realm belonged to the god Tangaroa, whose offspring were the fish.

Tangaroa needed to be appeased through karakia(incantations) because taking fish was seen as an attack on the children of Tangaroa. (Hutching, Gerald. Walrond, Carl)

Māori have a strong spiritual connection with the realm of Tangaroa, this relationship with the sea shared many practical elements, including Rāhui (bans, as mentioned earlier) and tapu which saw restrictions to ensure respect for Tangaroa was respected. This type of management reflects the standards of balance, life-force, caretaking, and duty of care present within Māori culture towards taonga.
Article two of the Treaty of Waitangi, explains that Māori have joint management over the foreshore and seabed. Accordingly they want to be active participants at all levels as a Treaty partner

These points discussed, briefly share insight on the significance of land and sea and Māori disposition to actively participate. The interface between these two environments of land and sea embraces an important transitory connection commonly known as the inter tidal zone or foreshore. This zone holds inherent significance to Māori; it is considered Taonga due to its abundance in sea life. Many activities are associated with the foreshore such as bringing in canoes, recreation, fishing, battles, burials, and collecting seaweed. (Figure 4-1)

\subsubsection{Wellington Waterfront History}

In the context of Wellington the connection between land and sea has been interrupted by the urban landscape. In particular a wharf covers a considerable area along the city's boundary with the sea, which has interfered with the landscape and altered the intertidal zone dramatically. The history of Wellington Harbour will be discussed as well as the current state of the intertidal ecologies. 


\section{Wellington Harbour}

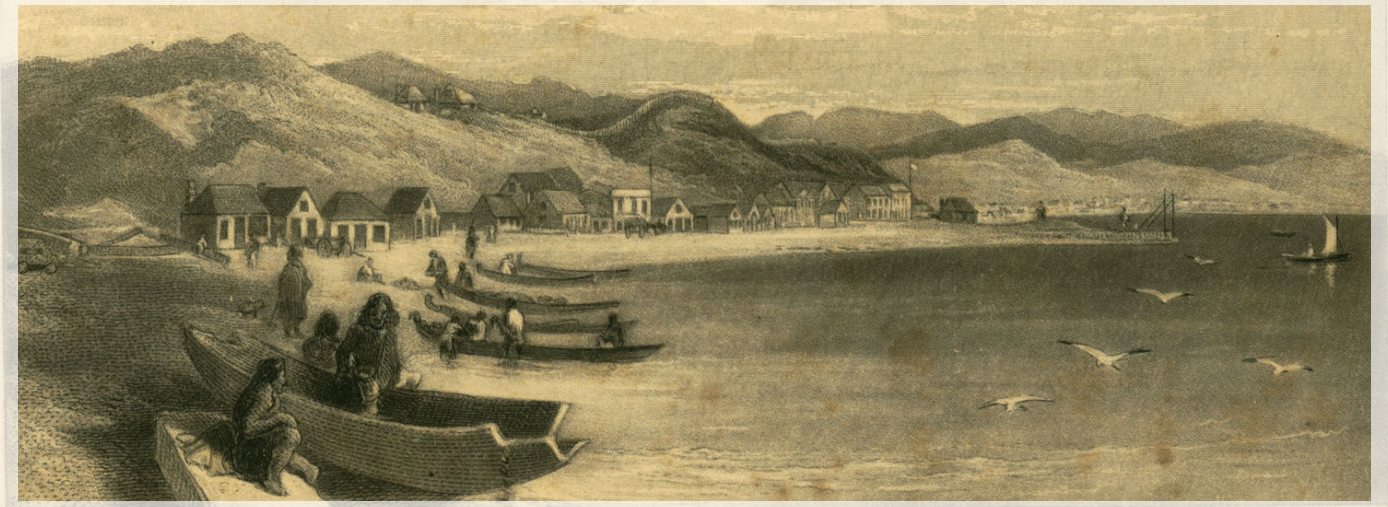

Figure4-1 Beach at Te Aro

Image by S. C. Brees

source: www.enzb.auckland.ac.nz
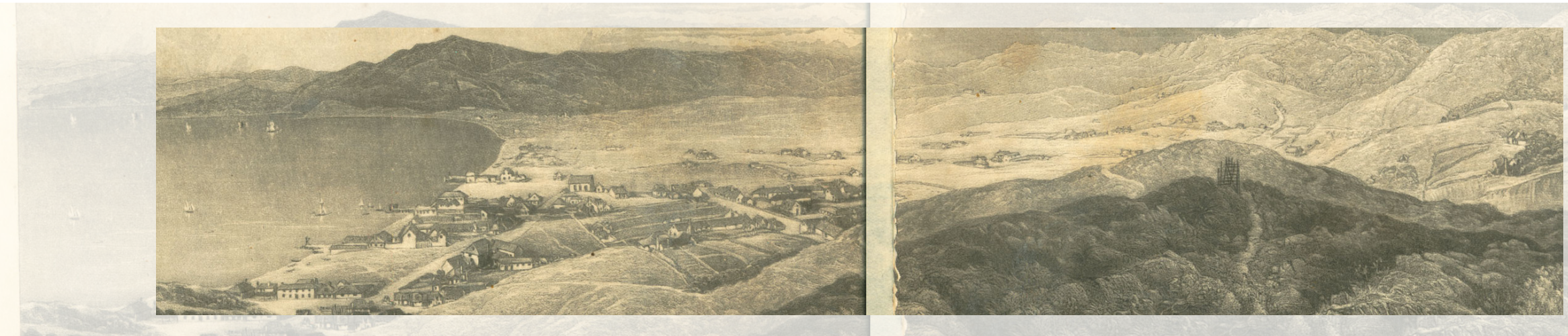


\subsubsection{Early History}

According to Māori tradition, Wellington Harbour once had a second entrance through the low area that now connects Miramar Peninsula and the mainland. It was raised during an earthquake (probably in the 15th century) known to Māori as Haowhenua. The superimposed water level (Figure 4-3) shows land before the earthquake. The lithograph (Figure 4-4), published in 1842, illustrates the low-lying nature of the land around Miramar. (McSaveney) This evidence reveals that the harbours edge began as essentially raised sea bed, flat and exposed.

For hundreds of years, the Māori people held activities along the shoreline including fishing, sea trade, cultivation of land and building settlements. Te Aro Pa was established by Ngati Mutunga of Taranaki in 1824. (District) Another earthquake in 1855 raised the land and drained the low-lying areas of Te Aro. The subsequent marshy areas provided shellfish and eels, and also the large quantities of flax that were in demand by the European settlers. The population of Te Aro Pa dwindled rapidly from that time due to the complexities wrought by the Taranaki land wars and the impact of colonization. In 1870 most of the remaining land was sold to extend Taranaki Street down to the waterfront.

When the Europeans arrived in the early 19th century they found thriving settlements and active water based trade. A number of settlements extended from Waiwhetu on the eastern side of the Hutt
Valley, Petone, round the settlements near the Kaiwharawhara Stream, continuing to Pipitea Pa, Kumutoto Pa, Tiakiwai Pa and finally into Te Aro Pa in the heart of the waterfront. Te Atiawa, had settled within the inner harbour area

\subsubsection{Wharf construction}

Wellington harbor was settled by Europeans In the early 19th century.

The area developed and established as a merchant center and port trade city, it is in the 19th century that extensions of reclamation began. (Figure 4-5) At the end of the 19th century and the beginning of the 20th century wharf piers protruded out into the waterfront, these exist today and interfere with the intertidal zone, by blocking out the sun. The Lambton Bay intertidal ecology and the transitional significance of it to Māori have been marginalized. The bustling indigenous aspect of sea trade and immediate consumption once present along the shore has been over taken by the stresses and advancements of the industrial age. 


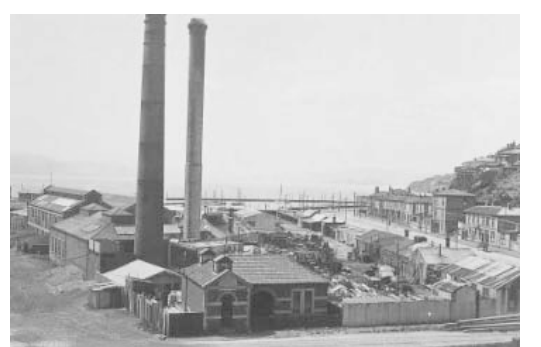

Figure4-2 Wellington Waterfront historic images, 1980

Source: Wellington Waterfront

Framework, 2001 p8.

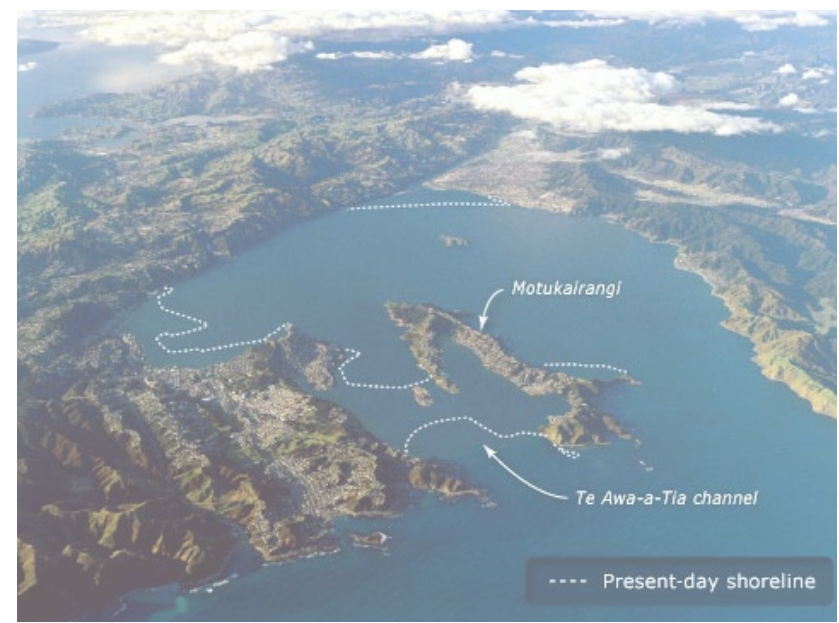

Figure4-3 Wellington harbour before

haowhenua earthquake

Source: www.teara.govt.nz
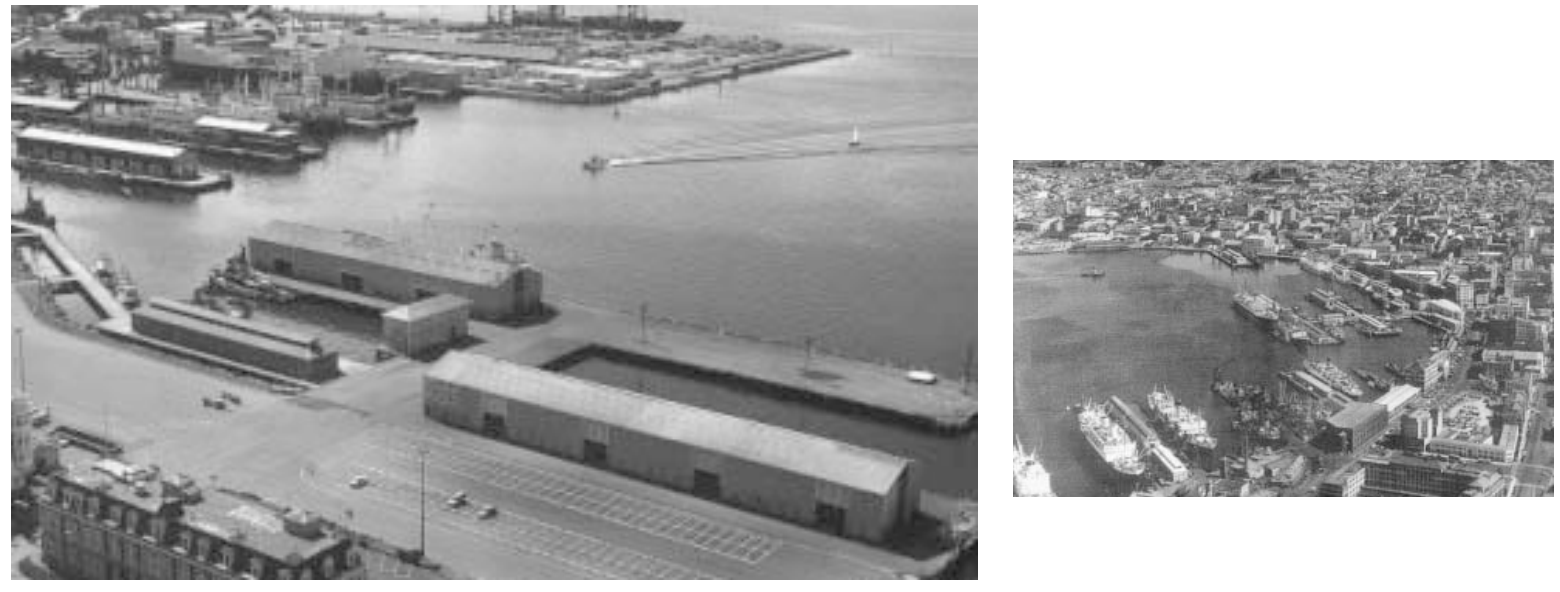

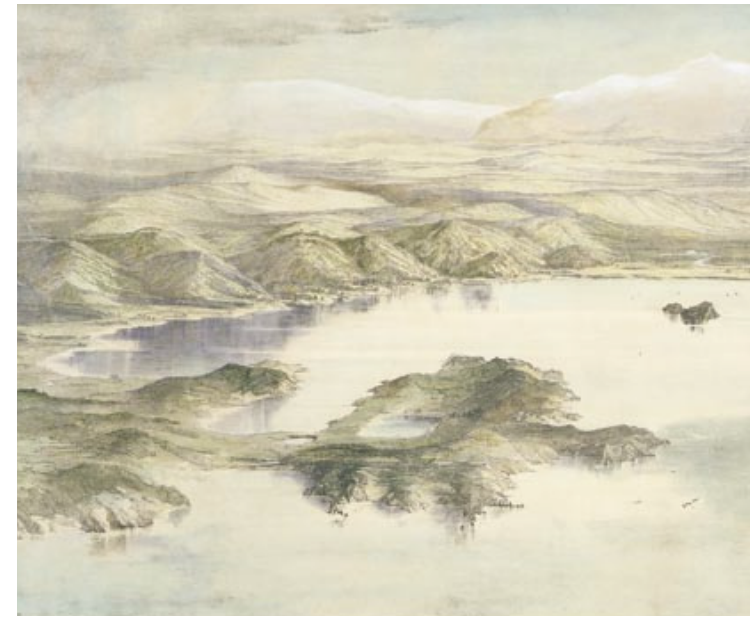

Figure4-4 Wellington harbour Port nicholson

Source: www.teara.govt.nz/en/artwork/4382/

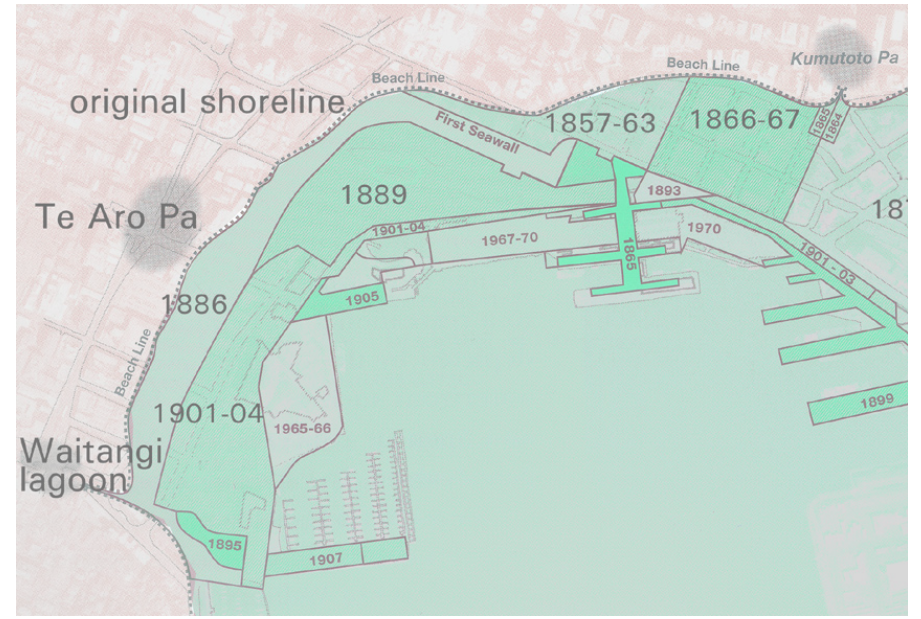

Figure4-5 Wellington harbour Port nicholson

Source: Wellington Waterfront

Framework, $2001 \mathrm{p} 1$. 


\section{Site analysis}

\subsection{Introduction}

The wharf consists of wide connected long promenades with open spaces, historical and contemporary cultural insights, and diverse functions. This thesis explores the proposition of three typologies residing along the wharf that respond to specific contextual conditions. This chapter of the thesis explores factors that bear universal significance over the three specific sites chosen. Each site is then individually further analyzed.

\subsection{Existing land to sea threshold analysis}

Sections throughout the site explore the separation of human activity and levels of the intertidal zone. The wharf rests two metres above mean water level on average. Connections with water are prominently visual with exception to the lagoon that encourages the interaction with water for sports and recreation.

\subsection{Occupation and activity}

Developing a potential for human interaction with future ecologies depends on gathering research of human occupation and activity along the site. Graphs were used to illustrate legible relationships and opportunities in facilitating human and intertidal animal activity. The activity graphs combined onsite observations with previously collected data of activity numbers (Gehl). The collected data entails that when the tide is out intertidal species are dormant, and human activity is

\footnotetext{
facilitated.
}

The activity/movement graphs (Figure 5-1) show typical levels of human activity along the water front and animal activity within the intertidal zone, the graphs also show data correspondence with a typical semidiurnal (two low tide, two high tides in one day) tidal phase. Correspondence factors were complicated with further investigation of tidal phases. The tidal phase graph showed patterns of inconsistency regarding the timely occurrence of tidal changes. Illustrated patterns expressed that the time of the first low tide on one day would be roughly a one hour later the next. This finding initially complicated development progress by demanding a design that is flexible enough to cater for human occupation at any tide level. Further design development explored and embraced the identified irregular nature of tidal change and used it to inform space, function, and encourage people to read and engage with cyclic processes, inherently heightening attentiveness to the natural environment. 


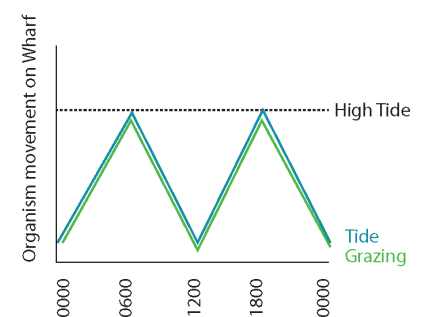

Figure5-1 Activity and tidal Graphs Images by Author

Framework, $2001 \mathrm{p} 1$

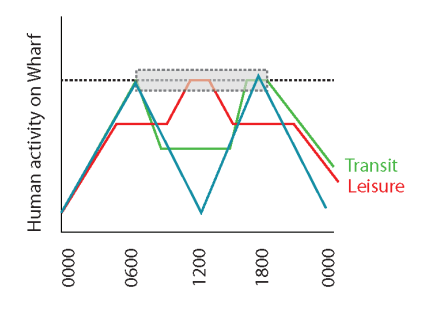

Low tide/high tide averages of each month.

$0.6 \mathrm{~L} / 1.7 \mathrm{H}$ January

$0.6 \mathrm{~L} / 1.7 \mathrm{H}$ Febuary

$0.6 \mathrm{~L} / 1.7 \mathrm{H}$ March

$0.6 \mathrm{~L} / 1.7 \mathrm{H}$ April

$0.6 \mathrm{~L} / 1.7 \mathrm{H}$ May

$0.6 \mathrm{~L} / 1.7 \mathrm{H}$ June

$0.5 \mathrm{~L} / 1.65 \mathrm{H}$ July

$0.6 \mathrm{~L} / 1.7 \mathrm{H}$ August

$0.6 \mathrm{~L} / 1.7 \mathrm{H}$ Septembe

$0.6 \mathrm{~L} / 1.7 \mathrm{H}$ October

$0.6 \mathrm{~L} / 1.7 \mathrm{H}$ November

0.6L/1.7H December

\section{Gehlreport analysis of water front activity}
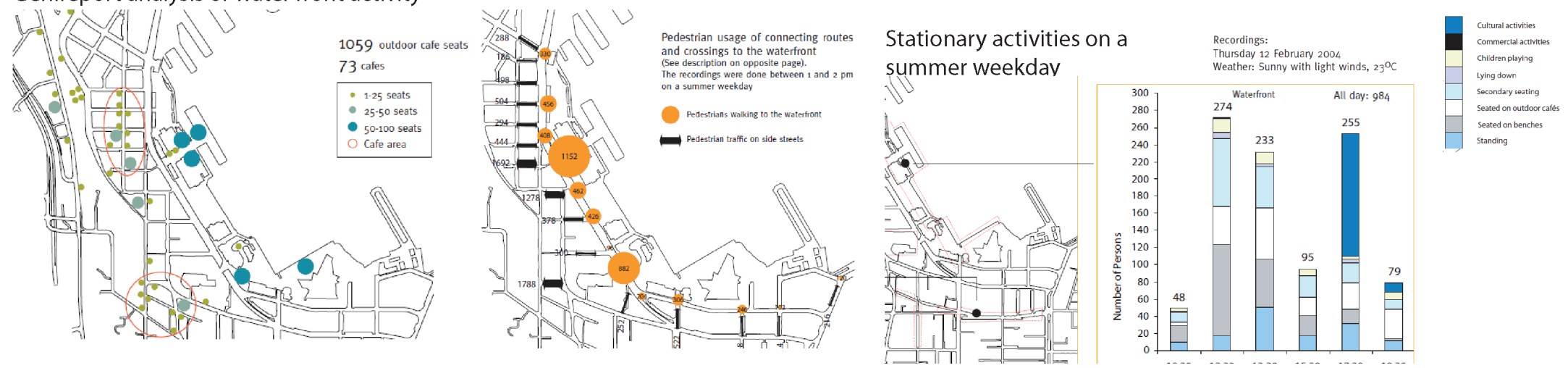

Figure5-2 Wellington waterfront analysis Source: City to Waterfront: public spaces and public life study

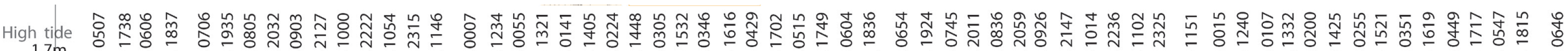

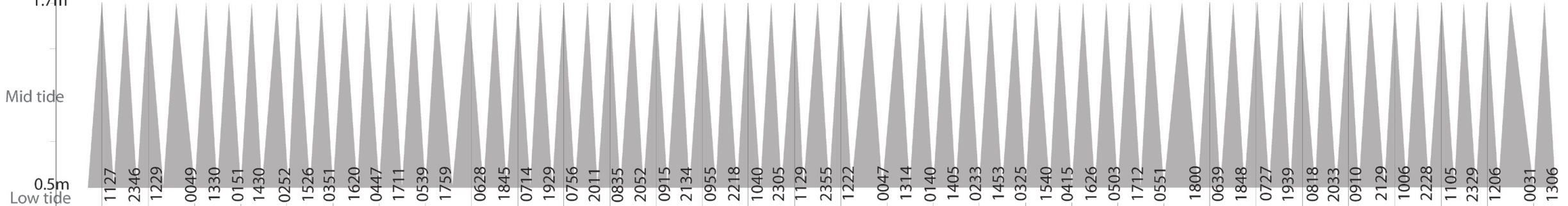




\subsection{A focus on the intertidal zone}

This section briefly introduces the ecological zone that will be regenerated through design. The intertidal zone is considered as one of the most physically harsh environments on earth. Invertebrates and algae living in this habitat are cyclically beaten by the waves and exposed to thermal extremes during low tide periods (Denny). Ecologies must endure strong selective pressures related to predation and competition for space (Connell). The intertidal zone has been chosen as the ecological zone of exploration through design because it is a marginalized area along the whole of city interface with the sea and holds historical significance to Māori.

The government regards the health of the coastal environment as a matter of national importance, and specifically states the significant relationship of Māori, with their associated cultural and traditional ties to the coast.

\subsection{Opportunistic ecologies}

The wharf structure typically covers the intertidal zone, blocking it from the sun and eliminating a regenerative ecology. With this abrupt alteration in environment conditions, nature has opportunistically adapted to alternative living circumstances by "clinging" on to manmade structures such as wharf piles. The following is a photo analysis of the existing ecologies that have adapted along the harbour, with identification of environmental conditions. 


\section{Site Map: Lambton Wharf.}

Reclamation site

Qstate highway 1

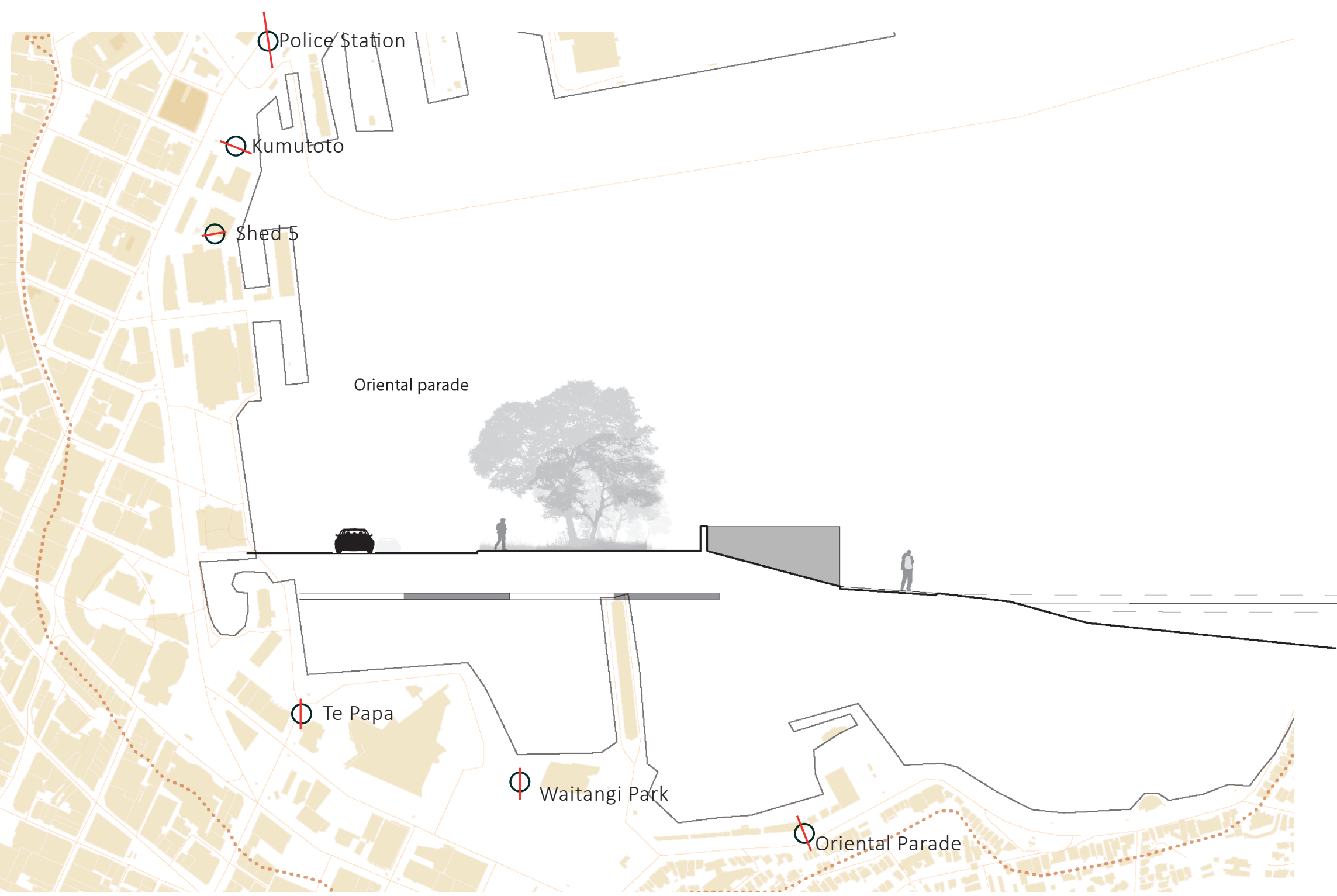




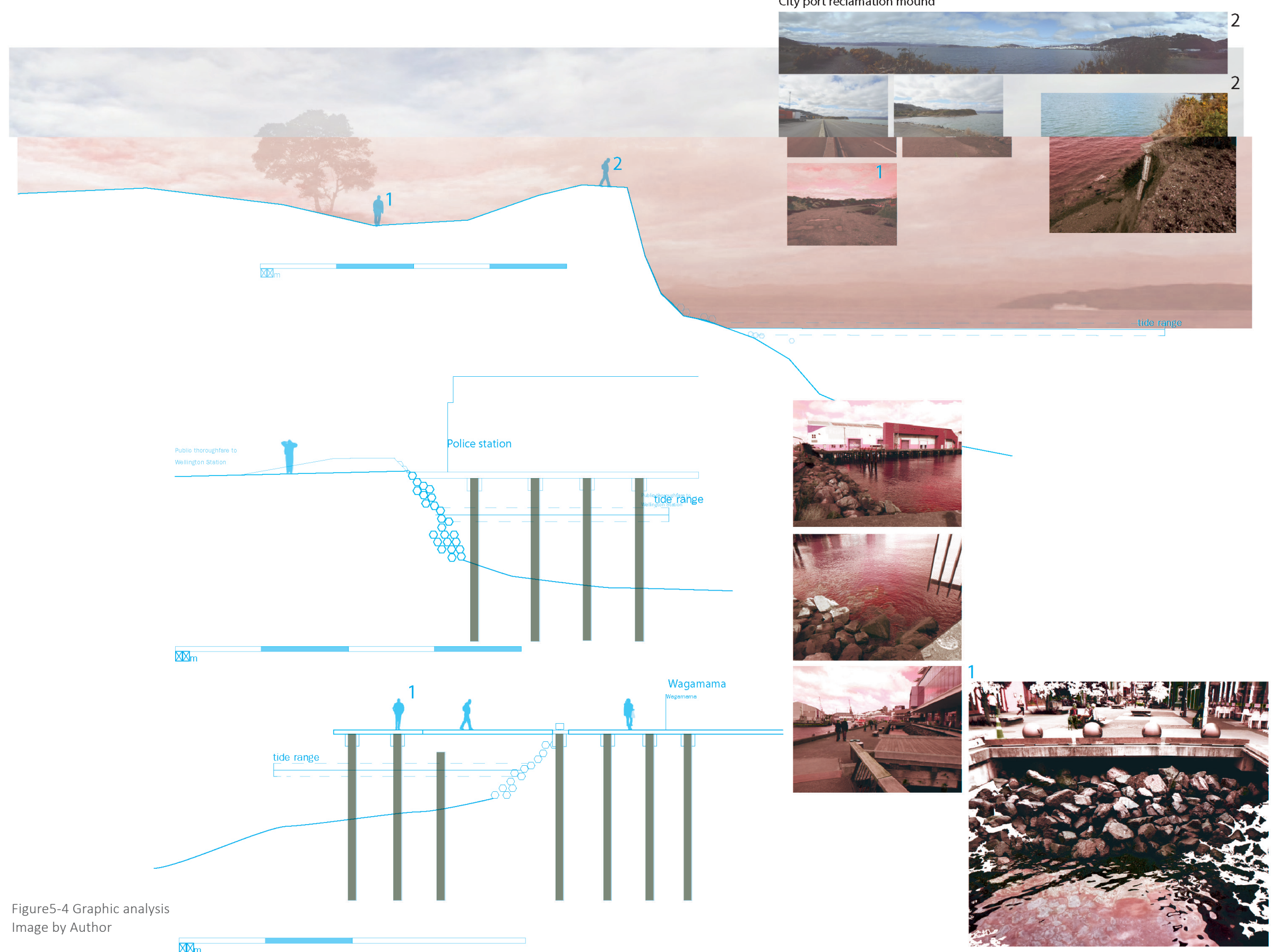



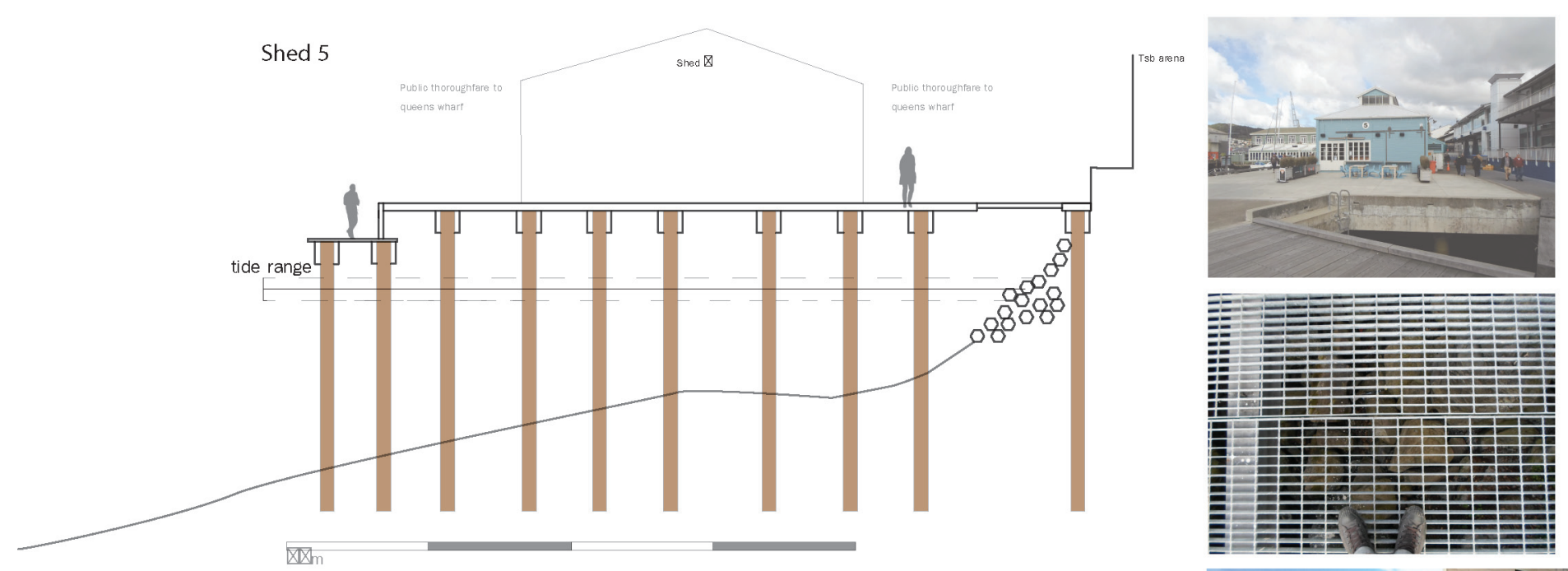

Tepapa
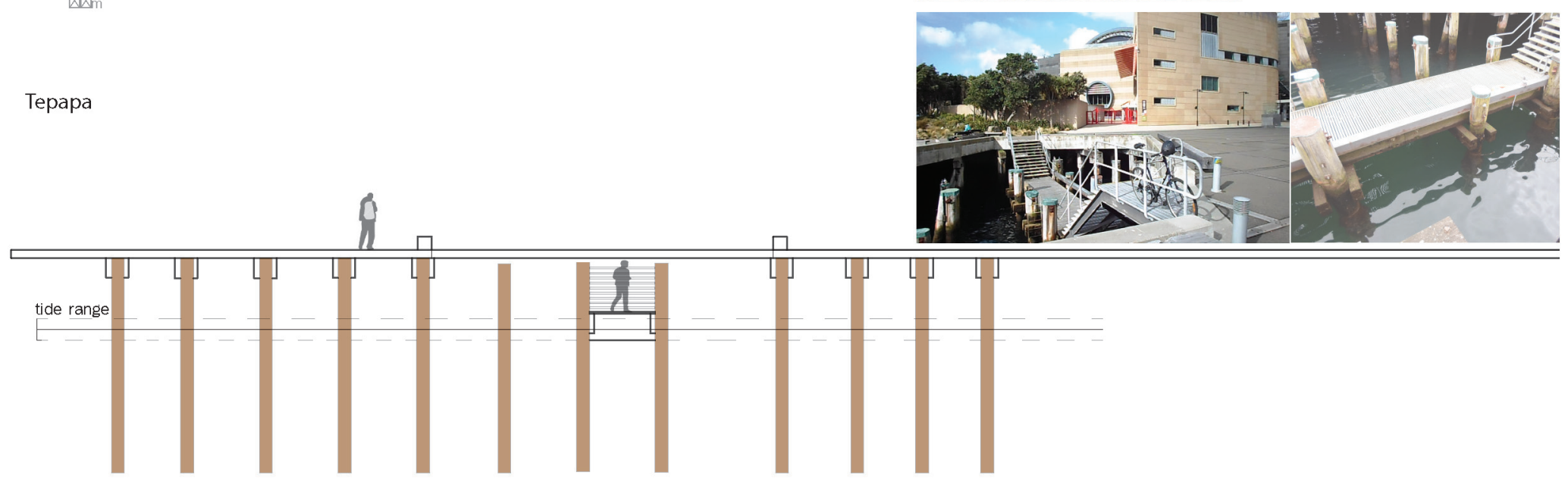

Waitangi park wetland

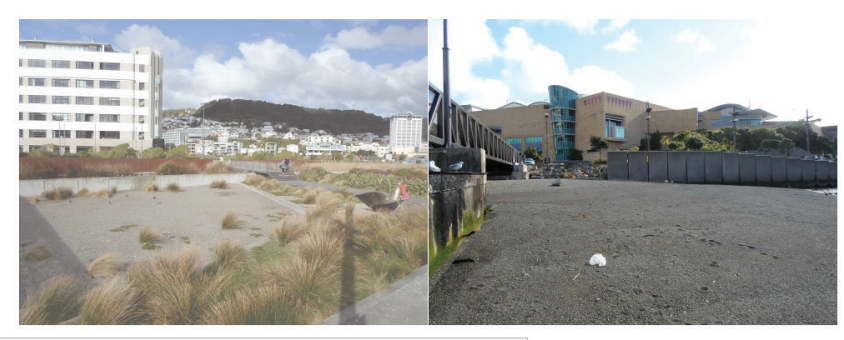




\subsection{Substrate findings}

Docking Ropes:

Mussels latch into the gaps presented in strands.

Wooden Piles:

Algae find anchor points within the exposed wood grain texture that consists of splits and gaps. Grazers are unable to live on the verticality of the piles, due to dropping off and being unable to return.

Large rocks:

Large rocks have steep large smooth faces that make it difficult for grazers to traverse and difficult for algae to attach and not be washed off by waves. While semi relative to the harbour aesthetic, large rocks is foe the most part decoration.

Crevices and cracks:

These areas are where nutrients, particles, and food collect; they are carried by currents and waves and encourage an advantageous settling and growth space. They also store moisture temporarily whilst the tide is out.
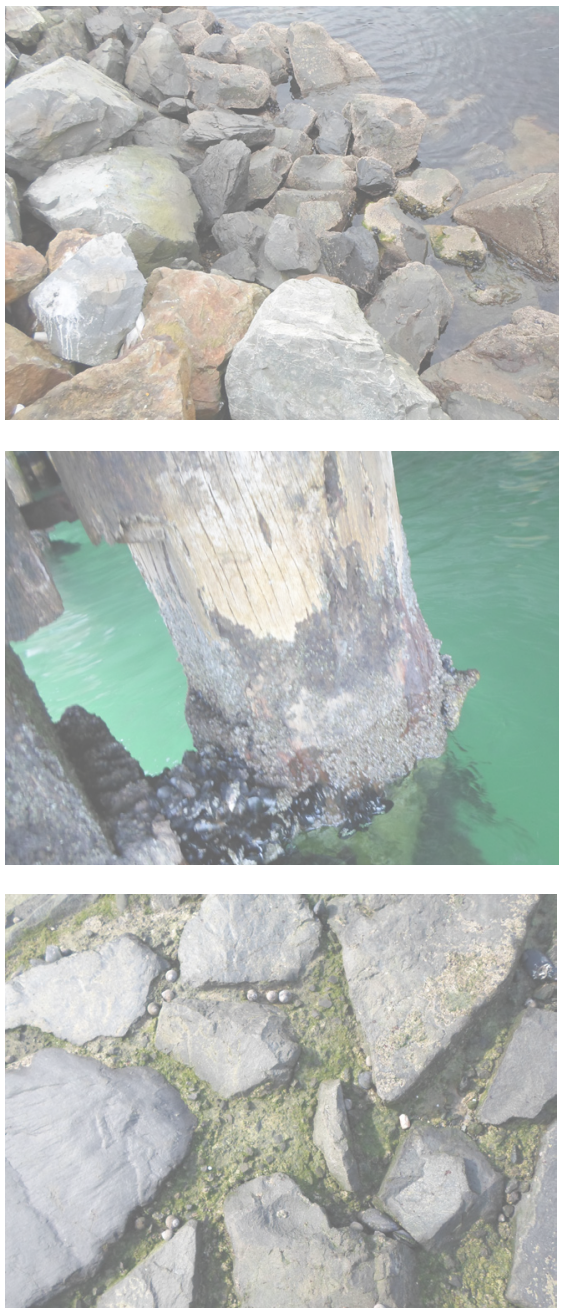

Figure5-6 Reference map Image by Author 


\section{Site Map: Lambton Wharf.}

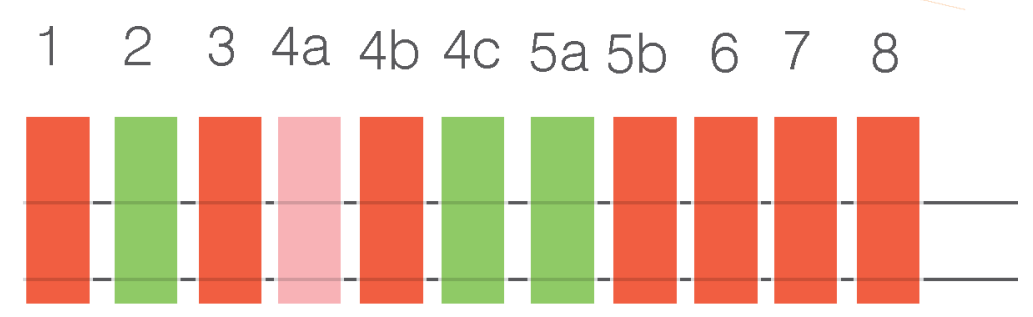

$V$ isual contact level between people and existing intertidal zone ecologies.

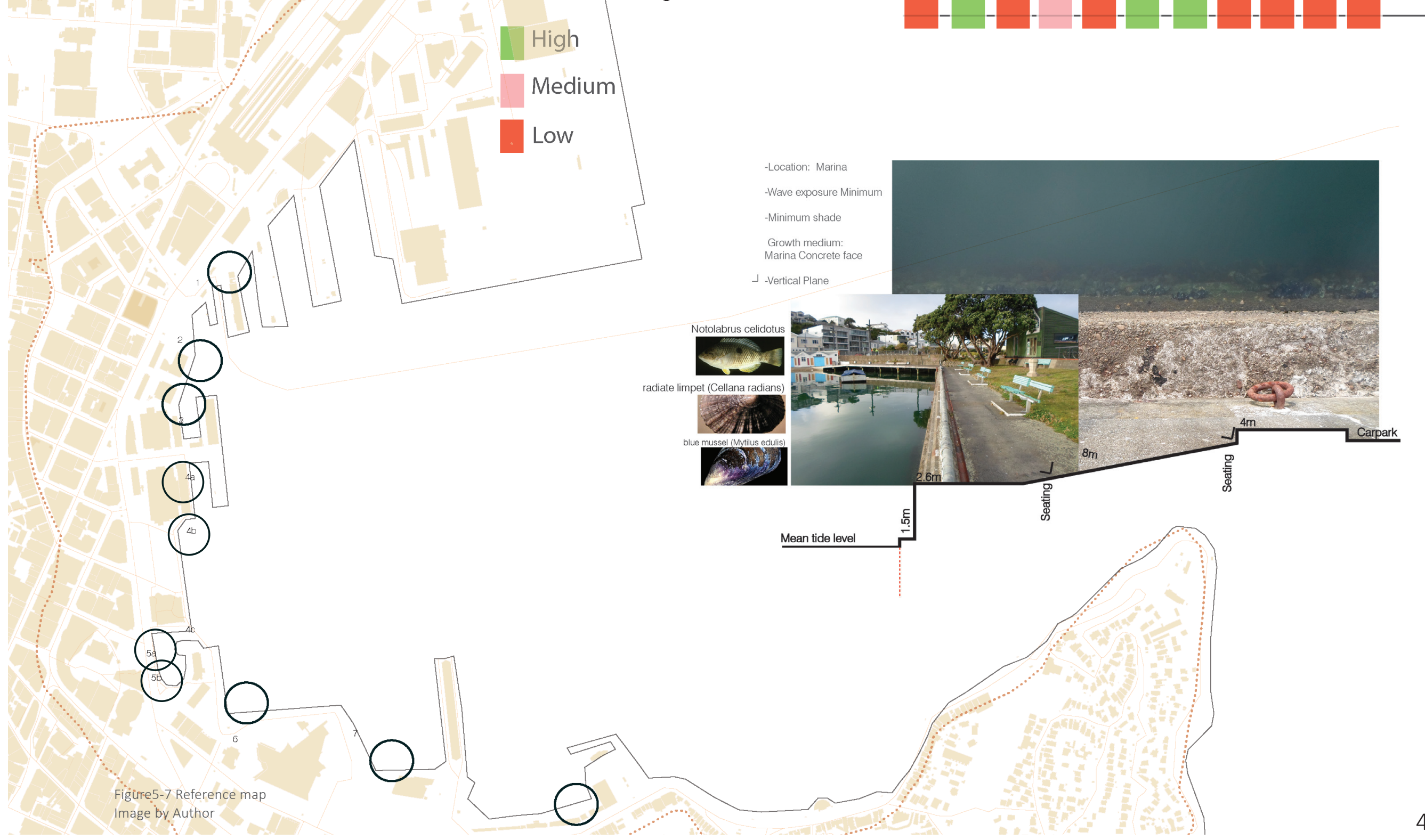



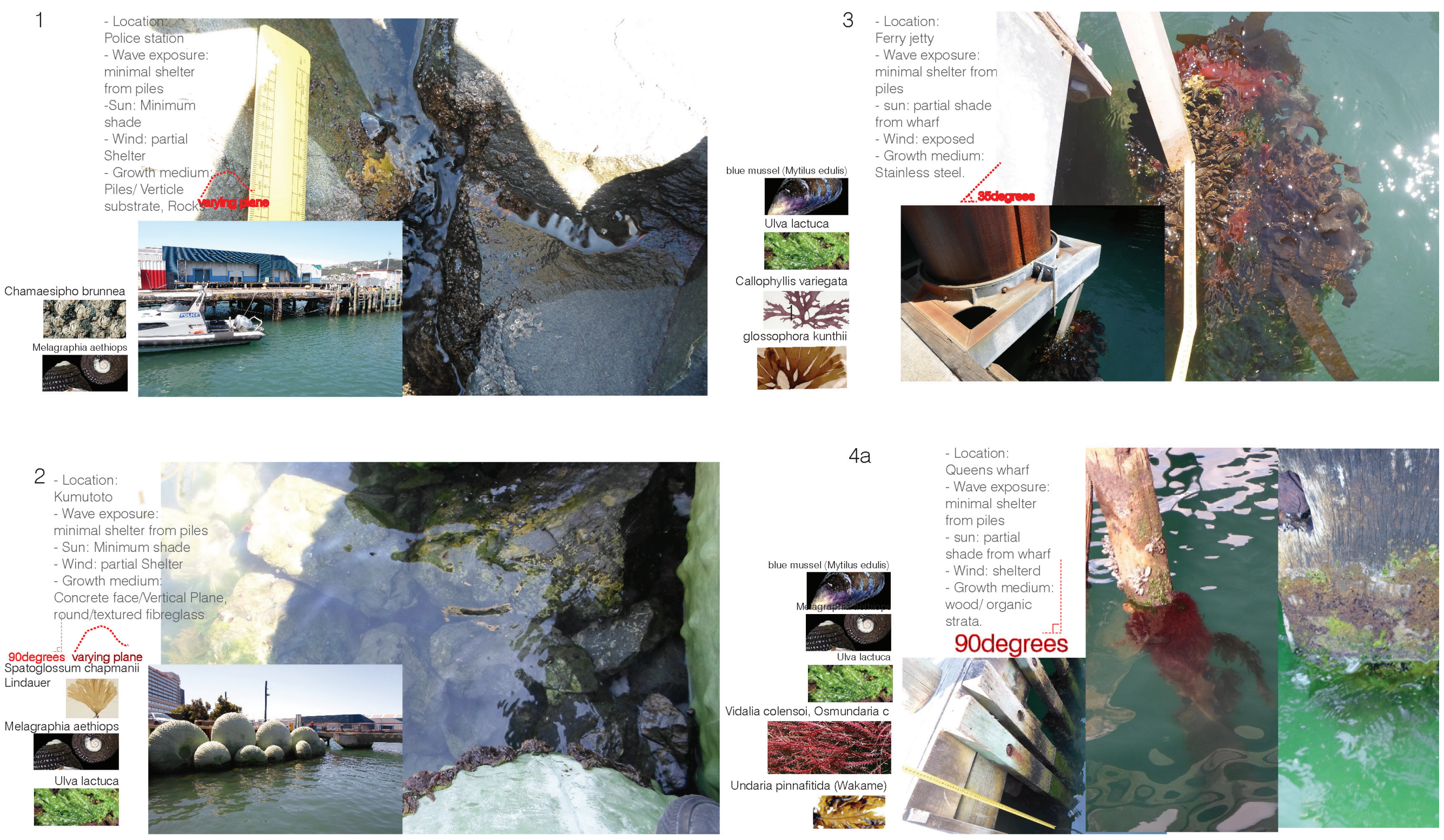

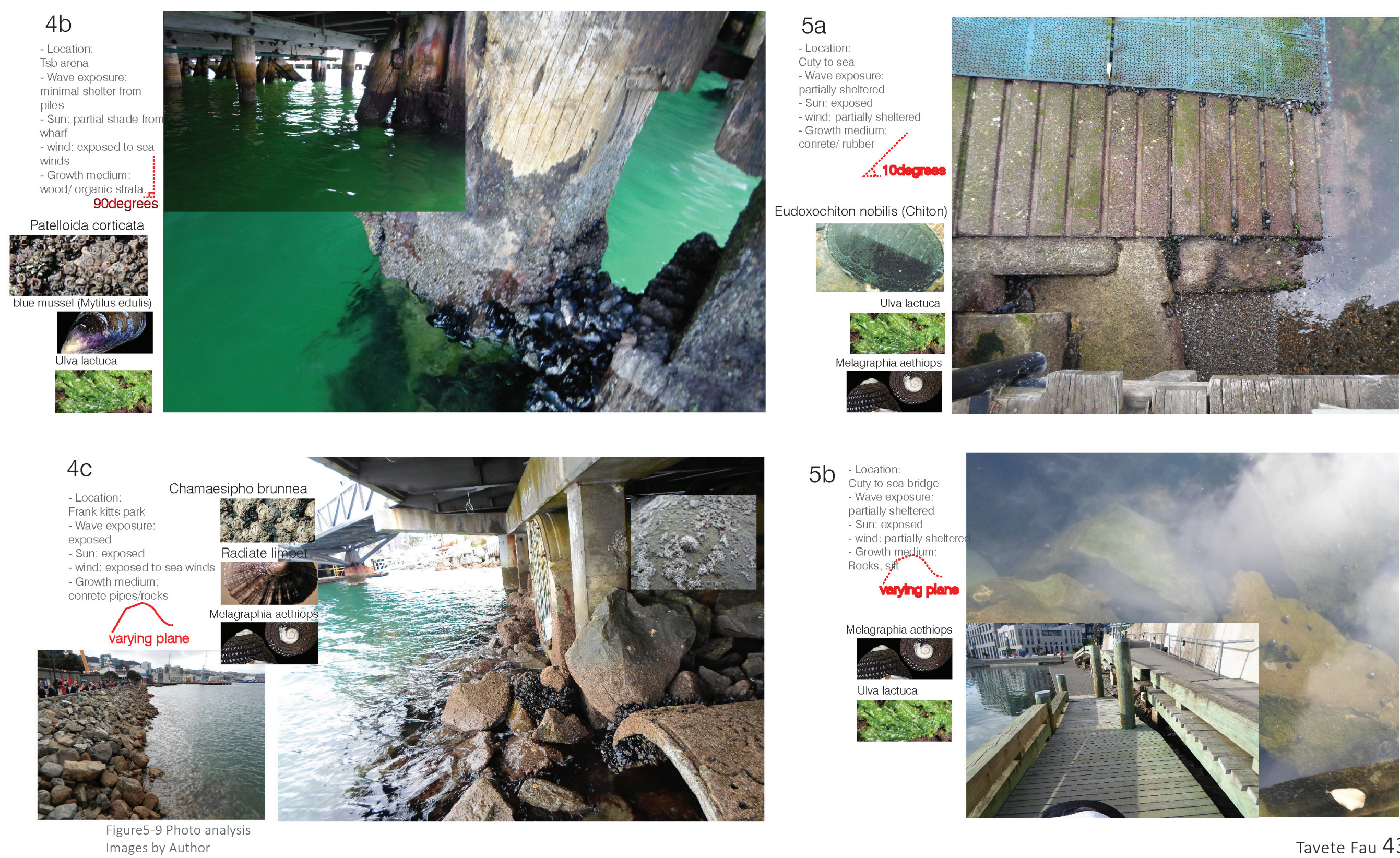
$5 b$ - Location: - Wave exposure: partially shellered
- Sun: exposed - win: expositilly shelltcis - Growth medjum: varying plane

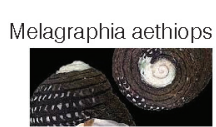 Ulva lactuca Nitis?

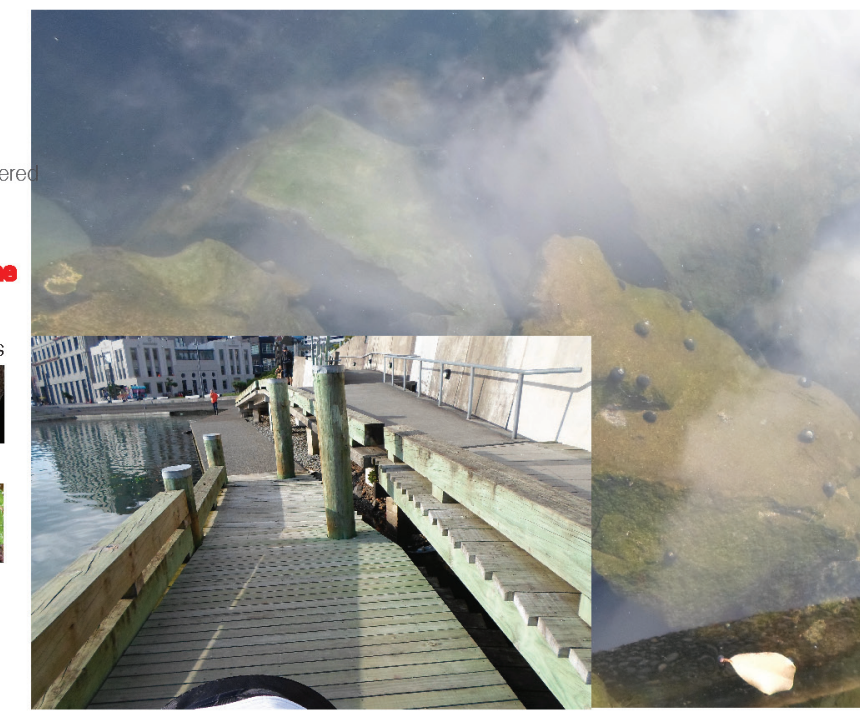


6

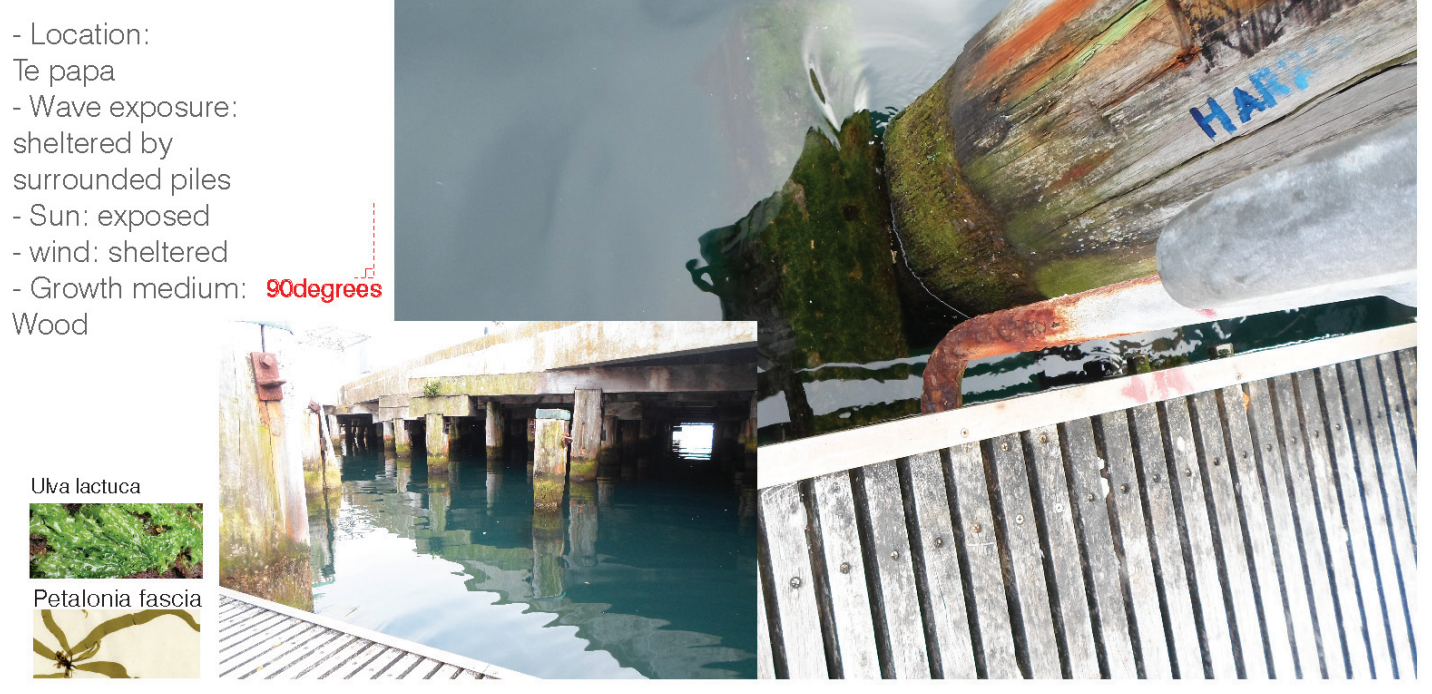

7 - Location:

Te papa/marina

- Wave exposure

Exposed

- Sun: partially

Sheltered

- wind: exposed

Growth medium:

Rocks, silt

Ulva lactuca

$2 \times 2.8$

Reef starfish (Stichaster australis)

6. 13

Figure5-10 Photo analysis

Images by Author
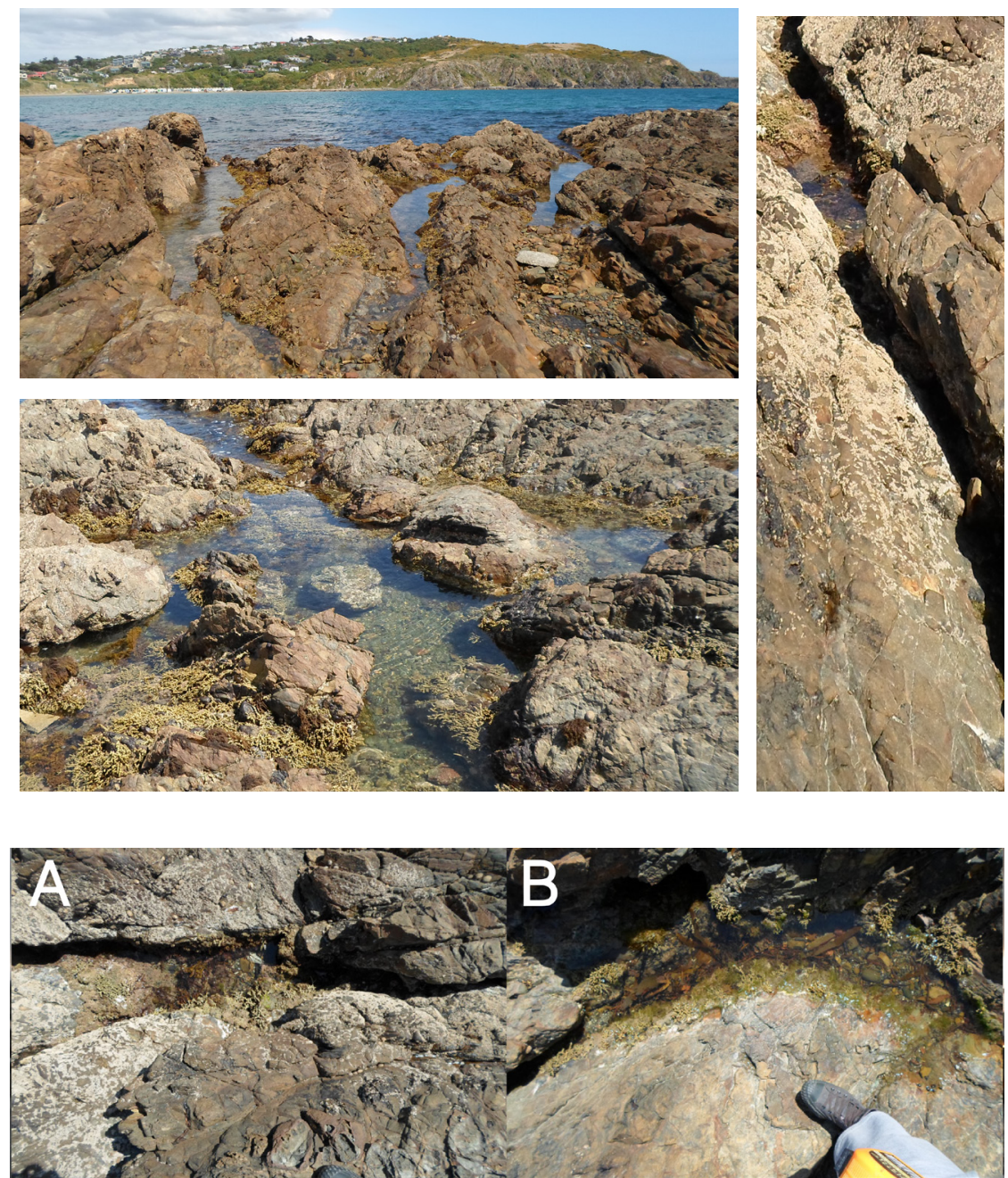

Figure5-11 Photo analysis of Titahi Bay rocky shore

Images by Author 


\subsubsection{Fundamental survival considerations for design applications}

The following section identifies reasonably controllable factors that can be modified through intervention. The factors consist of fundamental survival conditions that need to be improved and/or considered in restoring health to the intertidal ecologies within the site. This thesis identifies the rocky shore as the preferred substrate for supporting intertidal ecologies as opposed to a sandy shore ecology. This decision is partially due to rocky shore substrates containing denser ecologies and more species; further reasoning is discussed in chapter 7.5 .

Sunlight is needed for habitat survival, it is essential for algae growth via photosynthesis. Algae contribute to the ecology substantially for providing food, shelter and in some cases providing a living substrate for other species. Seaweed have different light requirements green seaweeds need the most, brown seaweeds need less and red seaweeds need the least. Existing seaweed in the harbour indicate light conditions in the harbour.

Ecology sustenance is predominantly dependant of tidal movement Barnacles, seaweed, and even Grazers to an extent (limpets) cover a substantial portion of the intertidal zone species, their main food source is delivered by ocean currents, therefore food is always available and when tidal flushing is evident. Only space is limiting.
Survival factors for intertidal species in a rocky shore substrate (Figure 5-11) pertain to the living space provided by surface textural composition. Composition consists of rocks that are broken, fissured (split or cracked, forming a long, narrow opening), shelved, tunnelled, caved, and arched. These manipulations encourage latching, protection and shelter for species. A substrate study was carried out in Titahi Bay to gather an observational and experiential understanding of a healthy ecology. Titahi bay shared similar environmental factors to the Wellington site without the wharf and other restricting factors, images $A$ and $B$ exhibit healthy tidal semi isolated pools of $80 \mathrm{~cm}$ deep and $10 \mathrm{~m}$ landward from low tide.. Living space factors are further explored in chapter 7.5.

These considerations inform design development for a substrate that can maximize diversity of species in the intertidal zone, increase attach rates, and allow for sufficient sunlight and tidal flux. These factors will be considered in conjunction with association with humans in the following sections. 


\subsubsection{Environmental considerations}

The following data identifies reasonably uncontrollable factors present in the larger context of the site that cannot be altered by intervention. The research suggests that environmental conditions of the harbour can support the basic necessary requirements for intertidal zone if interventions successfully address controllable factors mentioned in the prior section 5.7.1.

Projected sea level rise:

Current sea level trajectory (relative to 1990) estimates a rise in sea level to approximately 0.8m in 2090 (Bell, R. G. Hannah, J.)

Nutrient make up of sea water:

The mixing of sea water through currents in the ocean is necessary for sufficient nutrients to feed algae filter feeders and other species. Some nutrients necessary for growth are potassium, magnesium, oxygen, nitrogen, and hydrogen. Studies suggest the channel connecting Wellington Harbour to the open sea is large enough to ensure sufficient mixing of the harbour water with that outside.

"It would therefore be expected that although some special hydrological characteristics would be generated within the harbour, these would soon be assimilated by the circulation system, and would be reduced by the exchange with waters from outside the harbour". (Maxwell) (Gilmour)
Water Salinity:

Marine plants such as seaweeds and many lower organisms cannot control their salt levels and therefore can rapidly dry out under the sun if salinity rates are too high. Salinity levels in the harbour are at 34-35ppt (Maxwell) this figure is on par with the world average and is sufficient in supporting the potential regeneration of species.

Storm water discharge:

Storm water discharge outlets are often a considerable hazard as they carry sediments and other industrial substances into the sea that can cause harm to nearby ecologies. Storm water discharges in the Lambton Harbour are considered medium to long term risk to the health of marine organisms. (Stephenson) An exception is the fluctuations experienced in a storm. Special measures may need to be considered that are in areas in close proximity to storm water outlets.

Seashell food standards:

Seashell food standards must be met for consumption. The New Zealand Food Standard collected samples of shellfish in 2006 and specify that shell fish (blue mussel) along the harbour did not exceed national food standards in regards to bacteria content and metals (calcium, lead, mercury) and are edible (Milne) . 


\subsection{Species selection process for future ecological diversity}

Projections have been made in this thesis about what types of species will probably live in the intertidal environment. The scope of this thesis has informed the depth of research conducted on the potential ecologies that might exist once a substrate is established. From identifying the present species types, assumptions were made on probable future ecologies to flourish in conjunction with a new substrate. The parameters used to make the assumptions include;

A study of closely "related" species to species that exist

opportunistically, this includes species that are typically found within the same food chain.

A study of the preferred conditions to support existing opportunistic species, this informed the selection of species that hold similar requirements for living conditions to ensure survival.

The next chapter will develop a design methodology that responds to the criticisms and principles of previous chapters. The design methodology provides a way to design urban landscapes in the midst of urban problems and threatened ecologies.

The following chapter discusses and investigates materials that are needed to create a contemporary substrate to support the intertidal species mentioned.
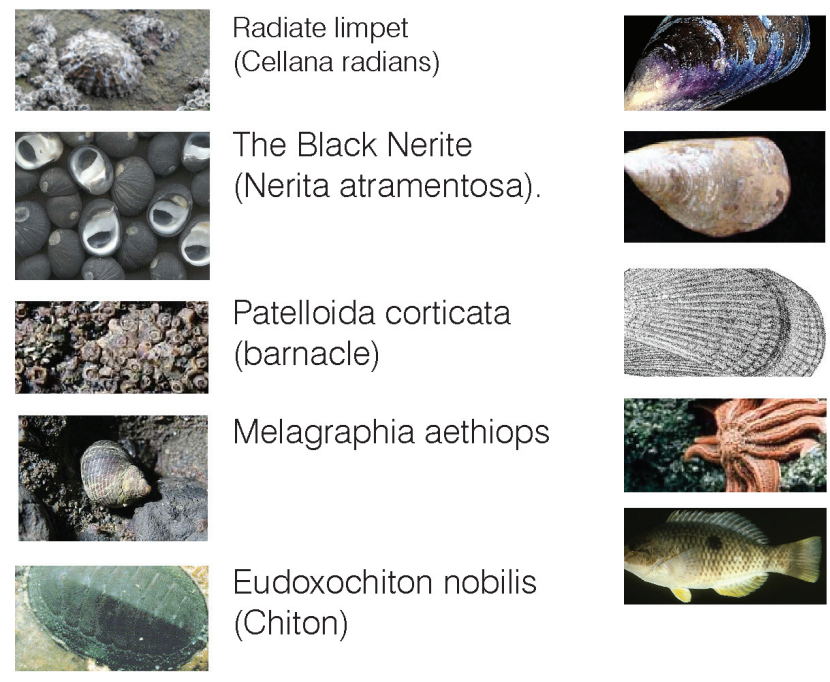

blue mussel

(Mytilus edulis)

Perna perna

(invasive)

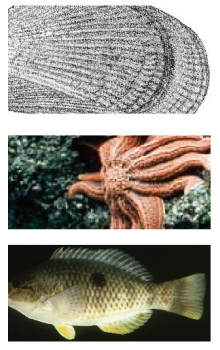

ibbed mussel

(Aulacomya atra mac

Reef starfish

(Stichaster australis)

Notolabrus celidotus

\section{Seaweed}

Seweeds provide nutrients and energy for animals; either directly when eaten, or indirectly when decomposing parts break down into finer particles and are later taken up by filter-feeding animals. Beds of seaweed provide shelter and habitat for many of intertidal animals.
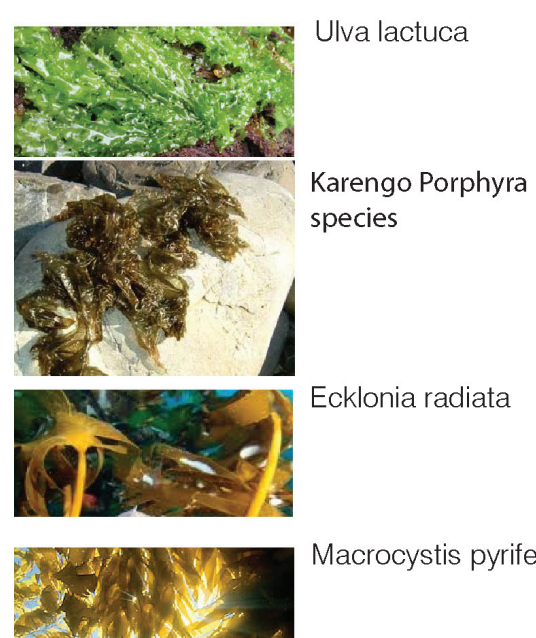
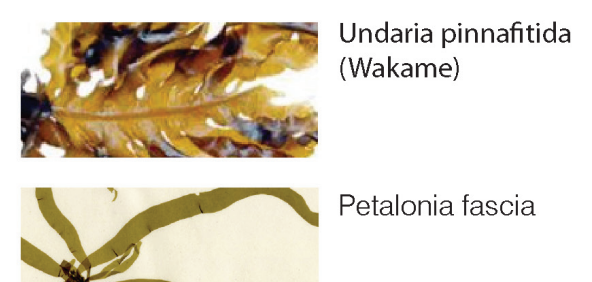

Macrocystis pyrifera

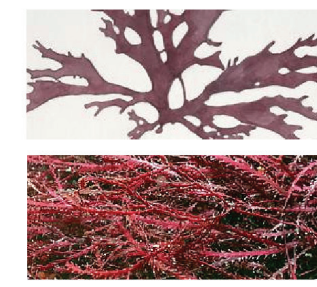

Callophyllis variegata

Vidalia colensoi, 


\section{Design methodology}

\subsection{Introduction}

The design methodology for this thesis began with researching the Māori worldview perspective to understand the core principles.

Design strategies have been interpreted from these core principles and have been explored through design research. Further research consisted of finding relative approaches evident in contemporary landscape architecture, sketching, mind mapping, all of which generates ideas. The derived design strategies are discussed in this chapter.

\subsection{Design methodology and strategies}

The development of a design methodology is based upon the premise that extracted principles from the Māori worldview present a beneficial approach to urban ecological restoration due to its environmentalist and holistic considerations. It considers the health of ecologies which humans are a part of. Encouraged interactions form bonds, associations, and relationships that are mutually beneficial and equal. The design criteria have been integrated with conservation strategies where appropriate to inform the design criteria.

\subsection{Design Strategies}

- To create spaces that use tidal fluctuation to encourage intimate human attentiveness to the natural environment and ecologies. Intimate attentiveness of the natural environment would develop emotional connections linked to wairuatanga.

- To horizontally manipulate intertidal platforms to create public accessibility and interaction with ecological restoration. Community interaction with conservation would increase the Mauri of the environment and the community linking to Mauritanga.

-To empower the individual and community to establish a collective guardianship over the natural environment. This would include clear indicators of ecology health that encourage public assistance.

-To develop a contemporary substrate to restore mauri of marginalized intertidal ecology

-To reveal marginalized cyclic processes, ecologies, and past social memories of the waterfront in a way that reorients people with the Māori world view concept of time governed by the natural environment. 


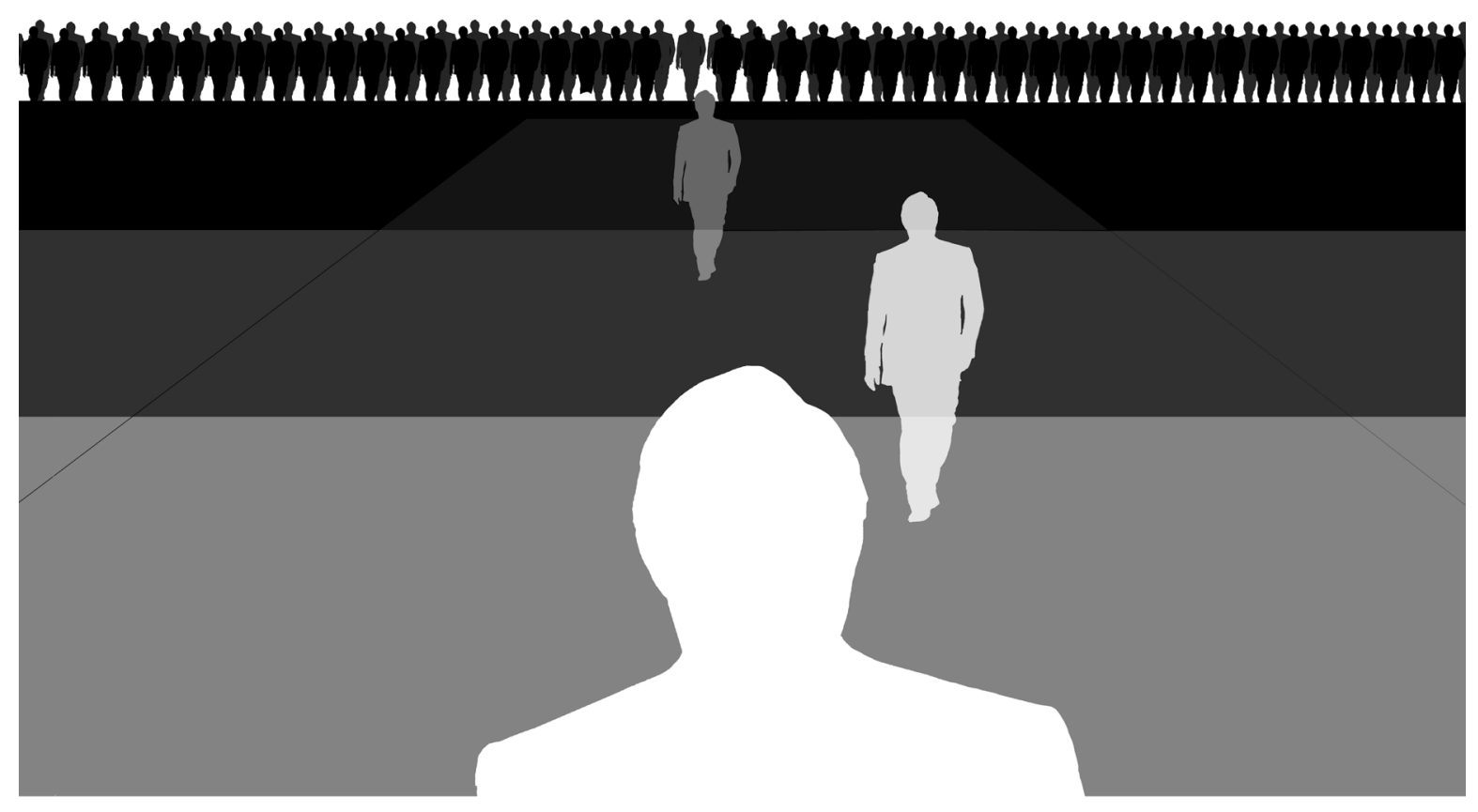

Figure6-1 Hunch illustration 1: Degrees of submersion Image by Author 


\section{Design}

\subsection{Introduction}

Research and development of principles, history, ecological needs and associated intricacies have generated design strategies and design ideas that dictate the design moves that will be discussed in this chapter. A preliminary hunch is first discussed to express the intuitive contributions and directions initiated early on in the research.

\subsection{A Hunch}

A hunch expresses an intuitive response to the site, "a method of catching intuition and first thoughts" that can "capture the idea that will drive the idea of an entire project" (Holl). The hunch illustrated (Figure 7-2) is derived from experiencing the Wellington wharf. It identifies the vivid segregation of past social memories tied with the intertidal zone against urban layers, as expressed with the bold outline of the harbour. The rocks rising tide level "define" a outlined countenance of a person, this expresses human's intrinsic place in nature. The level of tide submersing the persons "ear" identifies the lulling effect of water when being submersed, blocking out "noise". This effect entails the beneficial properties that nature holds for humans, particularly that of relief on the edge of a city environment.

\subsubsection{Experiential qualities}

The hunch has been explored through landscape architecture in the following pages, this section explores the potential experiential elements intended for the final design. The experiential elements consist of the following:

\subsubsection{Sounds of a sanctuary}

The proximity to the city embodies the associated noise that interferes with sounds of the tide. A rocky tidal zone exhibits a diverse range of sounds as observed from Titahi Bay. Tidal sounds include crashing of waves during rough spells, tricking sounds associated with rolling ripples lightly splashing into hundreds of crevasses. The diversity of sound is apparent with proximity. The predominant calming sound of waves is heard from a far. In close proximity this sound exposes itself as an array of different sounds from water colliding against different compositions of rock. Intimate proximity allows for a deeper level of immersion. Eliminating sound was possible by large drop in levels or barriers for this reason seats are in close proximity to the landscape substrate, with only one seat above and detached from the landscape. This juxtaposition encourages exploration and engagement by closer proximity. 


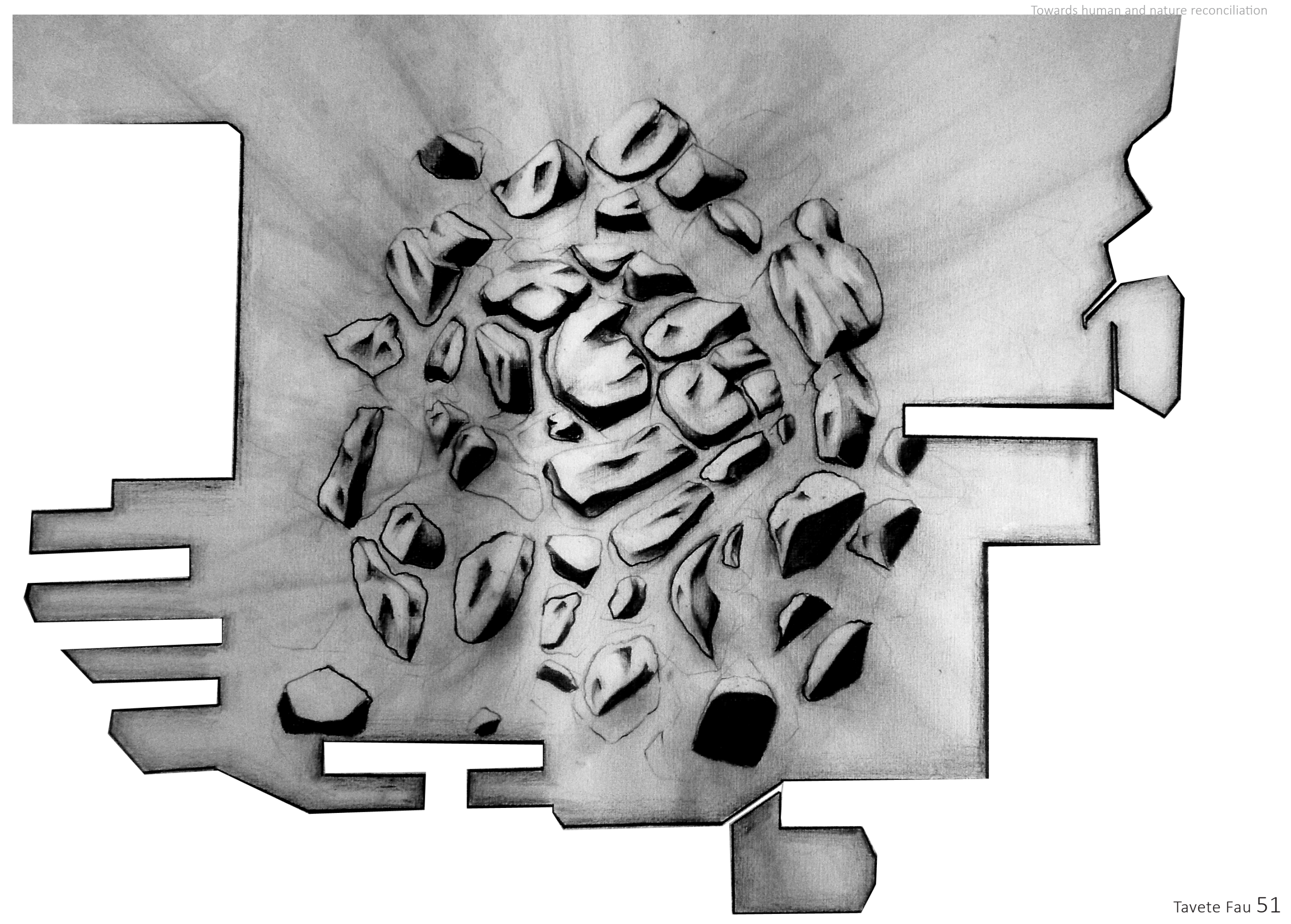




\subsubsection{Haptic initiation}

Exploration of the rocky shore in Titahi bay forced me to realign and reorient myself in the natural realm. This occurred as I traversed the rocky surface found myself rebalancing myself, and timing the landing of each foot correctly by cognitively reading the landscape. Haptic exploration involving cognitive responses to the landscape has been developed and used for initiation to the sites.

Haptic exploration involves communication through touch. Initiation is used to identify a rite of passage. A gradation of surface materials and topographical manipulation is used to inform a transition between thresholds and communicate to the visitor that they are entering a separate realm. The gradation of materials consists of large $(50 \mathrm{~mm})$ rocks set in exposed arrogate fashion. This is large enough for people to have to consciously navigate, and consequently physically reorient themselves to undulations of the landscape.

\subsection{Design Moves}

These design moves represent a holistic response to the wharf as a whole and are then designated to specific sites as deemed appropriate, sometimes being applied in their entirety and in some cases adjusted to specific site conditions. Application of a "humans in nature consonance" design and conservational approach, paired with supporting design strategies dictate that visitors to the site are aware and engage with the intrinsic interdependences between people with nature that have been marginalized along the waterfront. As aforementioned these include immediate reciprocal sustenance between humans and the natural environment(crops), orientation from nature (landscapes), mental stimuli and education from haptic discovery with nature (exploration), all governed by the time index from nature (cyclic processes).

\subsubsection{Reciprocal Mauri regeneration platforms}

Public engagement with ecologies introduce opportunities for conservation for use. People can assist the ecological balance in a site by reducing invading species to encourage more diversity as well as reduce potential problematic consequences of sea lettuce overgrowth to humans that releases toxic gases (Murphy). Accessible ecological platforms for reciprocal sustenance between humans and ecologies for two scales;

Individual scale: Research indicates that a few species of seaweed are edible, namely; Sea lettuce (Ulva lactuca) Karengo and Wakama (Undaria pinnafitida). The extraction of Sea lettuce and Wakama will reciprocally assist in sustaining the ecology as these algae can block out sun to lower species. There are also benefits of consumption at a community level. 

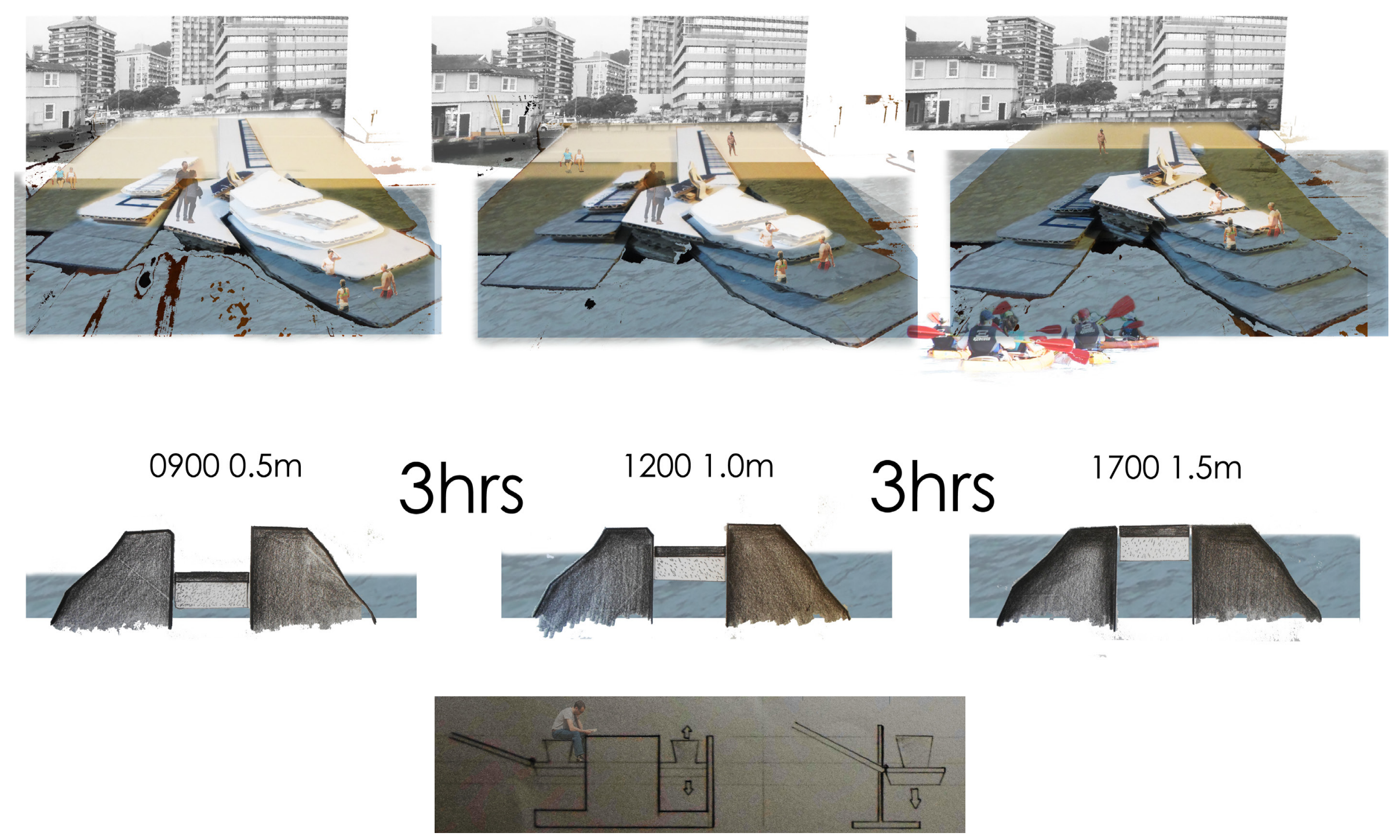
Community scale: Wakama is an introduced species and grows rapidly, its reduction on a community scale will retain balance in the ecology. Reduction of sea lettuce on a community scale will reduce excess algae build up and decomposition which inherently creates foul odors and even toxic hydrogen sulfide gas. Preemptive reduction will be assisted by supported habitats for species that also consume sea lettuce, namely Parora (Girella tricuspidata) which is a fish species, and Grazers with increased lateral movement along horizontal substrates.

These platforms will be spatially composed to inherently encourage haptic discovery to allure visitors and mental stimuli to attract return visits.

\subsubsection{Intimate spatial exchange islands}

The cyclic nature of the intertidal zone composes changing inhabitable spaces to encourage human attentiveness to the natural environment and emotional connections linked to wairuatanga. This creates a cognitive assertion to visitors that they are in a separate realm. Tidal change has been explored for its capacity to embody the cyclic tidal height change through use of floating perforated concrete (lighter) platforms consisting of a Styrofoam composite base. Exchange islands involve the interaction of humans with the intertidal zone. These images illustrate a study of the Wellington tidal range, and also lead to exposing possibilities of human interaction. Islands are to have a wash that occurs on more horizontal slopes. They are to be dispersed in a manner that breaks dispersed in a manner that breaks waves that may hinder the slightly sloped generation of algae and other species.

\subsubsection{Incision and rupturing to reveal and reestablish spatial, historical, and cyclic orientation}

A site contains layers of history, landscapes, and place names.

Consequently sites possess meaning and significance embedded in the memory of people once associated with it, such as past owners and inhabitants. A site may contain hidden layers of meaning and value that enables us to grasp a better understanding of the past. Professor Hirini Matunga who has extensive experience in indigenous approach to planning, advocates that it is the creation and manipulation of a space that potentially can shape new social and cultural identities, new landscapes, new monuments, new histories and new sites of significance. (Matunga)

Time as prescribed through research of Māori culture is that the past resonates in the present. The incision and rupturing of the industrial layers of the wharf allows past storehouse of social memories to resurface. These consist of the day to day memories that framed the lives of Māori people on the significant threshold (intertidal zone) including the active water based trade that covered the foreshore as witnessed by European settlers. Redefining the intertidal zone spatially re orientates visitors with previously hidden landscape features (Figure 7-6). 


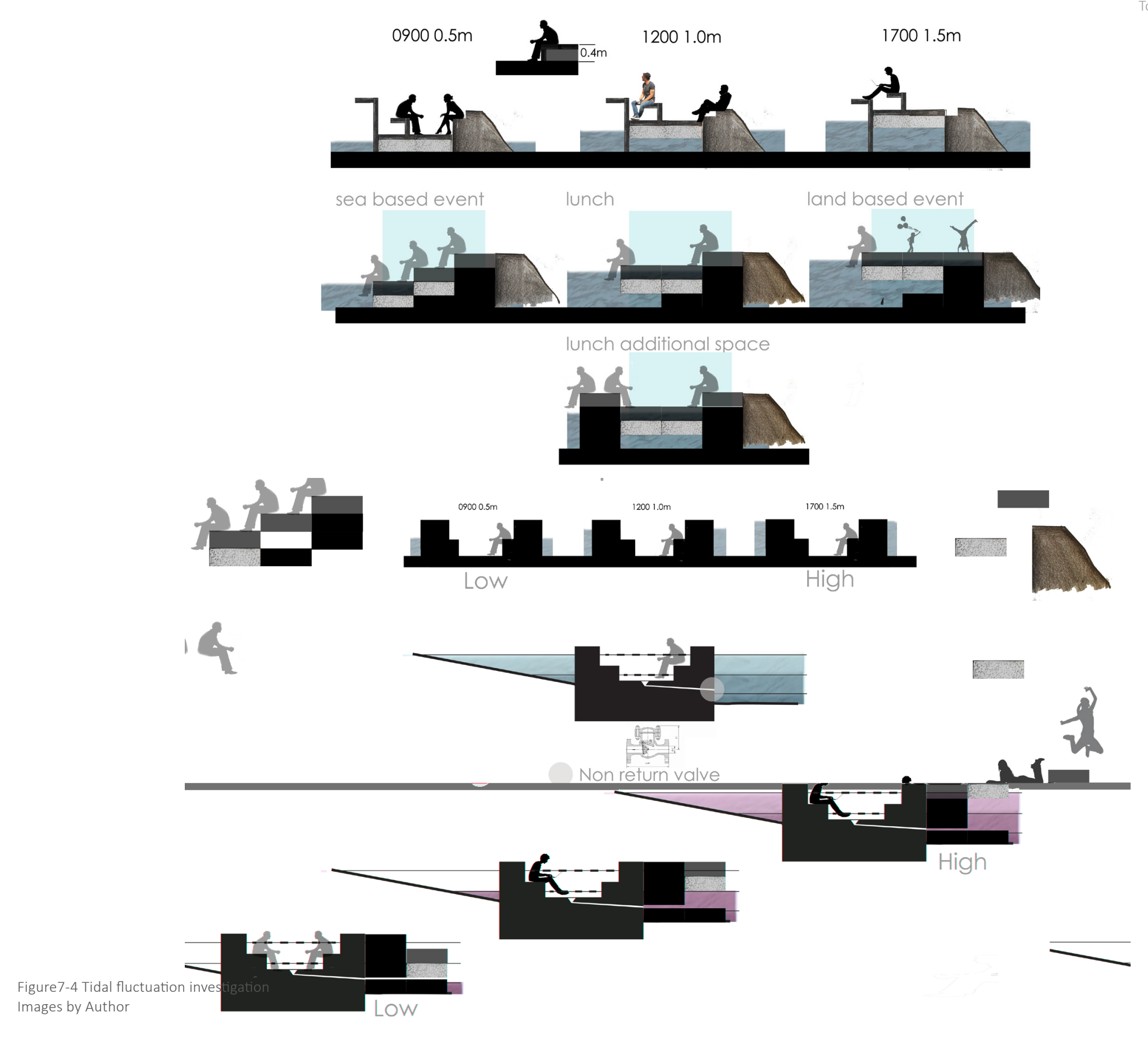




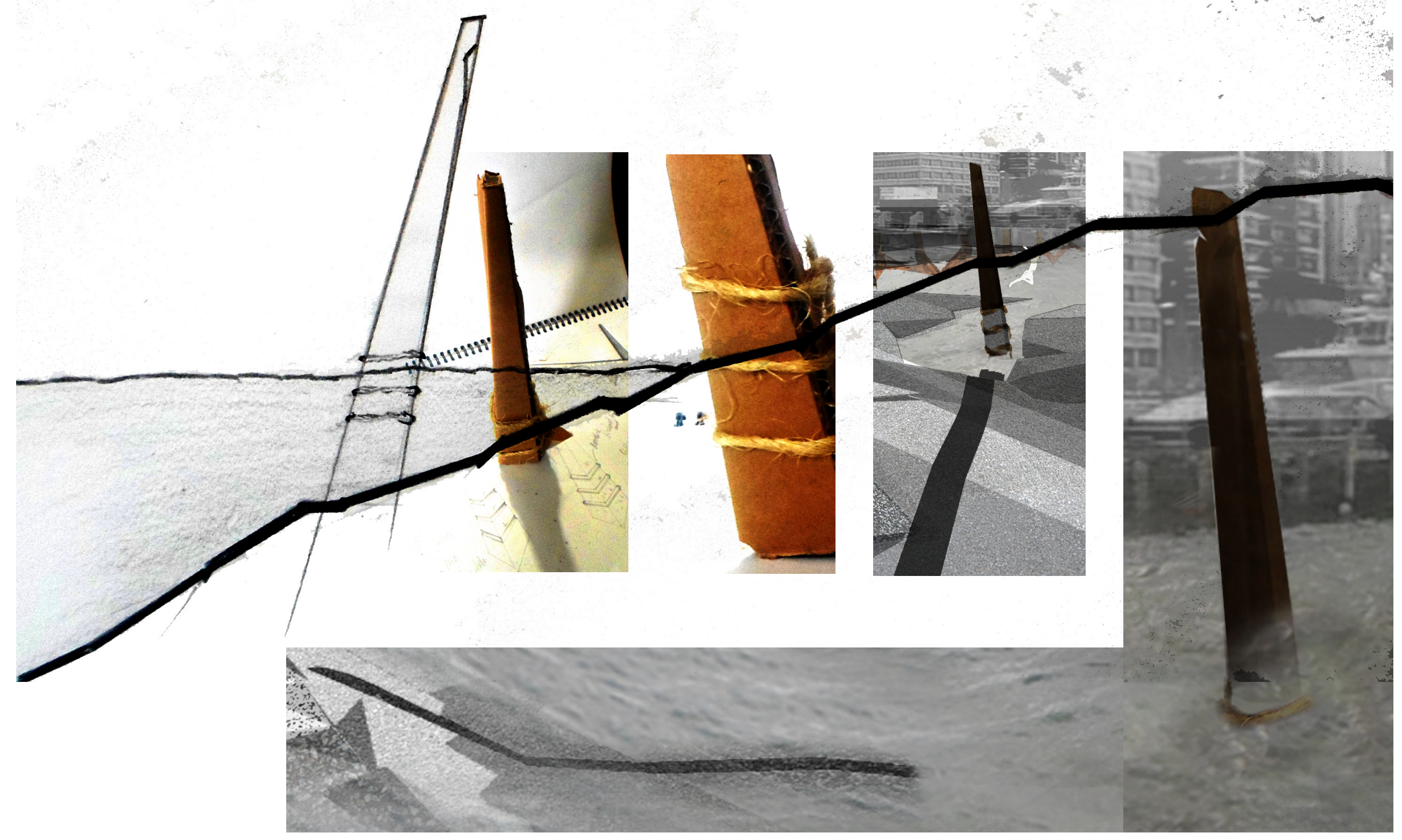



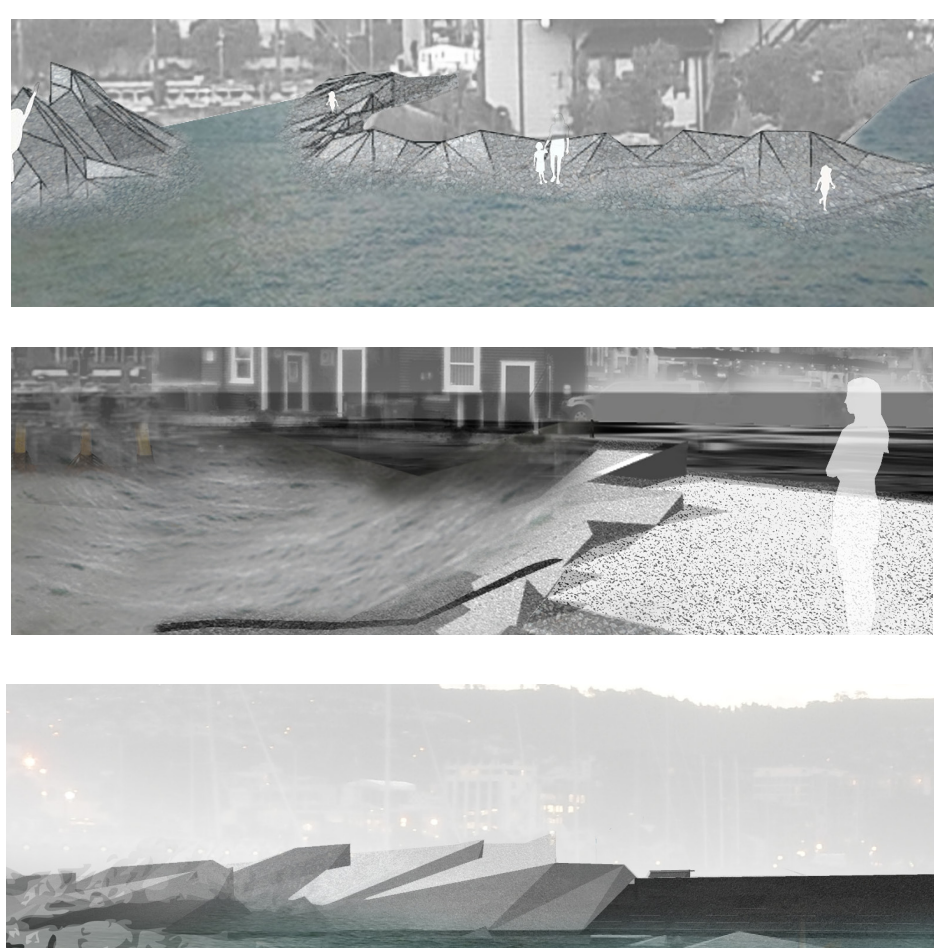

Figure7-6 Revealing by rupture: evidence in final esigns

Images by Author
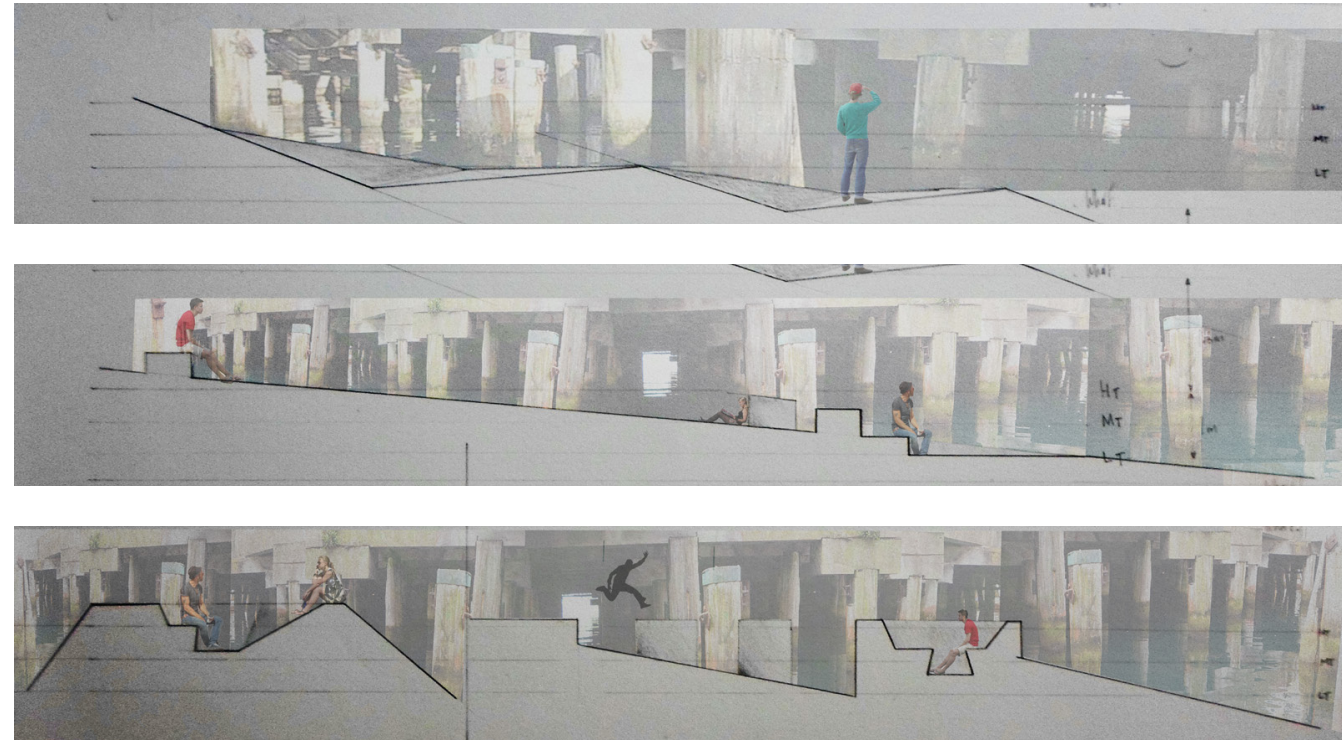

Figure7-7 Sections: slope investigation Images by Author 
An alternative time indication intervention is explored to unite visitors with the spatial, historical, and cyclical components inherent in time defined by Māori. This is achieved by making cyclic processes perceptible for means of witnessing passing time; the time witnessed is not in direct association with the mechanically measured time index. Rather it embodies the cyclic processes of the tide and sun phases to display the passing of the day (Figure 7.5). Visitors will discover the informative properties over time as they engage with the space.

The final design creates shadow throughout the day that sweeps the ground from one side to the other; appropriate readings can be taken subjectively throughout the day (Figure 7.5). Throughout the night it is a light source. There are three rope rings (Figure 7-5) that represent high tide low tide and middle tide (can be adjusted to compensate for sea level rise). The structure is to partially have the finish of the perforated concrete explored in this thesis; it will indicate when the tide is going out when the area above sea level line is wet and indicate when tide is coming in when area above sea level is dry. The design is to be extended out of the low tide sea level, the form and placement will draw attention to tidal change and possess allure for visitor investigation.

\subsubsection{Active Terraces to promote cultural association}

evident and explored through platforms and islands. Terraces are to designate space for functions that are associated with the intertidal zone, to drive community participation towards a collective idea of membership linked to Whānaungatanga principles, and incorporate human interactions one with one another. Design application of this design move is strictly specific to the context of individual sites and is explored within their description.

\subsubsection{Deriving a "humans in nature consonance" Substrate; A contemporary rocky shore}

The painting from 1820-1881 suggests that the Lambton Harbour consisted of sandy shingle shore and rocky shores further out towards the peninsula of now known Roseneath. A typical preservationist approach would explore possibilities of returning to semi sandy shores. The redefined conservational approach insists the consideration of the contemporary practicality of propositions and to ascertain a sustainable choice. This consideration exposes a sandy shore approach as irrelevant, as establishing a sandy shore will eventually lead to sand being pushed along the harbour interfering with survival of algae seeds and the subsequent death species. This occurs as the existing ecologies are those found on rocky shores, the contemporary environment forces ecologies to be opportunistically "clinging on" to whatever substrate may exist. 


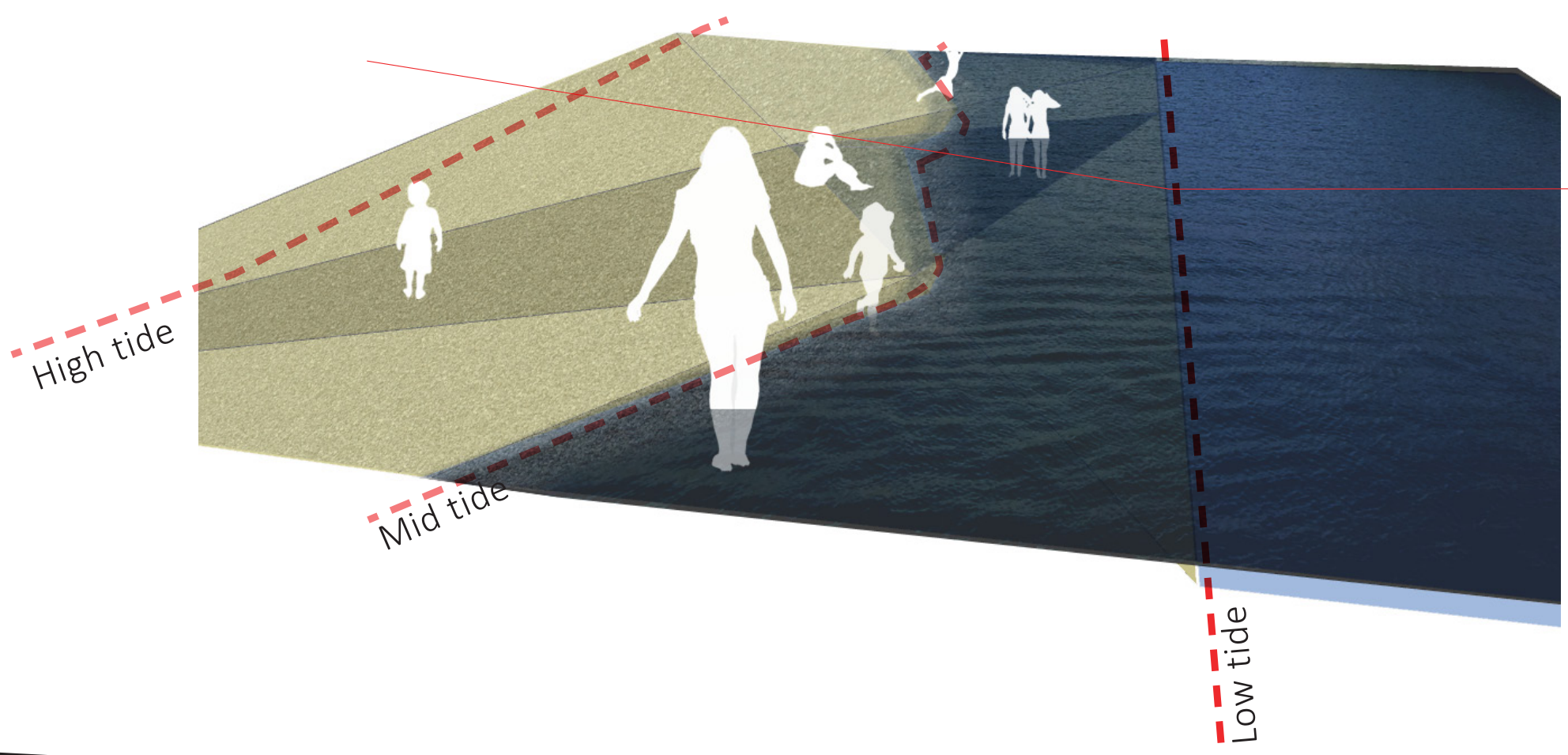

Section 1:1

Section 1:1
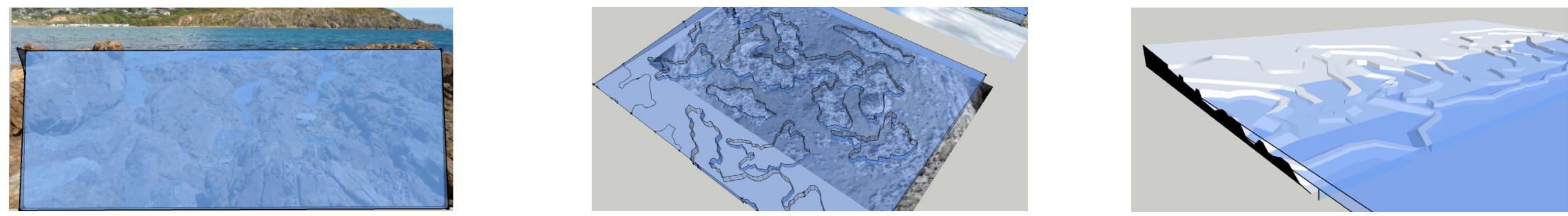

Figure7-7 Development of horizontal intertidalzon 
The strong crashing waves against possible substrates such as piers, large rocks, and piles which make up the prevalent stations for habitats all reflect the harsh conditions of the rocky shore. For the reasons discussed the design explores the potential of restoring the ecologies found within the rocky shore.

The further consideration of the revised conservation approach allows for further freedom in deriving a solution for a substrate. Substrates prescribed by preservationists would adhere to "untrammeled by man" rocks etc; the design explores a substrate designed by man that can potentially increase the survival rate of species, to offset somewhat the disadvantages presented by urban environment (pollution and constricted habitat).

The factors in developing a substrate for the intertidal zone cohere to the details mentioned in fundamental survival considerations for design applications in a earlier section. The main factor this development explores is the increase of space or surface area. Existing vertical piers and concrete walls minimize numbers of species as they live in designated sections of the vertical displacement of the tide. The consideration of a basic sloped ramp will "stretch" designated sections (vertical) for each species towards the horizontal plane and increase livable space. The increase of surface area for designated species is explored with the manipulation and configuration of the following materials.

\subsubsection{Rope as a substrate}

The conservation prescribed in this thesis allows the potential application of rope as a substrate in the final design because it promotes ecological diversity, the fact it does not look "pristinely natural" is irrelevant. The use of rope will look "natural" in its contemporary setting of a wharf and will mediate the ecological aesthetic with the harsh back drop of the harbour.

Rope is used as a medium to farm mussels and therefore valid as a potential substrate. The flexibility of rope allows for different shapes and configurations, it can sag for curvature or tighten for straight lines. It is easy to install and not expensive. The aesthetic relates to the harbour. Models explored the zone under, beside and along the piers which have been rendered unused. The manipulation of rope connected to piers and occasionally anchored to the sea bed creates intricate patterns reminiscent of a net. The nets intertwine particularly between high and low tide and will support filter feeders and seaweed species. A developed three dimensional pattern suspended between piers and anchor allows for people to access and interact with the ecologies. An extended path behind the wharf piles will allow access further out along the pier where the sea bottom becomes too deep (bottom right). Interactions include the active consumption of Sea lettuce (Ulva lactuca) and Wakame (Undaria pinnafitida) for sustainable reasons aforementioned. 


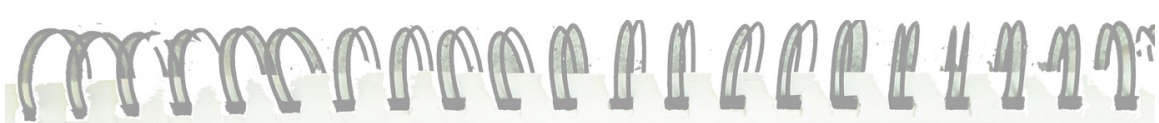
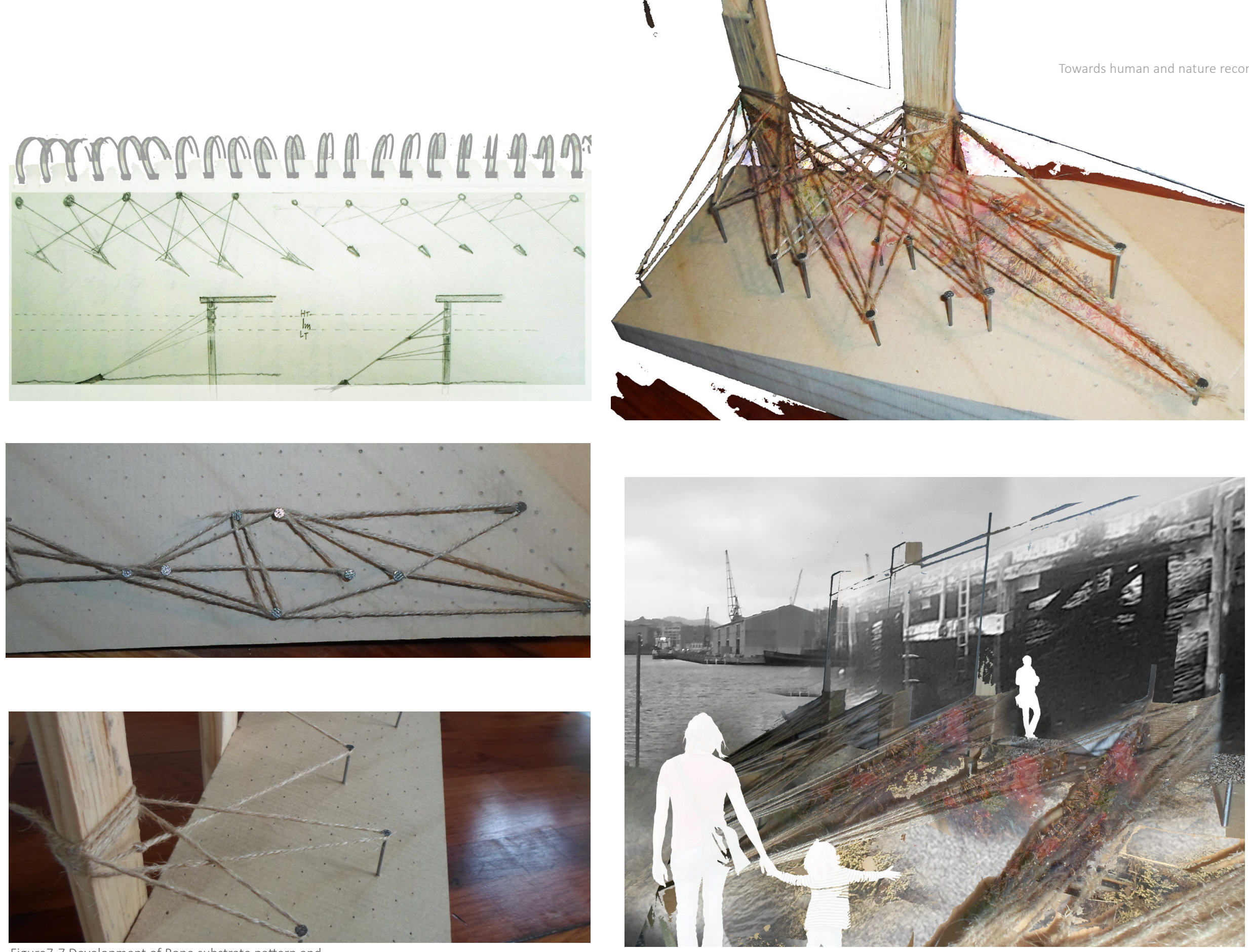


\section{Design precedent}

Oyster-tecture

This proposal for the Museum of Modern Art Rising Currents Exhibition consists of a massive wildlife restoration project. New York was once home to numerous oyster beds. A team led by Kate Orff proposed to transform the Gowanus Canal from a much-polluted waterway into a productive oyster hatchery. An armature for the growth of native oysters and marine life was designed for the Bay Ridge flats; it was intended to support oyster and mussel growth and attenuate waves and clean millions of gallons of harbor. The armature consists of "fuzzy ropes" that suspend nets underwater, this is a interesting take on a contemporary low cost and low tech approach that is viable.

The manipulation of rope within this thesis explores reaching similar goals in restoring species but supports a richer diversity as opposed to a focus on a single species. This focus is expressed by allowing light to travel to lower levels of the ocean instead of using "nets" that risk severely cutting off light from habitats below. Diversity ensures ecological balance and mauri restoration.
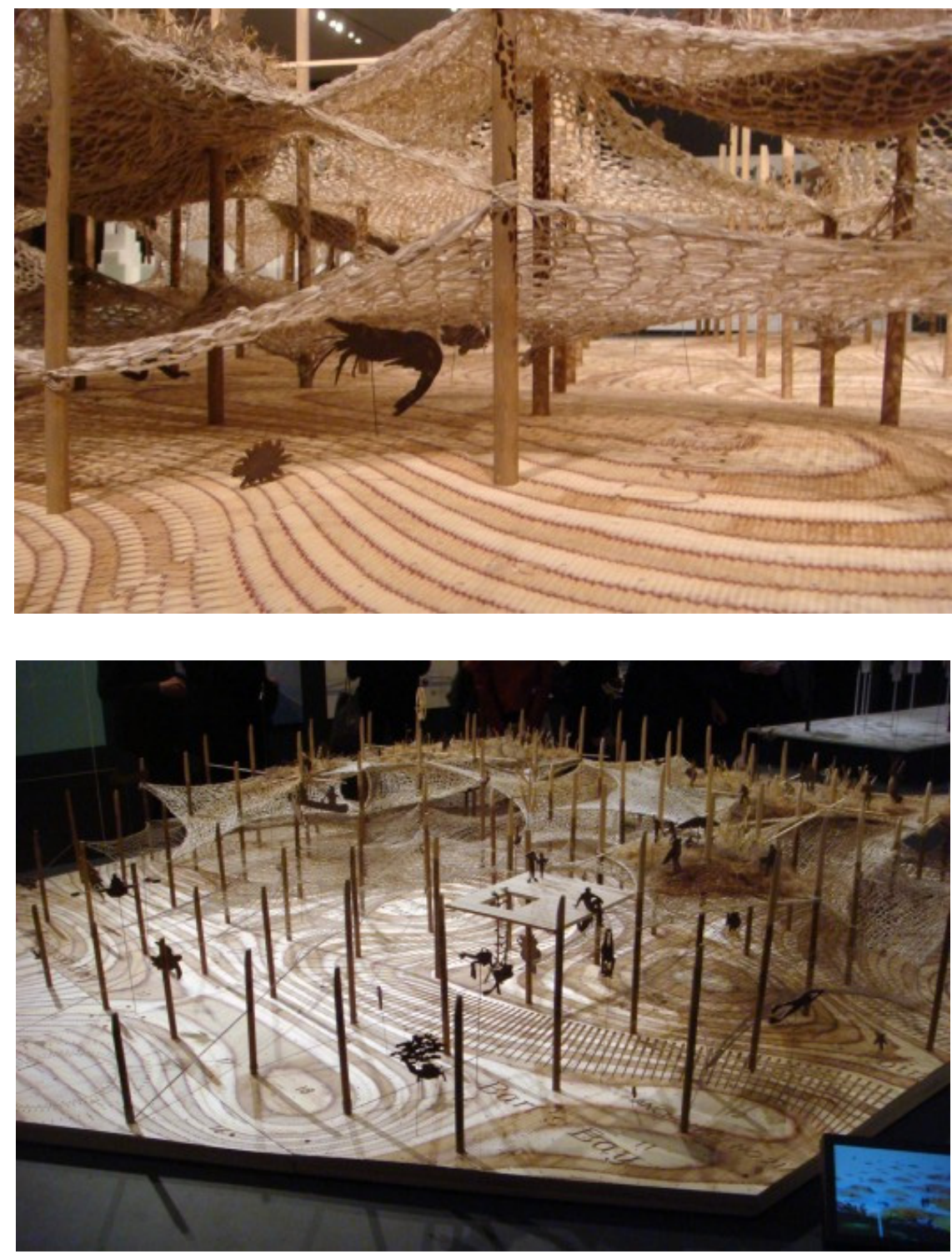

Figure7-8 Net composition model

Source: http://www.archdaily.com/165568/oyster-

tecture-and-the-gowanus-canal/ 


\subsubsection{Concrete as a substrate}

Concrete has sometimes proven itself a valid substrate along the wharf in some cases and in other times proven restrictive. The ramp at the city to sea lagoon is an example that shows it is the finish of concrete that entails its effectiveness for a growth medium (lagoon ramp). The barnacles, limpets and occasional grazers congregate in the crevices of the exposed aggregate surface and barely exist on the smoother finished surface of concrete. Collections also occur along the cracks of the concrete. The design of concrete explores developments towards, shelved, tunnelled, and caved textures. The use of exposed aggregate didn't hold enough of the desired aforementioned qualities. Exploration of different compositions of builders mix and cement were explored, it became apparent that the reduction of fines within the mix turned a more promising finish. The final iteration explored drainage chip and cement. Cement allows reaction to take place with medium hardness rock which can be dissolved by acids, which appears to invite the highest diversity. Use of this medium may initially create concerns of it being too soft for the site conditions. Further research suggests that the hardness of the rock has little bearing on its rate of wear (Taylor). Validation of this material sides with Taylor and the argument that a thin scum layer of algae (Lithothamnion) cover acts as a living skin that protects material from water and weathering.
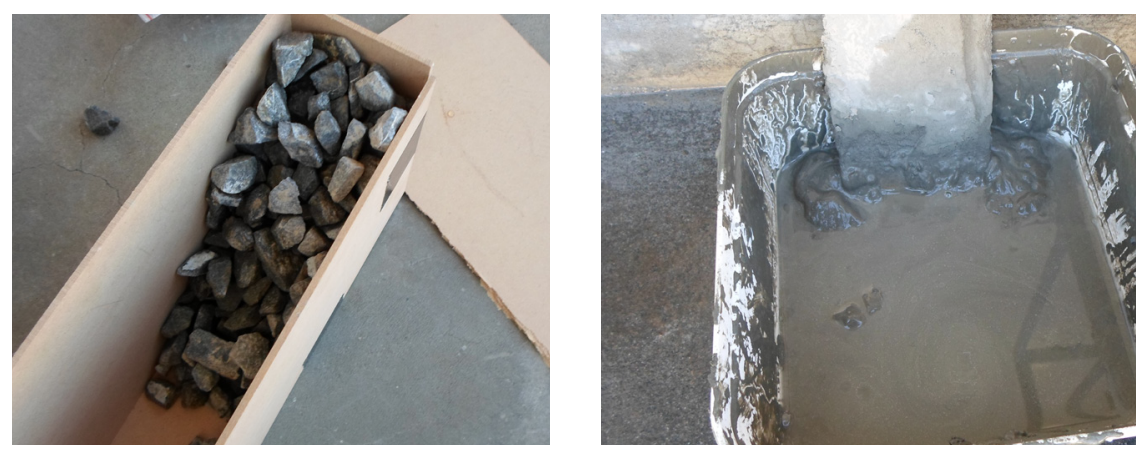

7
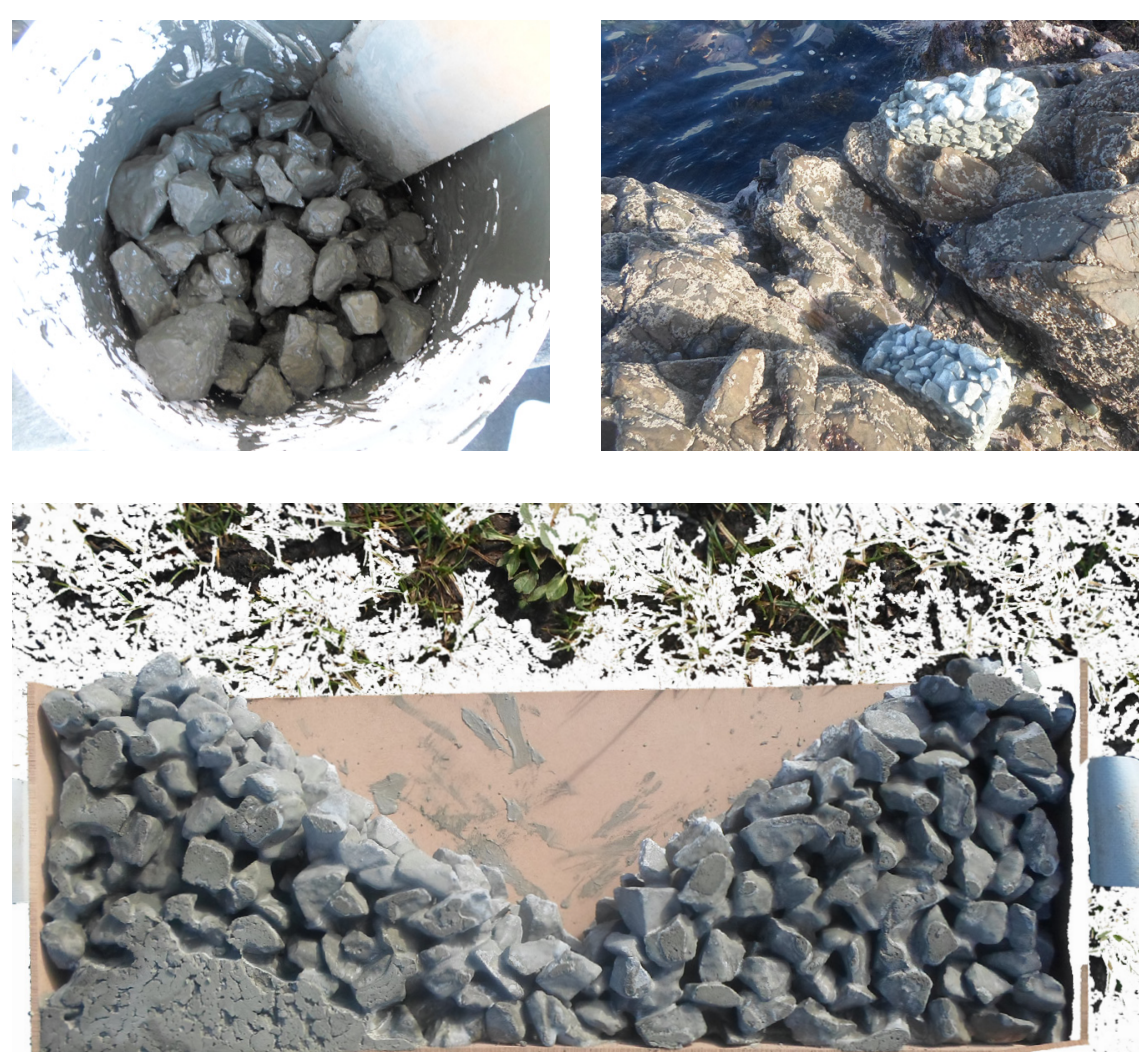

Figure7-9 Construction process of substrate.

Images by Author 


\section{Field testing}

Field testing was conducted with the proposed designed concrete substrate. The substrate models were tested with two different sizes of drainage chip. Molds were made to create an extruded triangle that has a sloped front and a vertical backing. Models were left at low tide for a period of two weeks and show plausible sign of supporting a ecology.

The site chosen was situated in Titahi Bay beach that has a semi healthy ecology, this was done to accelerate the rate of growth. Findings are as follows:

- The porous concrete supported inhabitance of a crab and a star fish, both being resting out of harm's way of foot traffic.

- The fissured, tunnelled, and caved makeup of the models successfully collected seaweed urchin spines and other biomass, these conditions would promote and support algae growth if test was longer.

-The colour of the models changed from a harsh grey to shades of brown that would not stand out as mush against growing algae.

- Limpets and barnacles take a long time to attach to surfaces and consequently had not attached by the end of testing. Discoloration suggested the cement was chemically reactive which is preferred for latching of limpets and barnacles that would probably attach if the test was longer.

These findings suggested that the designed manipulation of concrete is plausible for use. The larger drainage chips would be used away from foot traffic while smaller granules closer to and under foot traffic. 

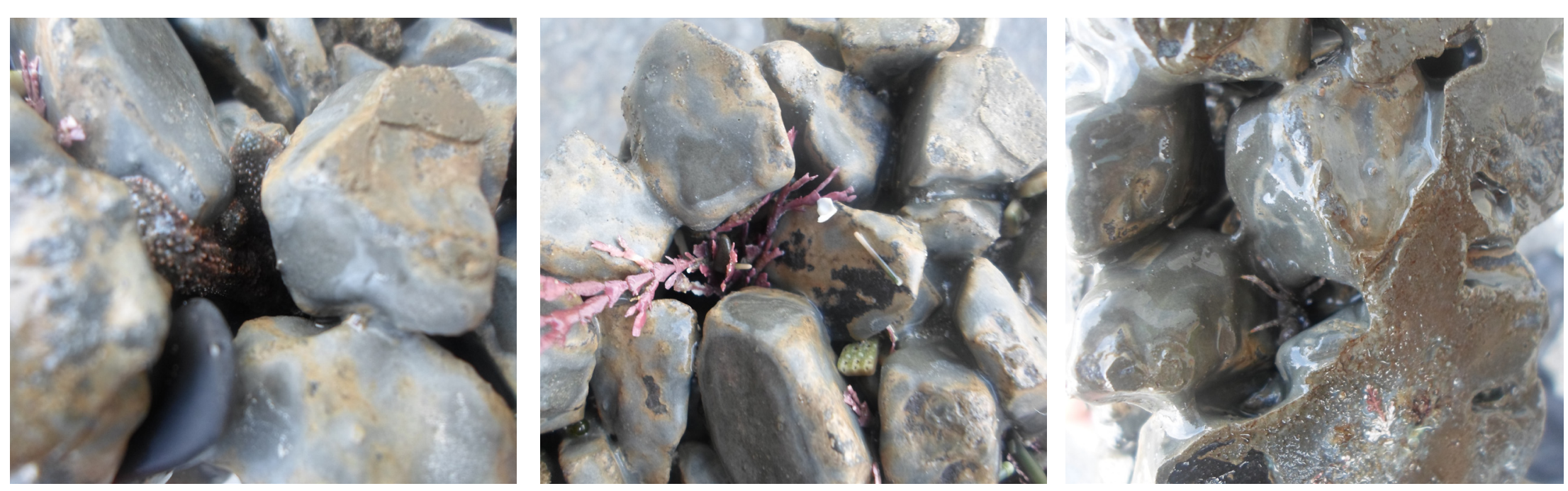


\section{5 case study- ecological substrate}

Daniel Metcalf has created a series of tile designs that explore the potential of a synanthropic surface, which is a surface that supports activity for both humans and other species which are in this case barnacles, limpets, and other intertidal species. Daniel explores "softer" physical barriers between humans and microorganisms rather than the harder physical barrier examples that are evident in the wharf. Creating grooves along the walkway minimizes surface area in contact with shoes and creates crevices tor trapping water and offering habitat. Undulating the grooves in the middle section create a visual effect that makes part of the walkway seem safer and in consequence keep foot traffic away from vulnerable habitats. The design prescribes three degrees of separation; concepts. The scale is appropriate and has been used as a platform in development within this thesis. The proposed degrees of separation are further pursued in this thesis (IMAGES) and have directed approaches in this chapter's habitat design.
1. Physical separation- Habitats in the grooves are protected from people walking even if foot traffic is directly above them. This position holds as long as the creatures are immobile, which grazing species mostly are as long as the tide is out.

2. Temporal separation- When the tide comes in species become mobile, this is not problematic due to the absence of foot traffic. 3. Behavioral separation- The surface is designed in a way that makes the centre more appealing to walk on, establishing a walking preference that avoids habitat damage.

Criticisms and observation

The precedent is attractive in its correlation to establishing a substrate that encourages inhabitance at close proximity for humans and intertidal animals that relate to Māori worldview

concepts. The scale is appropriate and has been used as a platform in development within this thesis. The proposed degrees of separation are further pursued in this thesis (Figure 7-8) and have directed approaches in this chapter's habitat design. 

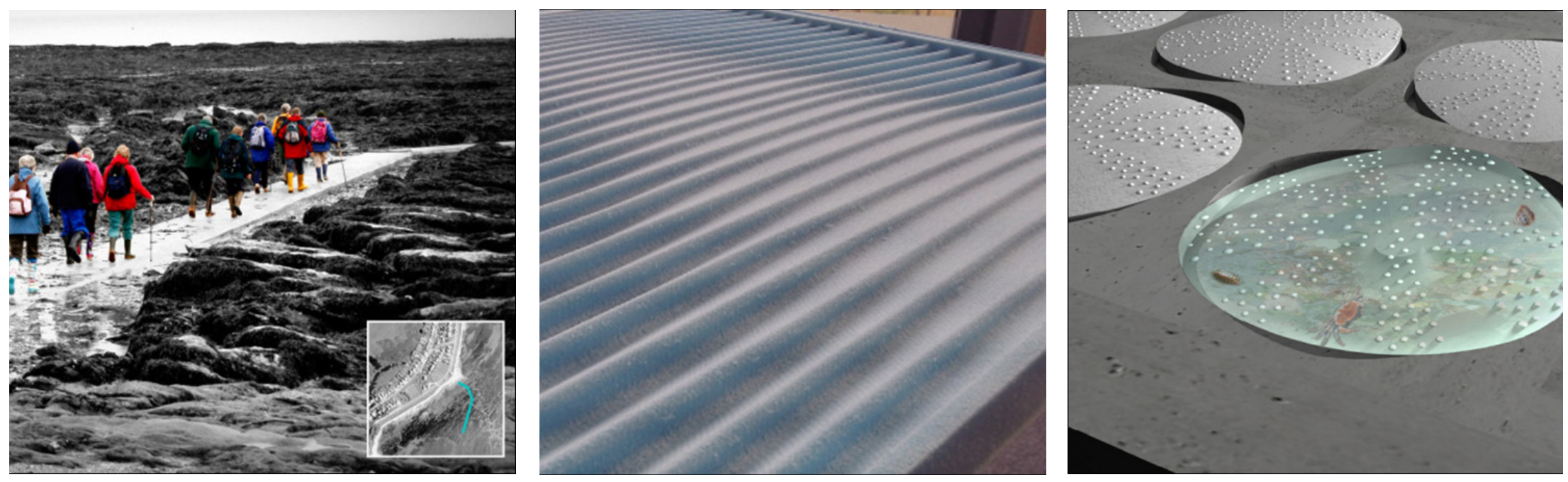

Figure7-8 Design development photos

Source: http://reconciliationdesign.wordpress.

com/2012/06/12/hannafore-project/
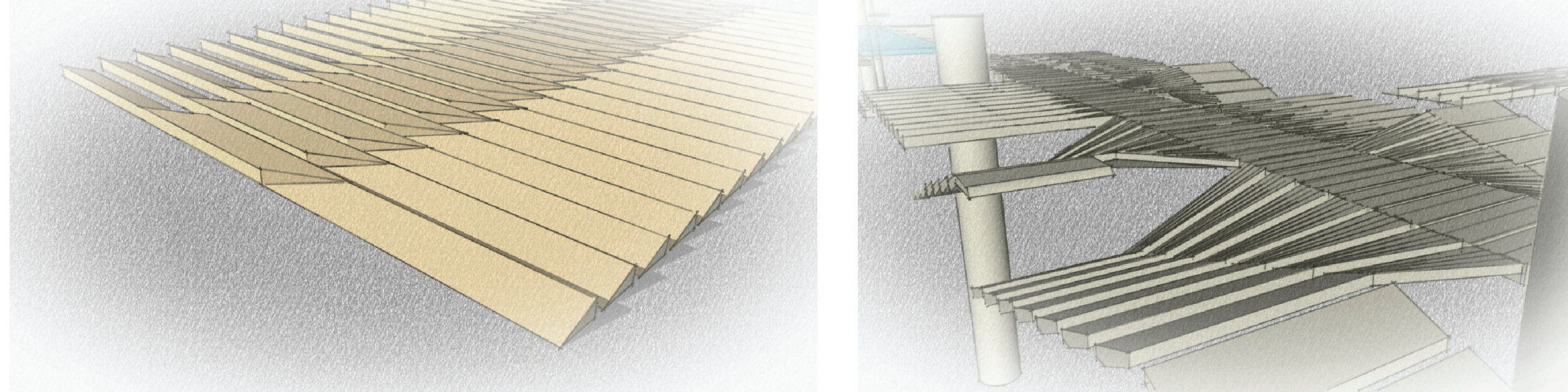

Figure 7-9 design development digital models

Images by Author 


\subsection{Site Typologies}

\subsubsection{Introduction}

One of the three sites is found at the beginning of Oriental Parade near Waitangi Park adjacent to the old Overseas Terminal and the causeway that shelters the small boat marina. The second site is the lagoon below the City to Sea Bridge outside the Wharewaka function centre and boatsheds. The third site is situated next to the caravan site in the docking area of the old ferry of 1912 and beside the old ferry building (now Maritime police unit). 


\section{Site Map: Lambton Wharf.}

Figure 7-10 Site map locating typologies

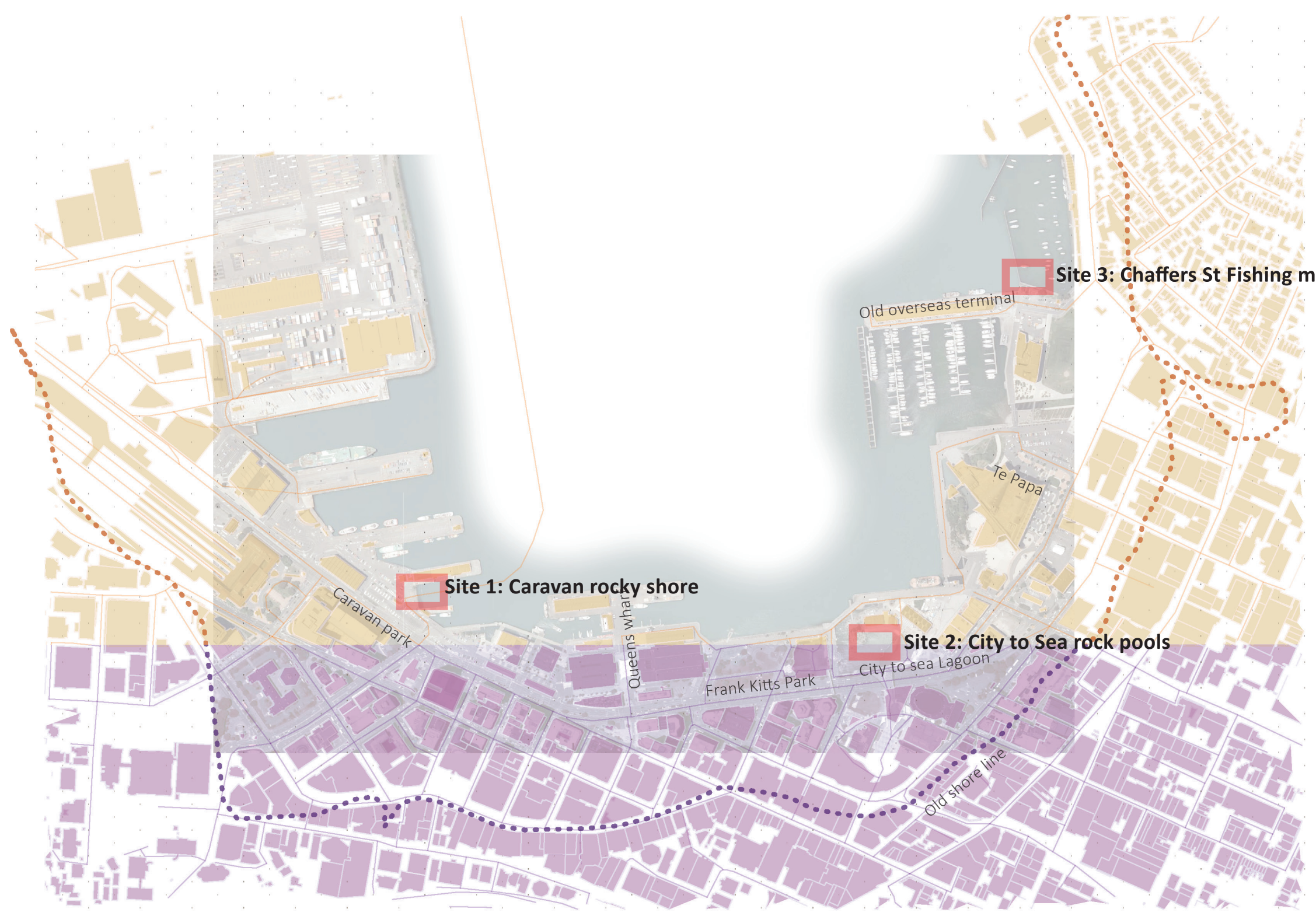




\subsubsection{Caravan rocky shore}

\section{Site observations}

Low intertidal ecology due to lack of sufficient substrate

Existing substrates consist of large rocks, piles, and rope

Large rocks limit access to water

Buildings and structures:

Marina police unit in old Ferry building

Caravan Park (approx 20m away from water)

Blue bridge shed

\section{Hunch}

The site is close to a caravan park (Figure 7-15), the residents introduce an increased level of dwelling and permanence within the transient nature of the site that can initiate a communal intervention that associates with ecologies. The development of interaction and associations create opportunity to express a "humans in nature consonance" and Māori principles.

This design applies the following design moves:

\section{Intimate spatial exchange island}

The island encourages cognitive negotiation to allow people to inhabit the site when the tide is at a particular level; it consists of two moving platforms that alter the way space it used (Figure7-14,7-15). The spatial exchange island attenuates waves to shelter habitation growth further inland. Swimming, paddling and diving are encouraged by multiple depths (Figure 7-11).

\section{Reciprocal Mauri regeneration platforms:}

The developed rope substrate is tied to piles. A platform extends along the back of the piles to allow access further out during low tide where the seabed would be to deep to walk on (Figure 7-7). The caravan community can contribute to the Mauri of the ecology and receive sustenance. The concrete substrate replaces the large rocks that created minimal inhabitable spaces for microorganisms. The composition of concrete creates numerous slopes and turning points to increase surface area shelter (Figure 7-15).

\section{Incision and rupturing to reveal and re-establish spatial, historical,} and cyclic orientation:

A ruptured form is present throughout the design; this is evident along the sides of the path that draw visitors and funnels into a threshold of entry. Haptic initiation as prescribed in section 7.3.3 has been applied. Exposed arrogate is the first material walked on, the path narrows and changes to exposed arrogate with larger granules that orient and initiate people into the landscape. (Figure 7-12)

The developed intervention that embodies and exhibits cyclic processes as prescribed in section 7.4.3 is applied to orient people with the landscape (Figure 7-12, 7-13). 


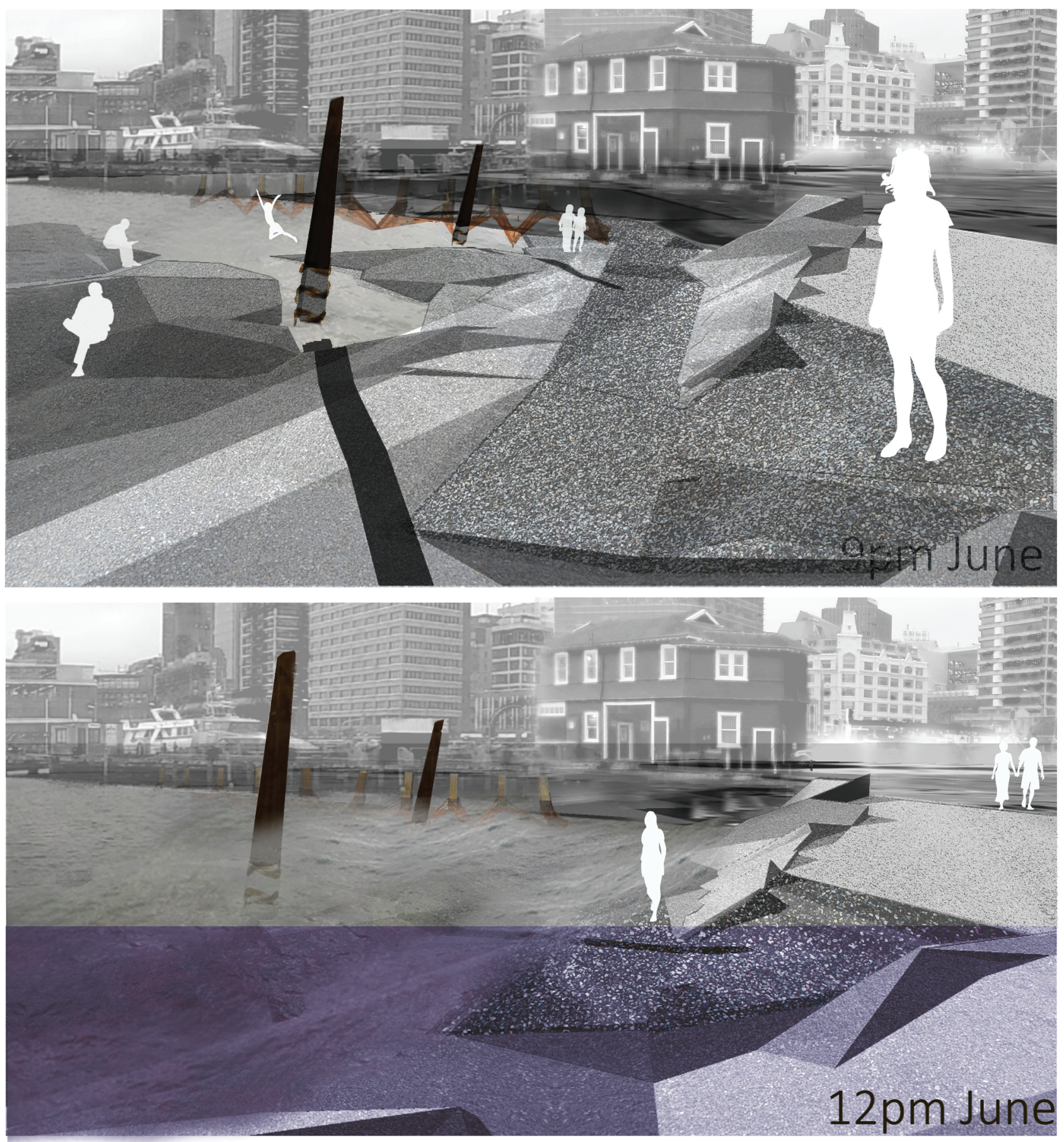


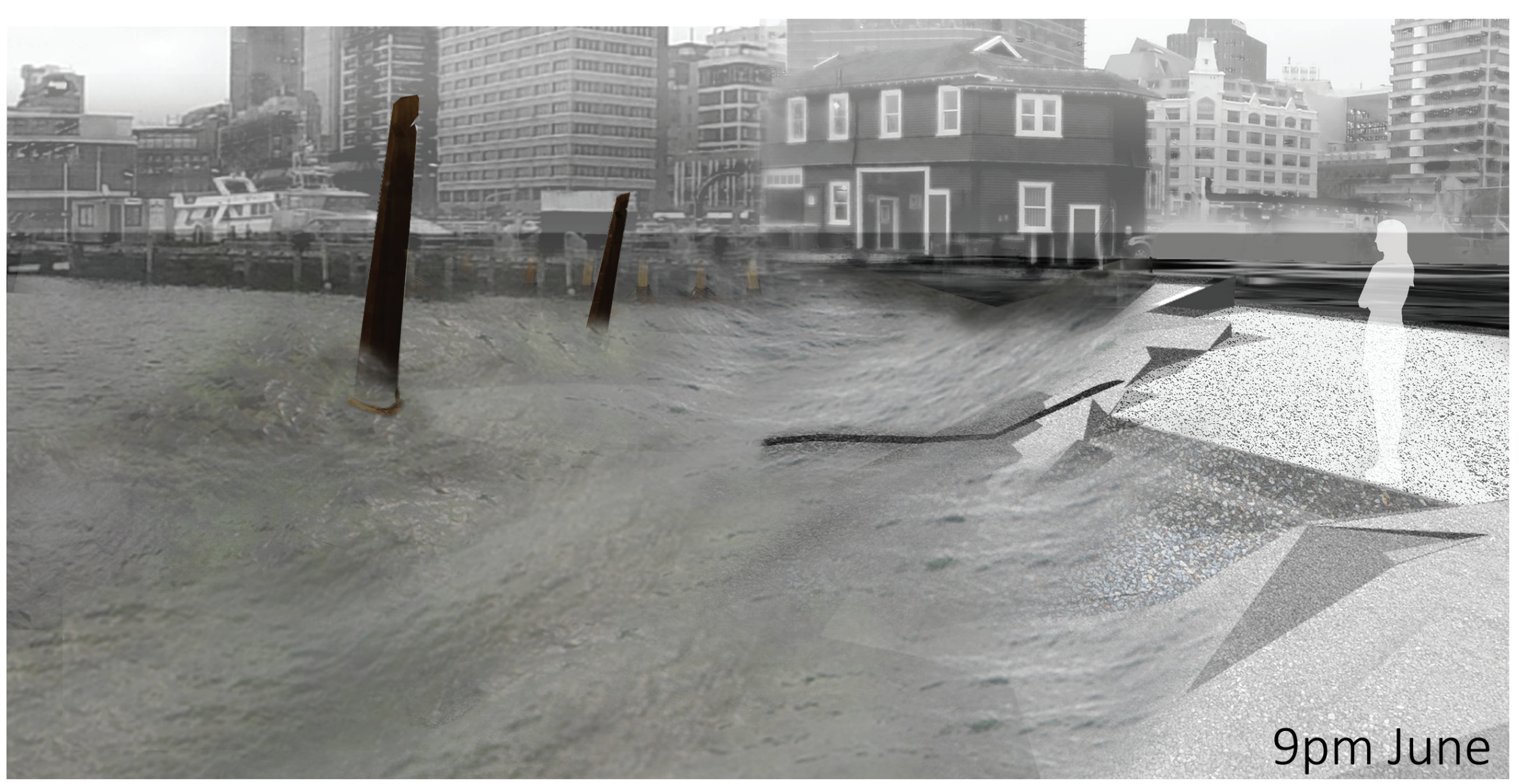



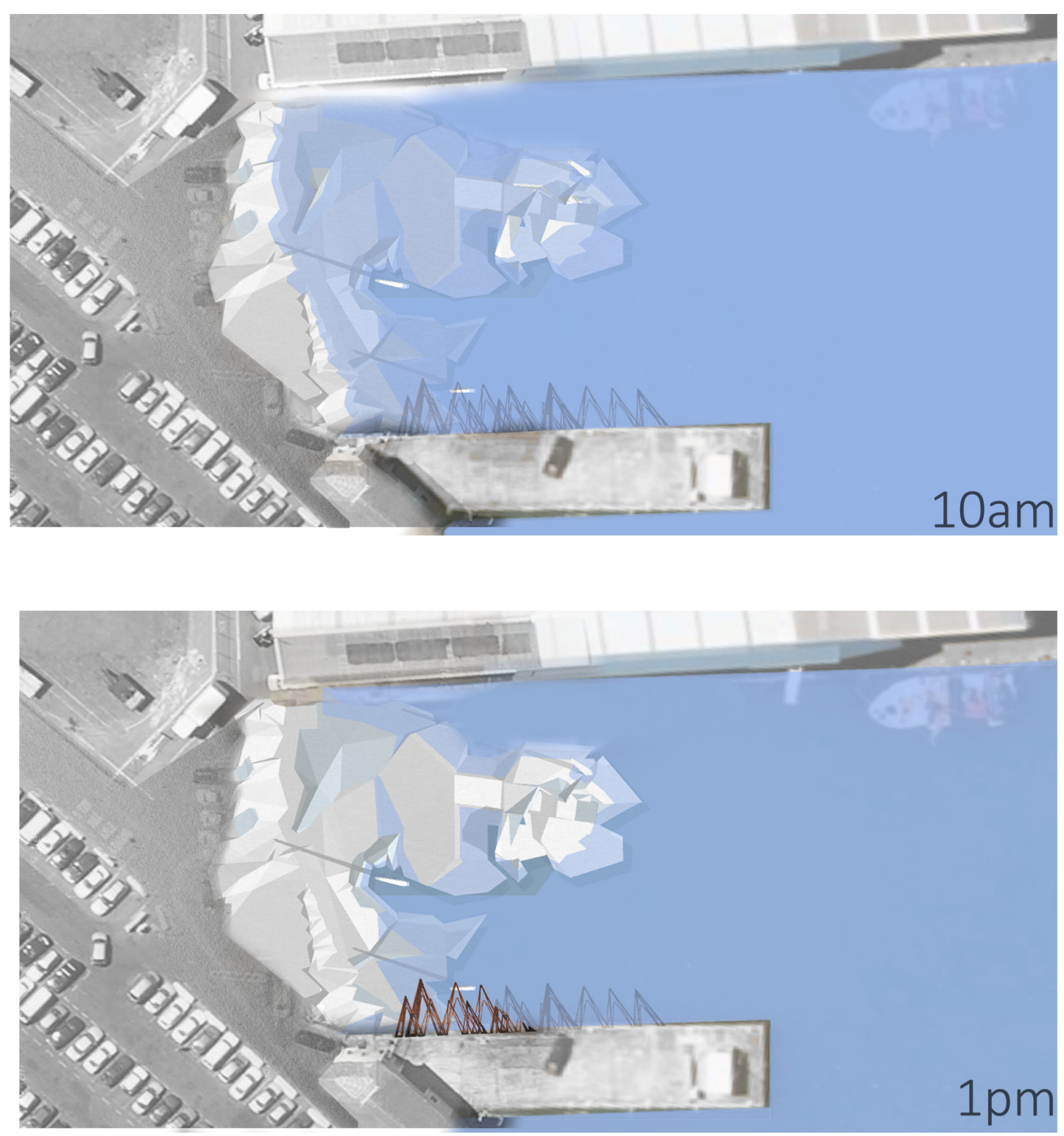

Figure 7-14 High tide medium tide plan 


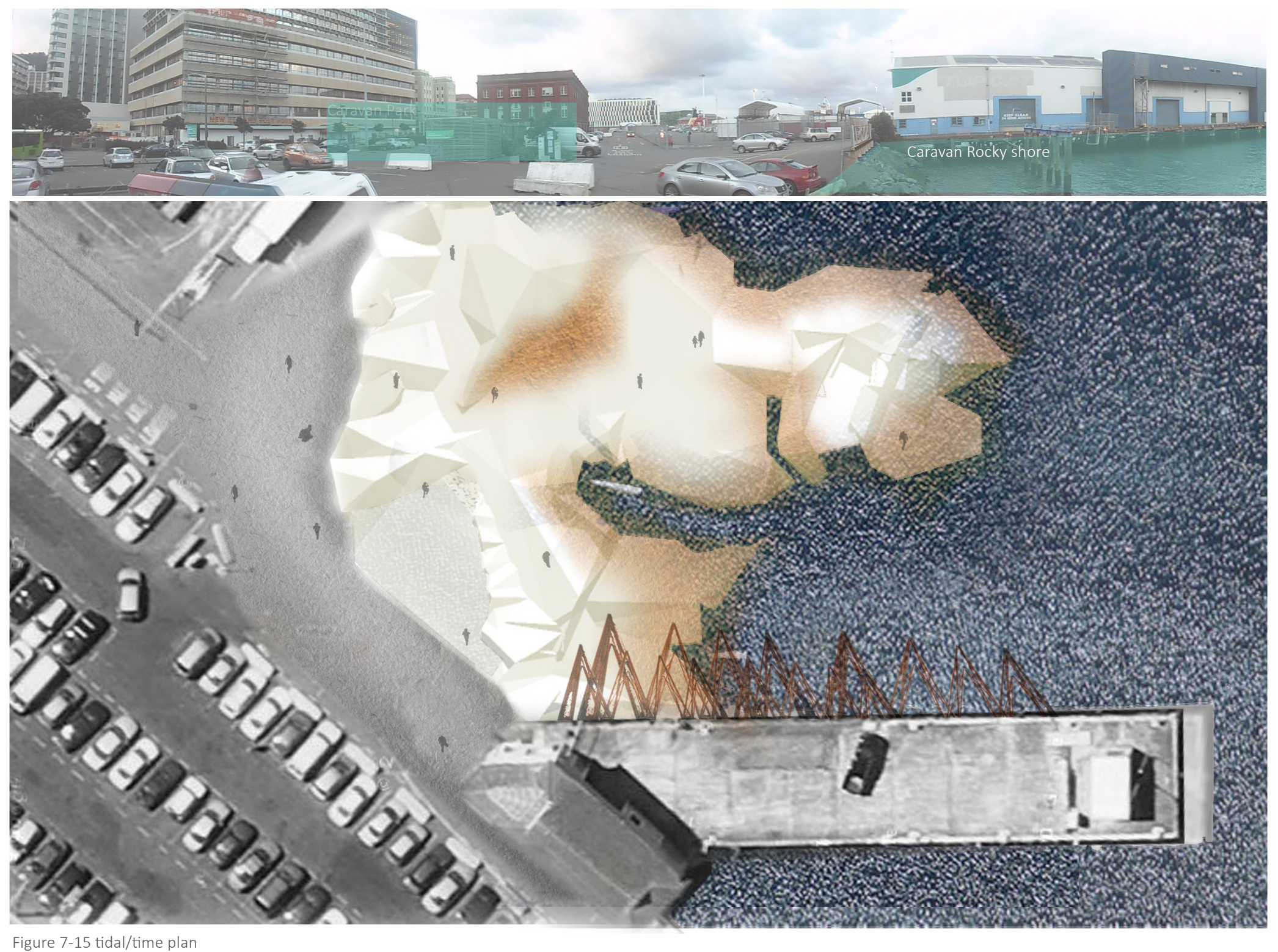

$4 p m$ 


\subsubsection{City to Sea lagoon}

\section{Hunch}

The city to sea lagoon acts as a roundabout defined by transient foot traffic. A void rests at the centre that lacks any response to the setting. Opportunities can be explored to possibly take advantage of the intrinsic theatricality of the water and surrounding terraces quality of the site.

The verticality of the surrounding sites (City to Sea Bridge, Frank Kitts park platforms) further informs the theatricality of the space.

\section{Site observations:}

Due to lack of sufficient living space intertidal species numbers are low. Existing substrates predominantly consist of concrete.

Access to water with ramps

Buildings and structures

- Prominent City to Sea bridge (approx 8m tall)

- Upper terrace level overlooking lagoon from Frank Kitts park (approx $2.5 \mathrm{~m}$ tall )

- Commercial stores on northern edge of lagoon that continue northward along promenade to Frank Kitts park.

- Strong boating historical value with Boating club, boat shed, rowing club building

- Wharewaka

- Lagoon is sheltered

\section{Intimate spatial exchange islands:}

The islands require cognitive negotiation to allow people to inhabit the site (Figure 7-16).

\section{Reciprocal Mauri regeneration platforms:}

The concrete substrate replaces the existing "treasure island" that cannot support intertidal species with its intertidal interface consisting of large rocks. The composition of concrete creates numerous rock pools that take advantage of the sheltered area to thrive. (Figure 7-17, 7-21).

\section{Incision and rupturing to reveal and re-establish spatial, historical, and cyclic orientation:}

A ruptured form is present throughout the design, particularly behind the boat club where the landscape protrudes up the side of the pedestrian bridge. Extended islands further exhibit the natural cyclic changes of the tide (Figure 7-17). .

\section{Active Terraces to promote cultural association:}

The active terrace is detachable and used in conjunction with public events to further promote cultural association and activity and take advantage of theatricality of site. It would act as a stage and be governed by the tide to reinforce the natural realm (Figure 7-18). 


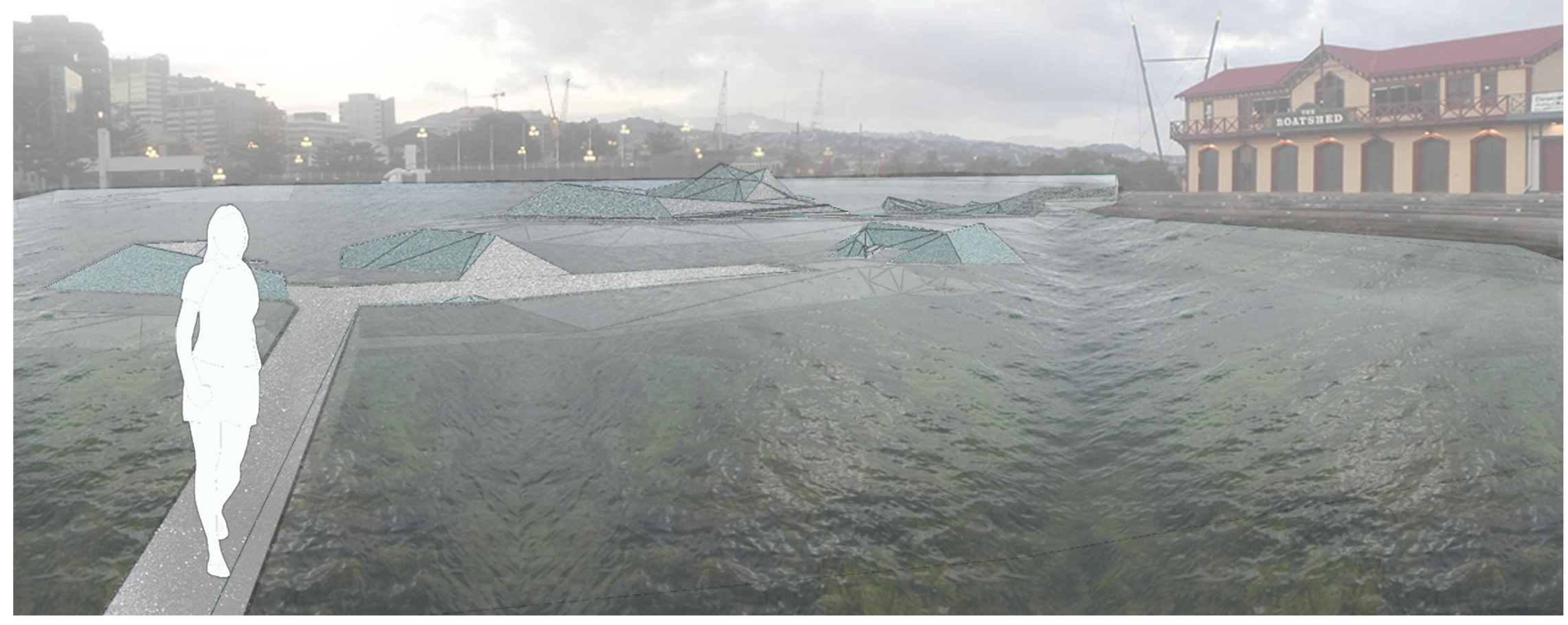

Figure 7-16 Mid tide perspective Image by Author 

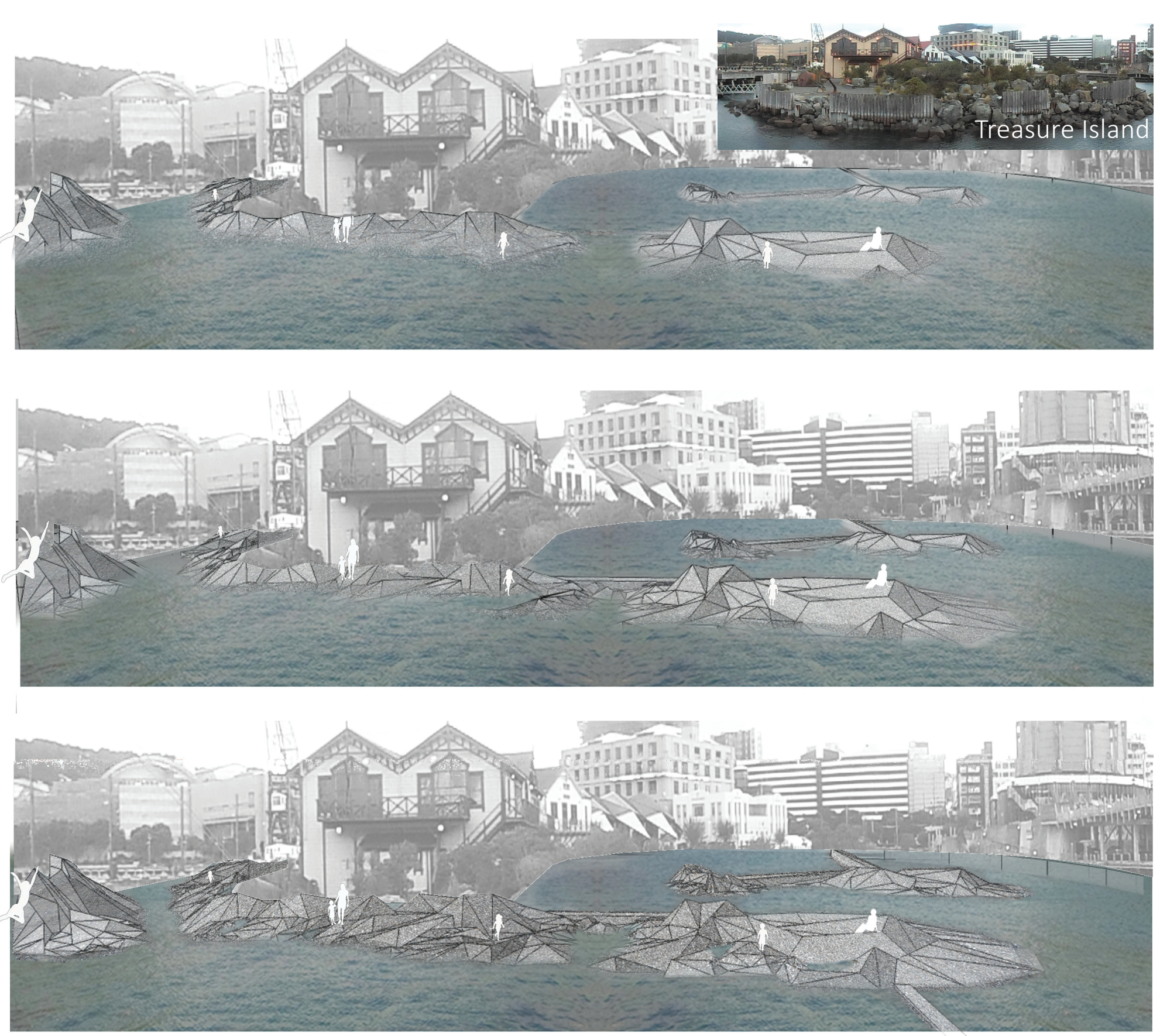

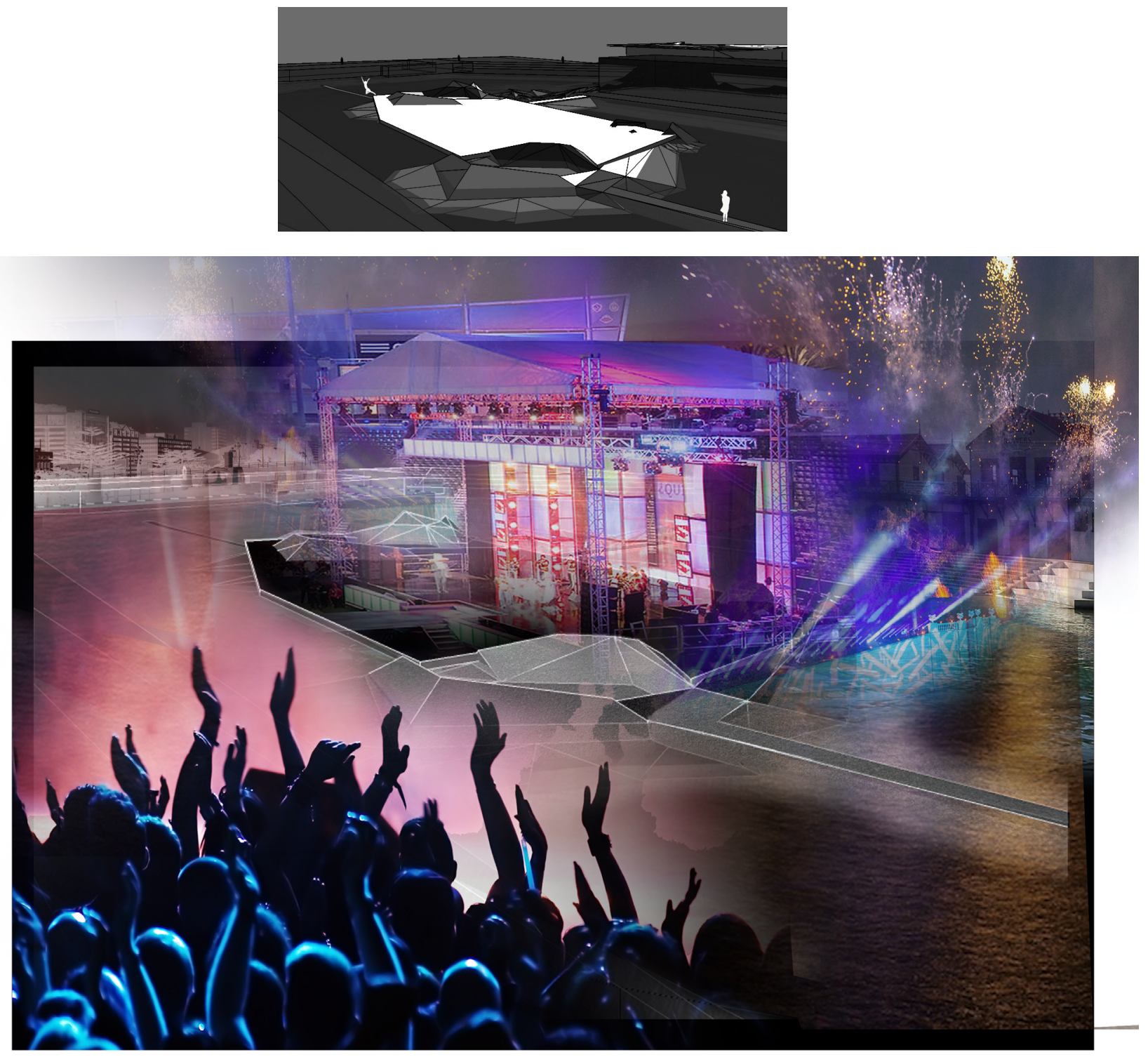

Figure 7-18 Functional space 

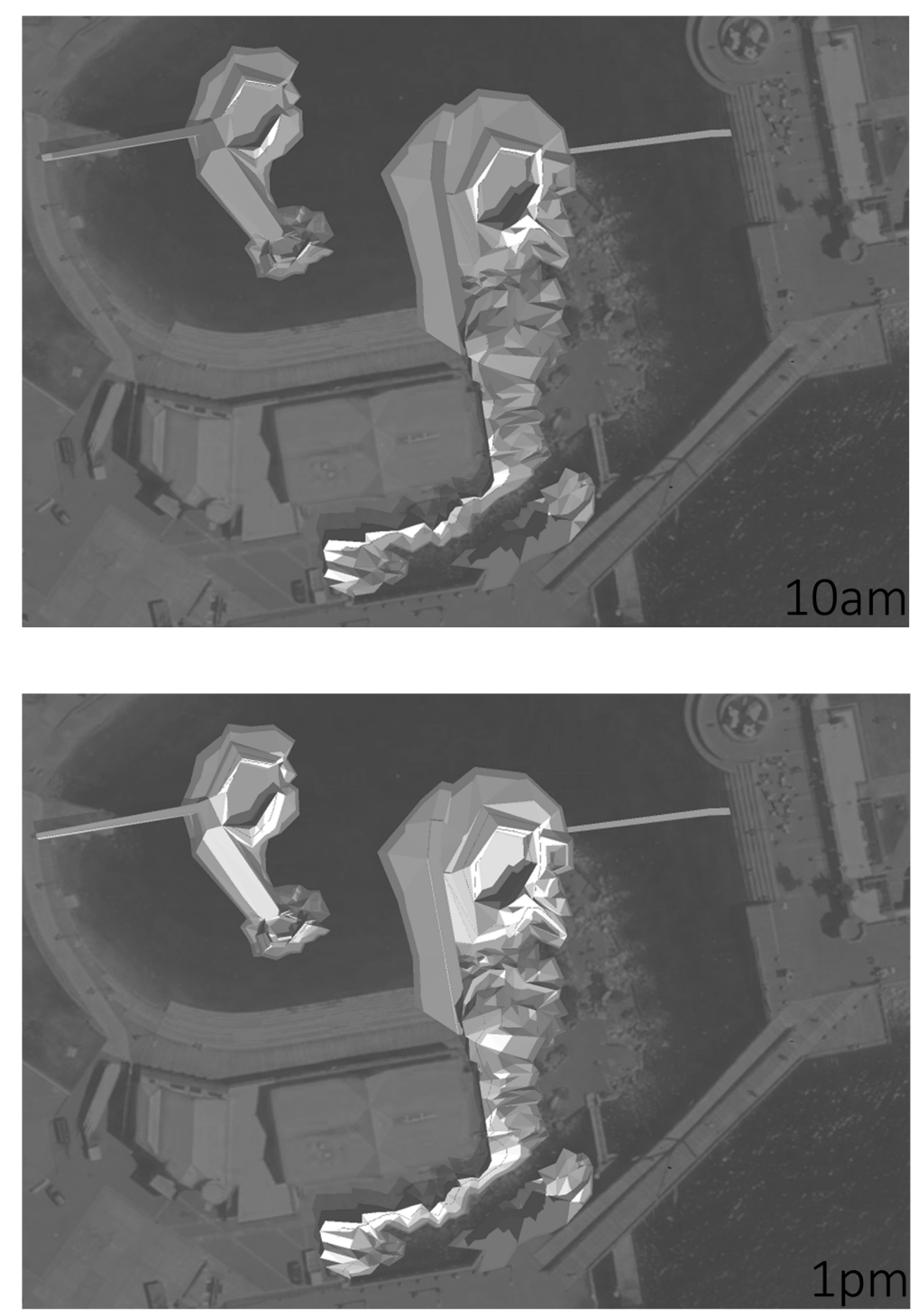

Figure 7-19 High tide, medium tide 


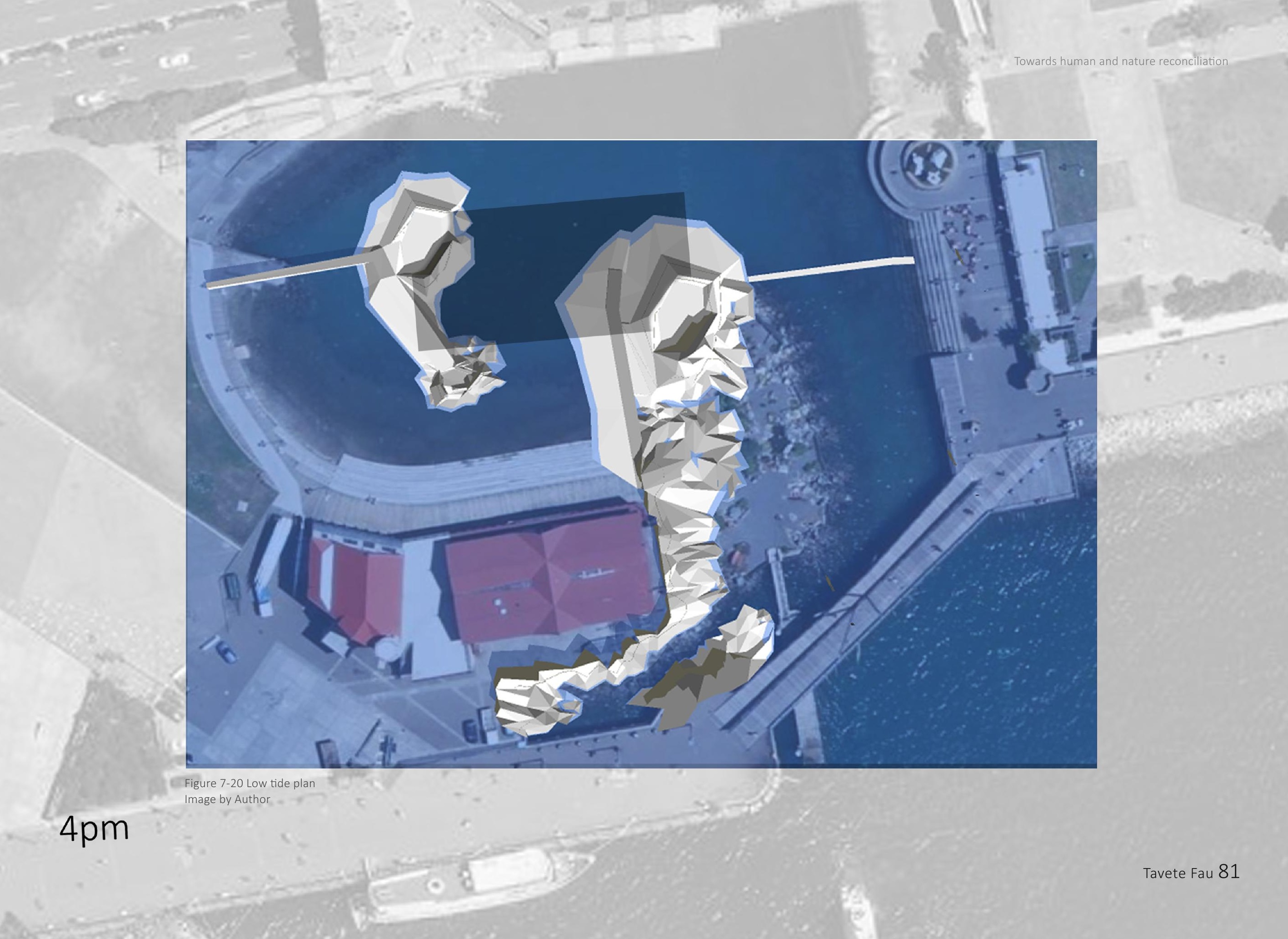




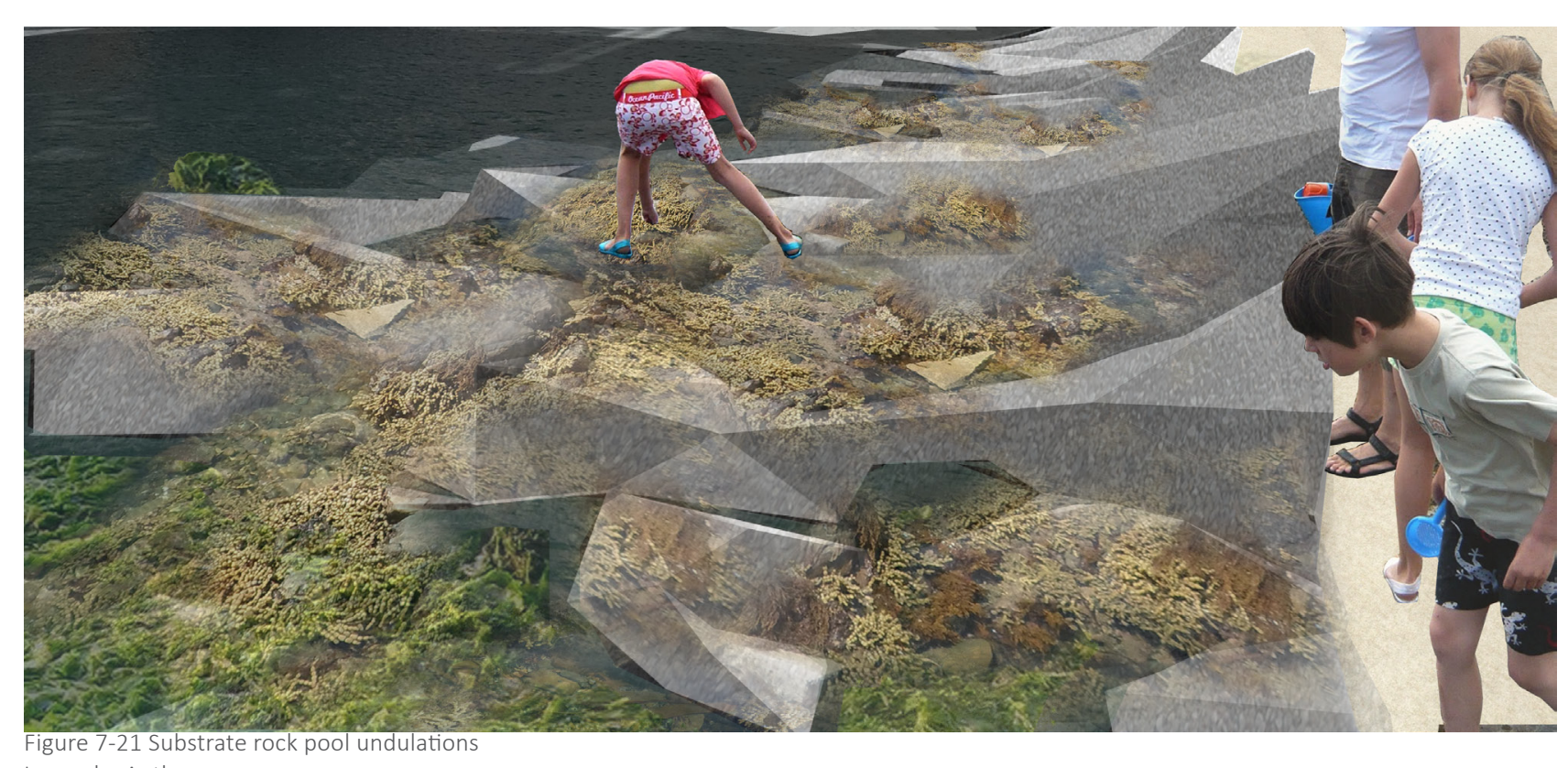
Image by Author 


\subsubsection{Chaffers Street Fish market}

\section{Site Observations:}

Low intertidal ecology due to lack of sufficient substrate

Existing substrates consist of large rock along the causeway, piles below the wharf and a vertical concrete face along water's edge of Chaffers street.

Access to water in dock area via ramp outside chain of boatsheds Buildings and structures:

Causeway sheltering docking bay (approx 120m long)

Pier extension into harbour (approx $255 \mathrm{~m}$ long) Top end apartments, old overseas terminal site

Dilapidated grass landscape

Boat building complex

Alligator cart garage

\section{Hunch}

The site presents an open expansive un obstructed relationship to sea, both visual and potential to re establish land to sea transitory space. Its resides at the "tail" of the waterfront and presents a opportunity of the water front to spatially retreat and return to a ecological premise.

\section{Active terraces to promote cultural association}

Past historic sea trade is revived along the lower terraces. A coarse way extends public activity further out to sea by facilitating for a fish market. Platforms cater for smaller boats for local sustainable produce to be traded. A lower terrace is revealed at middle tide to accommodate for further activity. Small terraces accommodate people on their breaks and invite a theatrical element to the rectangular terrace below.

\section{Reciprocal Mauri regeneration platforms:}

The developed concrete substrate is dispersed throughout the design and allows for a substantial ecological restoration.

\section{Incision and rupturing to reveal and re-establish spatial, historical, and cyclic orientation:}

The form "ruptures" at street level and descends to the bottom terrace that interacts with the tide. This form informs the harbours point of retreat in submitting to the natural environment. At high tide the coarse way is still above water level and only accessible from the staggered terraces while the entrance from the street is cut off. The interplay with the tide requires cognitive negotiation to inhabit or traverse spaces.The developed intervention that embodies and exhibits cyclic processes as prescribed in section 7.4.3 is applied to orient people with tide cycles. 


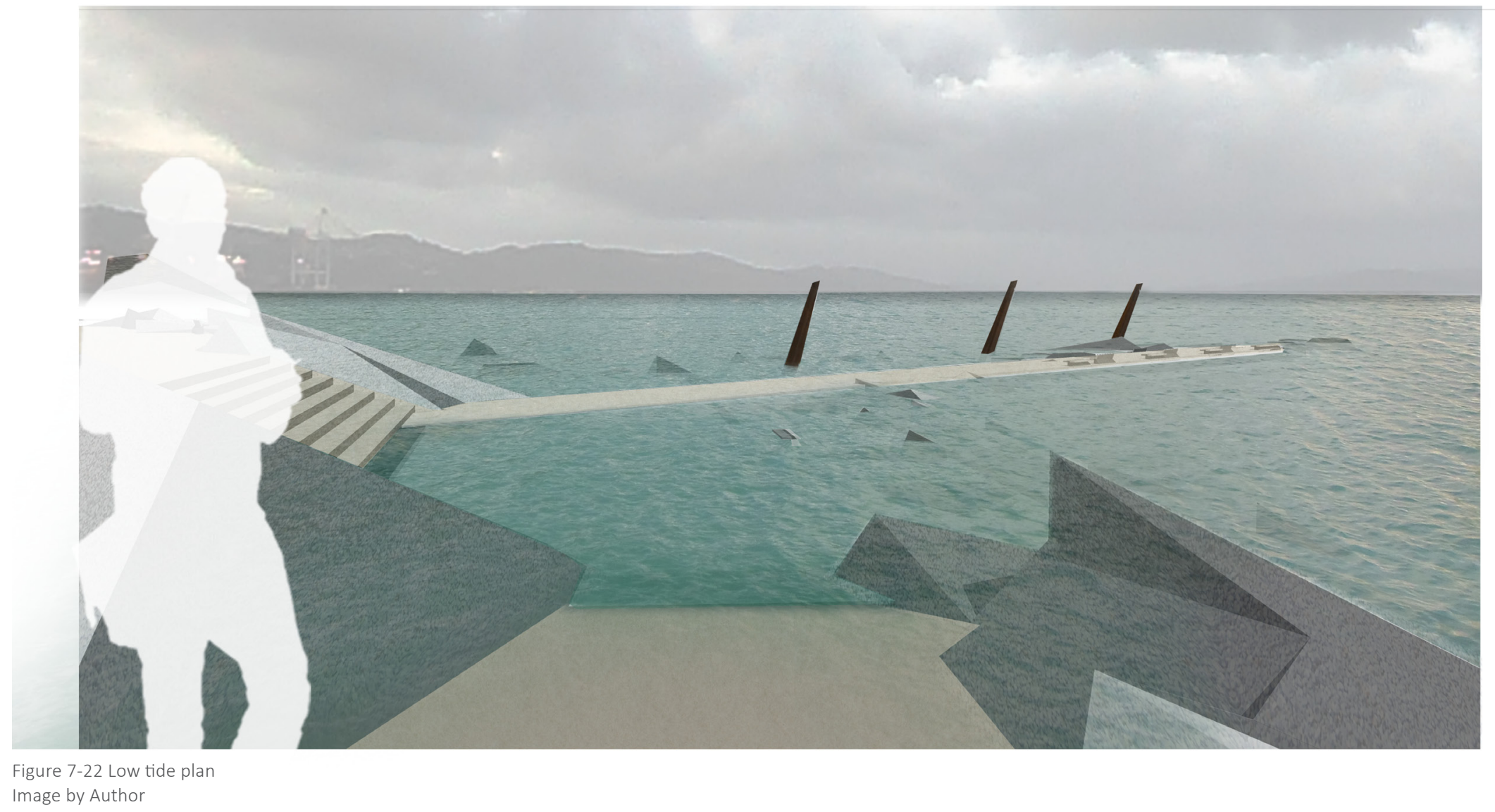




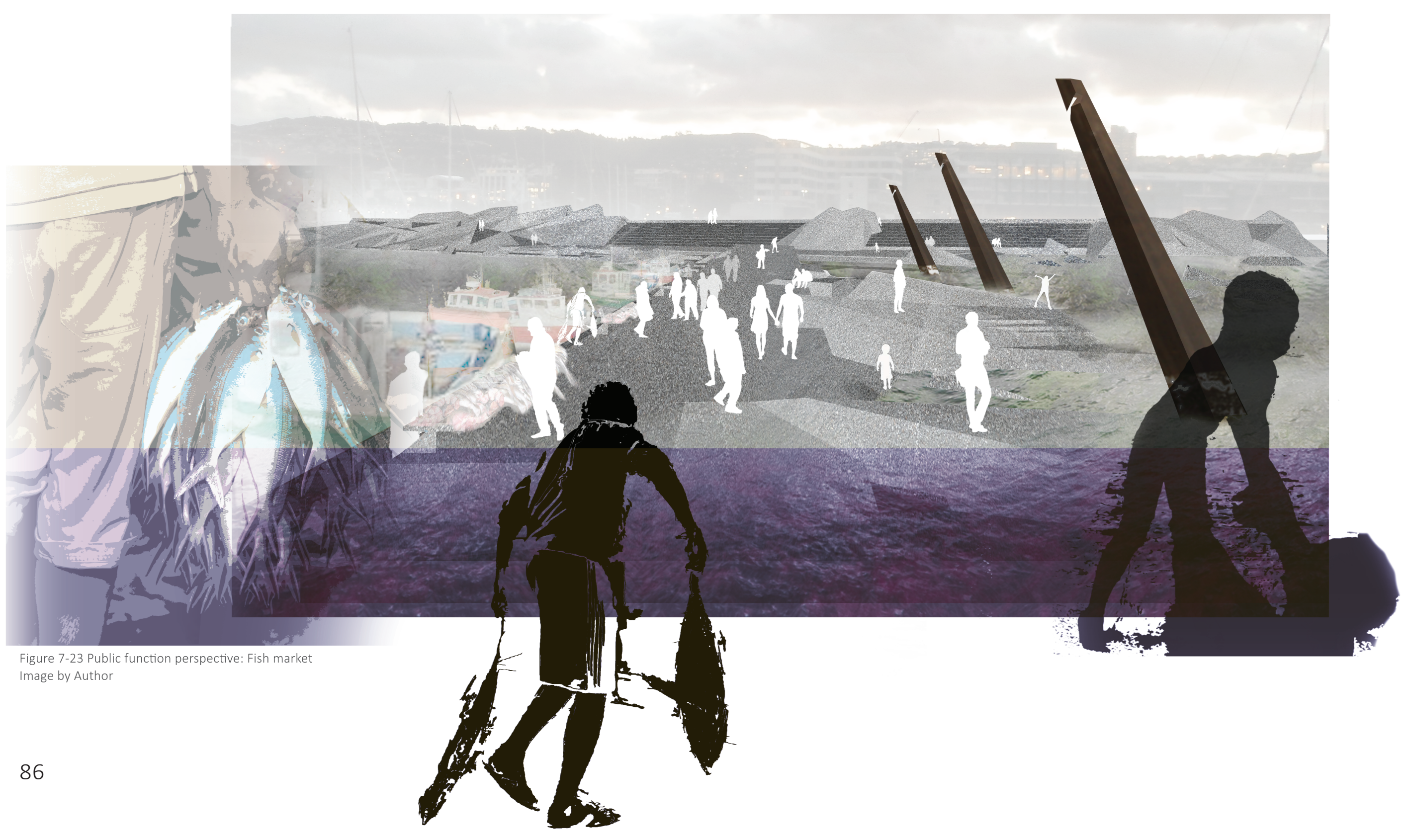




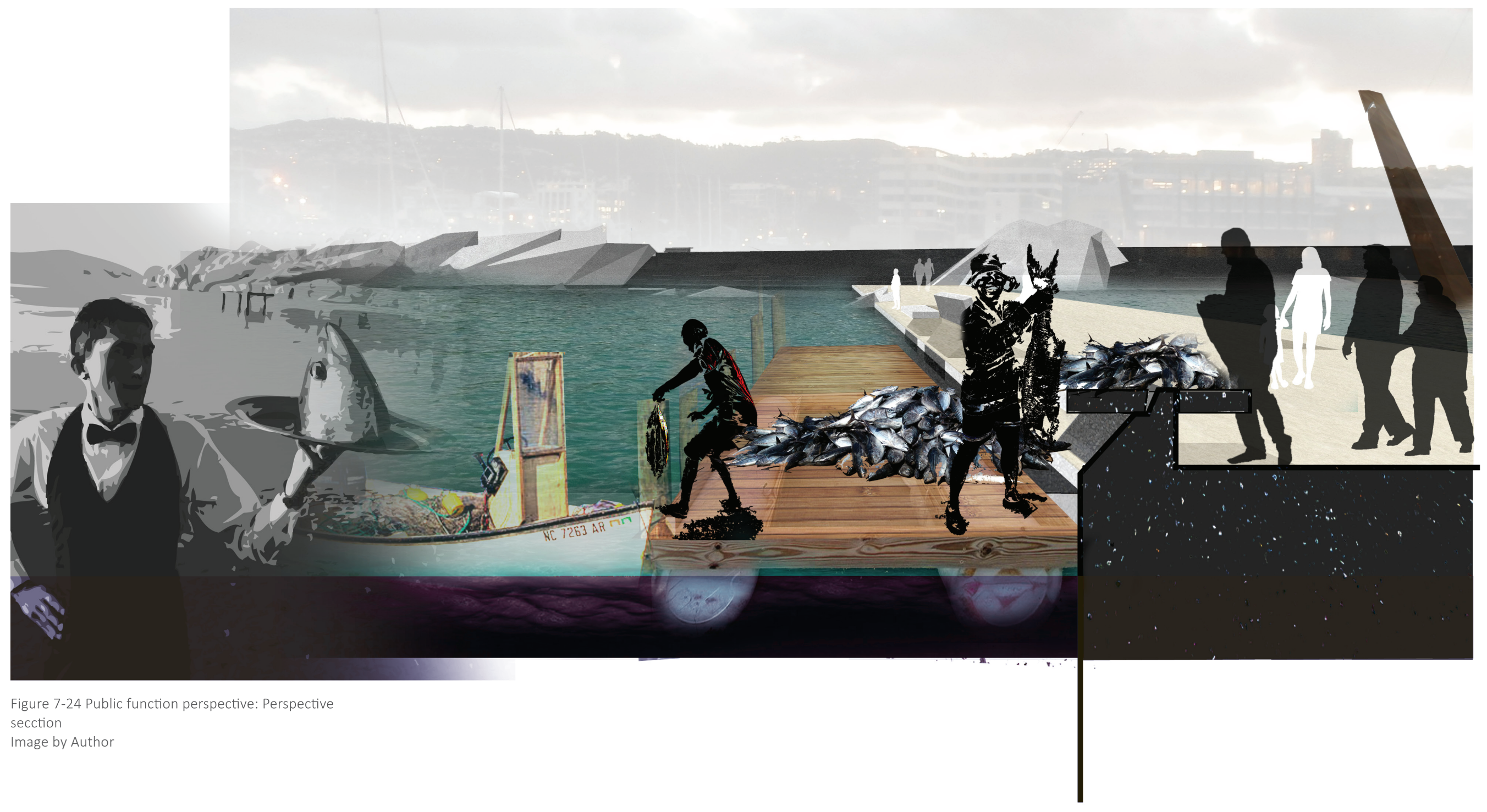




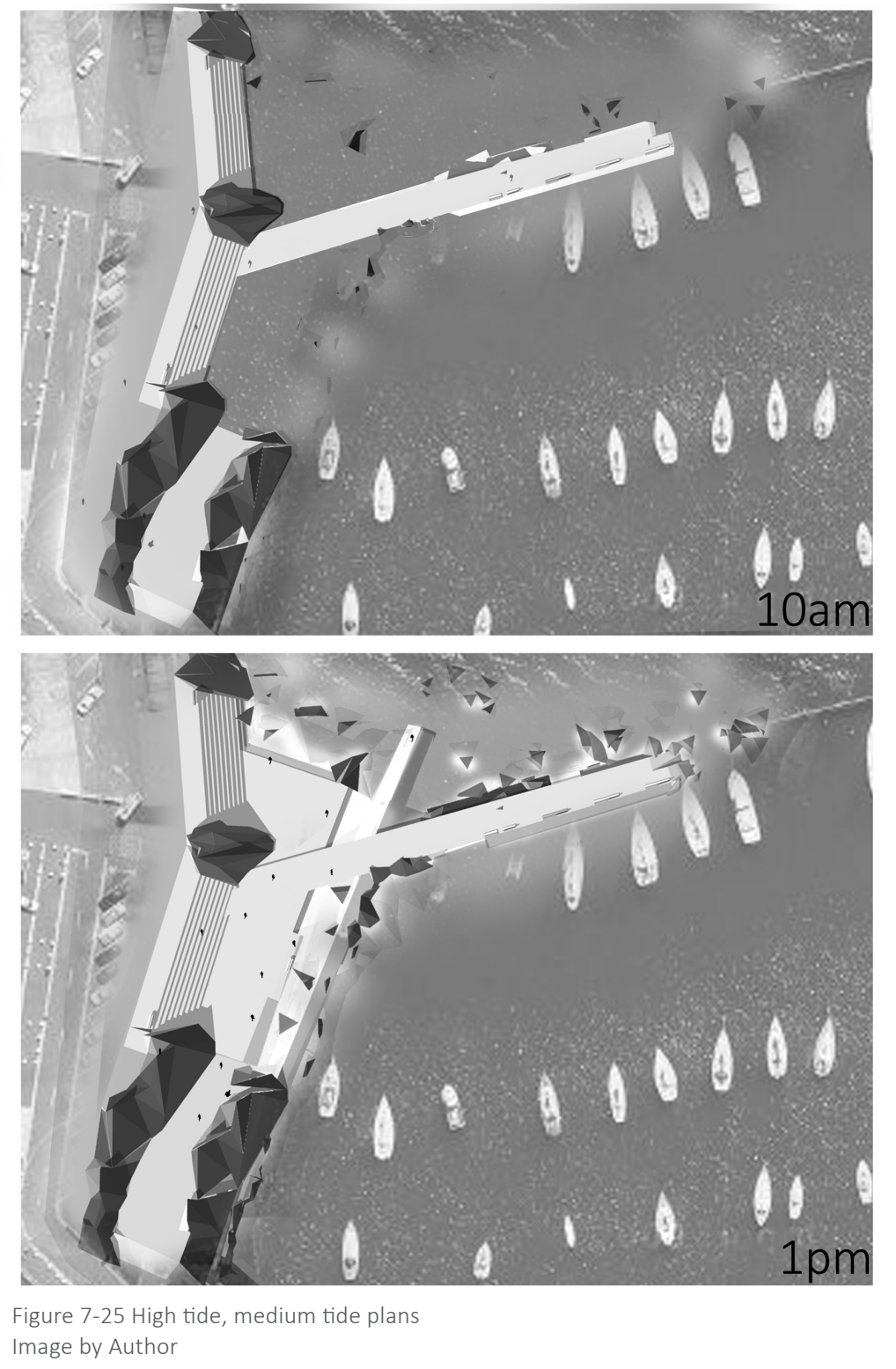




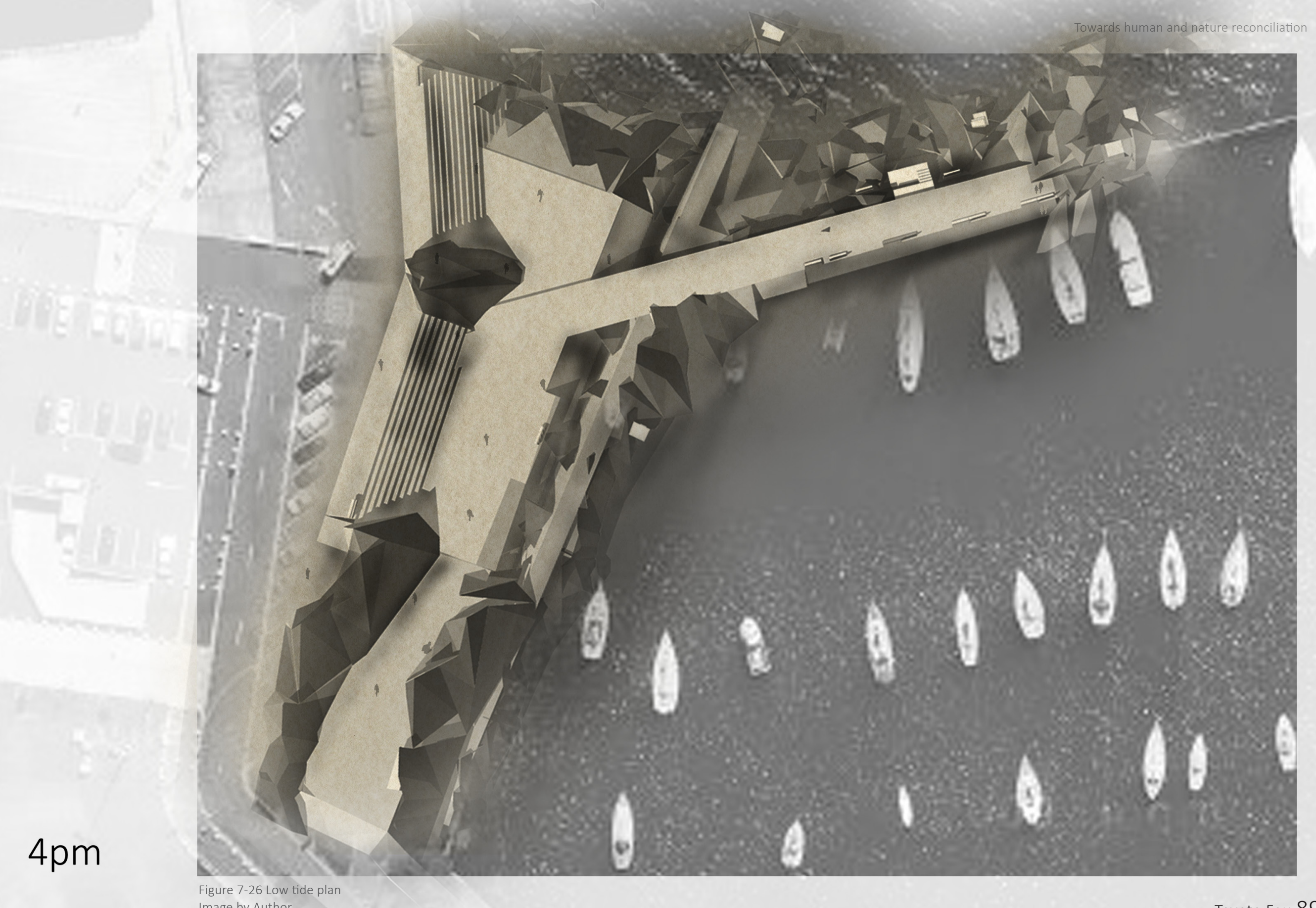




\subsection{Conclusion}

Applying Māori worldview principles, paired with a revised conservational "humans in nature consonance" approach has informed viable interactions between Humans and ecologies. Landscape architecture explores possibilities within a given context. This thesis suggests that in order for the landscape to be successful, one must consider the site in its entirety without excluding consideration for smaller scale factors such as the intertidal species.

The Māori worldview and its associated principles cannot be confined to a single factor, instead encompassing a whole. Some of the issues considered here include the immediate site, the wider landscape, the collections of social memories, the occupants consisting of human and ecologies as well as cultural principles that tie them together These issues must all be acknowledged for inhabitants to form relationships and ties with the natural environment, particularly the intertidal zone.

This design research suggests that learning through the experience of interacting and minding ecologies is a important tool in the process of human and nature reconciliation, specifically when the design has carefully considered the cultural understanding of its occupants.
In reflection, the proposed design is found to be successful in many ways:

-Acknowledging Māori principles as a viable approach to intertidal design

-Finding a mutualistic platform for microorganisms to thrive in close proximity to humans

- Dissolving typical boundaries of conservation. 


\section{Note}

It is important to note that design applications drawn from Māori principles represent personal interpretations and further Knowledge of Māori culture may reaffirm the design intention. The collected research has been contained to a particular scope and time frame, further research may be needed to reaffirm and further validate design decisions.

The research offers a model in terms of the approach to resolving a problem and a model in terms on how to articulate landscape architecture and its surroundings. 


\section{Bibliography}

Awatere, Donna. Maori Sovereignty. Christchurch: University of Canterbury, 1984

Baldwin, A. Dwight, Judith Deluce, and Carl Pletsch. Beyond Preservation: Restoring and Inventing Landscapes. Minneapolis: University of Minnesota Press, 1993.

Barlow, Cleve. Tikanga Whakaaro: Key concepts in Maori culture . Auckland: Oxford University Press Australia and New Zealand, 1994.

Bell, R. G. Hannah, J. Sea-level variability and trends: Wellington Region. Regional council report. Wellington: NIWA, 2012.

Bielawski, Ellen. Inuit indeigenous Knowledge and Science in the Arctic. Northern perspectives. 1992. 2014. <http://www.carc.org/ pubs/v20no1/inuit.htm>.

Connell, J. H. "The influence of intra-specific competition and other factors on the distribution of the barnacle Chthamalus stellatus." Ecology (1961).

Denny, M. S. "Physical processes that generate patterns in marine communities." Marine community ecology (2001): 3-37.
Diamond, J M. "New Zealand as an archipelago: an international perspective." Conservation Sciences Publication 2 (1990): 3- 8.

District, Report on the Wellington. Te Whanganui a Tara me ona takiwa. Report on the Wellington District. Wellington: Legislation Direct, 2013. 15 July 2013.

Durie, Mason. Nga Kahui Pou Launching Maori Futures. Wellington : Huia Publishes, 2003.

Gehl, Jahn. City to Waterfront: public spaces and public life study. Wellington: Wellington City Council, 2004.

Gilmour, A. E. "The hydrology of Cook Strait and Wellington Harbour." Science in Wellington (1960): 40.

Gousmett, Chris. What is a Worldview and Why Would I want one. Wellington: Christian Faith and action trust, 1997.

Hamsworth, Garth. Indigeneous concepts, values and knowledge for sustainable development: New Zealand case studies.

Palmerston North: Landcare research, 2002.

Hayden, Dolores. The power of place: Urban Landscapes As P ublic history . Cambridge: The MIT Press, 1999. 
Hettinger, Ned. "Nature Restoration as a Paradigm for the Human Relationship with Nature." (2008): 1- 16. draft document.

Holl, s. Written in Water . Baden: Lars Muller , 2002.

Hutching, Gerald. Walrond, Carl. Marine conservation- Māori and the sea. 13 July 2012. 2 July 2014. <http://www.TeAra.govt.nz/en/marineconservation/page-1>.

Irwin, James. An introduction to Maori Religion: Its Characterbefore European contact and its survial in Contemporary Maori. South Austrailia: Austrailian Association for the Study of Religion, University Relations Unit, Flinders University, 1984

Jackson, John Brinckerhoff. Discovering the Vernacular Landscape. Yale University Press, 1984.

James, Bev. The Maori relationship with the environment .

Wellington: Department of Conservation , 1993.

Matunga, Hirini. "The concept of indigineous planning as a framework for social inclusion." Paper presented at the New Zealand Planning Institute and planning institute of Australia. 2006.

Maxwell, Brian E. "Hydrobiological observations for Wellington Harbour." Transactions of the Royal Society of New Zealand 83 (1956): 493-503.
McKee, Charles J. L. "Conservation for the future." ISANA No. 14 (1996)

McSaveney, Eileen. Historic earthquakes- Earthquakes in Māori tradition. 14 November 2012. 6 July 2013.

Mead, Hirini Moko. Tikanga Maori: Living by Maori Values. Wellington : Huia Publishes, 2003.

Milne, J. R. Contaminants in shellfish. Wellington : Greater Wellington , 2006.

Murphy, Gerry. "Effects of macroalgal mats on the ecology of intertidal mudflats." Marin Pollution Bulletin (1982): 162-166. Nathan, Simon. Conservation - a history- Māori conservation traditions. 1207 2012. 1506 2013. <http://www.TeAra.govt.nz/en/ conservation-a-history/page-2>.

Press, Oxford. Oxford Dictionaries. 2014. 10 July 2014.

<http://www.oxforddictionaries.com/definition/english/ consonance? $\mathrm{q}=$ CONSONANCE $>$.

Rolleston, Shadrach and Awatere, Shaun. "Nga hua papakainga: Habitation design principles." MAI review (2009): 5. Stephenson, G. Wellington Harbour marine. Wellington: Hummingbird, 2008. 
Taylor, Anna. "Erosion of shore platforms, South Island, New Zealand." International Coastal Symposium (2000).

Waitangi Tribunal. "Report on the Crown's Foreshore and Seabed Policy." 2004.

Walker, Dean. Te Ao Maori/ A Maori Worldview. Nelson: Takina te Taiao Itd, 2008.

Zahniser, howard. The Wilderness Act of 1964. Act. Washington: U.S Government, 1964 
